\title{
Muscle wasting and the role of glutamine : metabolic studies in a catabolic rat model
}

Citation for published version (APA):

Rooyackers, O. E. (1995). Muscle wasting and the role of glutamine : metabolic studies in a catabolic rat model. [Doctoral Thesis, Maastricht University]. Rijksuniversiteit Limburg. https://doi.org/10.26481/dis.19950120or

Document status and date:

Published: 01/01/1995

DOI:

10.26481/dis.19950120or

Document Version:

Publisher's PDF, also known as Version of record

\section{Please check the document version of this publication:}

- A submitted manuscript is the version of the article upon submission and before peer-review. There can be important differences between the submitted version and the official published version of record.

People interested in the research are advised to contact the author for the final version of the publication, or visit the DOI to the publisher's website.

- The final author version and the galley proof are versions of the publication after peer review.

- The final published version features the final layout of the paper including the volume, issue and page numbers.

Link to publication

\footnotetext{
General rights rights.

- You may freely distribute the URL identifying the publication in the public portal. please follow below link for the End User Agreement:

www.umlib.nl/taverne-license

Take down policy

If you believe that this document breaches copyright please contact us at:

repository@maastrichtuniversity.nl

providing details and we will investigate your claim.
}

Copyright and moral rights for the publications made accessible in the public portal are retained by the authors and/or other copyright owners and it is a condition of accessing publications that users recognise and abide by the legal requirements associated with these

- Users may download and print one copy of any publication from the public portal for the purpose of private study or research.

- You may not further distribute the material or use it for any profit-making activity or commercial gain

If the publication is distributed under the terms of Article $25 \mathrm{fa}$ of the Dutch Copyright Act, indicated by the "Taverne" license above, 
Muscle wasting and the role of glutamine

Metabolic studies in a catabolic rat model 
CIP-DATA KONINKLIJKE BIBLIOTHEEK, DEN HAAG

Rooyackers, Olav Egidius

Muscle wasting and the role of glutamine : metabolic studies in a catabolic rat model / Olav Egidius Rooyackers. - [S.1. : s.n.]. -IIl.

Thesis Maastricht. - With ref. - With summary in Dutch.

ISBN 90-9007864-9

Subject headings: muscle physiology / metabolism.

Vormgeving: Olav Rooyackers

Druk: Datawyse Maastricht/Krips Repro Meppel

Publication of the thesis and the presented research were supported by a grant from DMV International, a division of Campina-Melkunie bv, Veghel, The Netherlands.

De druk van het proefschrift en het daarin beschreven onderzoek werden mogelijk gemaakt door financiële steun van DMV International, een divisie van Campina-Melkunie bv, Veghel. 


\section{Muscle wasting and the role of glutamine Metabolic studies in a catabolic rat model}

\section{PROEFSCHRIFT}

ter verkrijging van de graad van doctor aan de Rijksuniversiteit Limburg te Maastricht, op gezag van de Rector Magnificus, Prof. dr. $\mathrm{H}$. Philipsen, volgens het besluit van het College van Dekanen, in het openbaar te verdedigen op vrijdag 20 januari 1995 om 16.00 uur

door

Olav Egidius Rooyackers

geboren op 20 april 1965 te Eindhoven 


\section{CIP-DATA KONINKLIJKE BIBLIOTHEEK, DEN HAAG}

\section{Rooyackers, Olav Egidius}

Muscle wasting and the role of glutamine: metabolic studies in a catabolic rat model / Olav Egidius Rooyackers. - [S.1. : s.n.]. - III. Thesis Maastricht. - With ref. - With summary in Dutch.

ISBN 90-9007864-9

Subject headings: muscle physiology / metabolism.

Vormgeving: Olav Rooyackers

Druk: Datawyse Maastricht/Krips Repro Meppel

Publication of the thesis and the presented research were supported by a grant from DMV International, a division of Campina-Melkunie bv, Veghel, The Netherlands.

De druk van het proefschrift en het daarin beschreven onderzoek werden mogelijk gemaakt door financiële steun van DMV International, een divisie van Campina-Melkunie bv, Veghel. 


\section{Muscle wasting and the role of glutamine}

Metabolic studies in a catabolic rat model

\section{PROEFSCHRIFT}

ter verkrijging van de graad van doctor aan de Rijksuniversiteit Limburg te Maastricht, op gezag van de Rector Magnificus, Prof. dr. $\mathrm{H}$. Philipsen, volgens het besluit van het College van Dekanen, in het openbaar te verdedigen op vrijdag 20 januari 1995 om 16.00 uur

$$
\text { door }
$$

\section{Olav Egidius Rooyackers}

geboren op 20 april 1965 te Eindhoven 
Promotores:

Prof. dr. ir. W.H.M. Saris

Prof. dr. P.B. Soeters

Co-promotor:

Dr. A.J.M. Wagenmakers

Beoordelingscommissie: Prof. dr. G. van der Vusse, voorzitter

Prof. dr. D. Halliday

Dr. D. Matthews (Cornell University, New York)

Prof. dr. M. von Meyenfeldt

Prof. dr. H.P. Sauerwein (Universiteit van Amsterdam) 


\section{Contents}

- Chapter 1 General introduction

- Chapter 2 Tracer kinetics are of limited value for measuring in vivo protein synthesis and degradation rates in muscle of anesthetized rats

- Chapter 3 Prolonged changes in amino acid and protein metabolism after zymosan treatment in rats

- Chapter $4 \quad$ Prolonged activation of branched chain $\alpha$-keto acid dehydrogenase in muscle of zymosan treated rats

- Chapter 5 Derangement of energy metabolism in muscle of zymosan treated rats

- Chapter $6 \quad$ Mitochondrial content and protein synthesis rates in skeletal muscle of zymosan challenged rats

- $\quad$ Chapter 7 Energy metabolism and contractility of electrically stimulated skeletal muscle of rats recovering from critical illness

- Chapter 8 Effect of an enterally administered glutamine rich protein on the catabolic response to a zymosan challenge in rats

- Chapter 9 General discussion

- Summary

- $\quad$ Samenvatting

- Dankwoord

- Curriculum vitae 


\section{Metabolic response during catabolic diseases}

In 1942 Cuthbertson described the metabolic response during severe illness to occur in two phases; an ebb phase or shock phase followed by a flow or catabolic phase (Cuthbertson 1942). The ebb phase is characterized by hypometabolism indicated by decreased oxygen consumption, reduced body temperature, low cardiac output and decreased tissue perfusion (Kinney \& Felig 1979, Kinney et al 1988). Nowadays, with improved resuscitation, patients are stabilized much faster during shock. Therefore, no clear ebb phase as previously described is observed very often today.

The flow phase is the phase in which the catabolic processes occur (Kinney \& Felig 1979). Duration of this phase depends on severity of the insult and development of complications (e.g. infection). The catabolic phase is characterized by weight loss which can be $400-800 \mathrm{~g} /$ day in severe cases (Kinney \& Felig 1979). This weight loss is predominantly the result of net protein breakdown and to a moderate degree of body fat breakdown. In more severely injured or septic patients proportional loss of protein will increase. These patients, however, do not lose body weight due to water and salt retention in the extracellular compartment.

The catabolic phase is characterized by hypermetabolism, including increased oxygen consumption and fever. Energy expenditure is increased depending on severity of the injury. Minor surgery increases energy expenditure by approximately $10 \%$, major injury, infection and peritonitis by $20-50 \%$ and severe burn injury by 40-100\% (Kinney et al 1988). The increased energy expenditure most likely results from a raised body temperature and activation of substrate cycles involving carbohydrates, lipids and proteins (Goldstein \& Elwyn 1989). Energy supply during this hypermetabolic phase is mainly dependent on fat utilization as indicated by a RQ approaching 0.7 and increased oxidation of fatty acids as measured with stable isotope techniques (Shaw \& Wolfe 1987, Shaw \& Wolfe 1989).

Hyperglycemia observed during this phase is the result of increased gluconeogenesis and hepatic glucose release rather than decreased utilization (Long et al 1971). It has been suggested that glucose in these situations is largely utilized via anaerobic pathways which results in an increased substrate cycling via the Cori cycle (Wilmore et al 1983). Additional hyperinsulinemia indicates insulin resistance, a situation often referred to as 'diabetes of injury' or 'stress diabetes'. This insulin resistance appears to occur in peripheral tissue, probably skeletal muscle, and is consistent with a postreceptor defect (Black et al 1982). Increased levels of glucagon, glucocorticoids and catecholamines may counteract the increased insulin levels resulting in a 'relative insulin resistance' (Wilmore et al 1983).

Nitrogen loss probably is the best known feature in catabolic diseases and is in contrast to the other changes described above, obviously present in all 


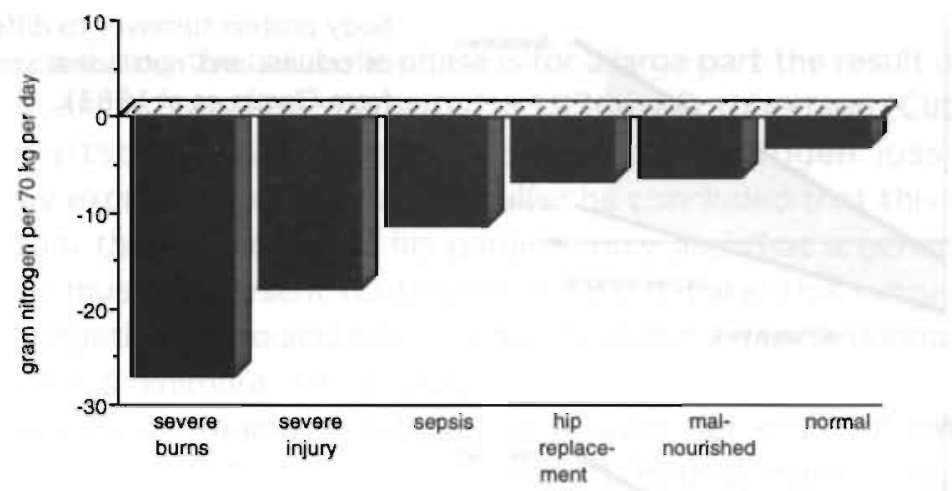

Figure 1 . Nitrogen balances measured during a $5 \%$ glucose infusion in human subjects (adapted from Elwyn 1987).

severely ill patients and animal models. Nitrogen balance becomes more negative with increasing severity of the insult (Fig. 1). Nitrogen balance studies, although difficult to perform accurately, still give a fair indication of the severity of the insult. This loss of nitrogen is mainly determined by protein losses but also decreasing concentrations of free amino acids may contribute, especially during the first 48 hours after injury (Rennie 1985). Whole body protein turnover measurements have indicated reduced protein synthesis and unchanged breakdown during minor insults (elective surgery) and markedly increased protein breakdown with to a lesser extent increased synthesis during more severe situations as summarized in Fig. 2a (Arnold et al 1993, Birkhahn et al 1980, Clague et al 1383, Long et al 1977, Rennie 1985, Shaw \& Wolfe 1989). Nutrition increases mainly protein synthesis rates (Fig. $2 \mathrm{~b}$ and c). Feeding patients improves protein balance. Severe illness, however, always results in a negative protein balance (Clague et al 1983). Also during convalescence net protein anabolism is obtained by increased synthesis rates despite slightly increased degradation rates (Wolfe et al 1989). A problem is, however, that rates of whole body protein turnover are obtained with these methods, whereas different tissues may respond to the insult in opposite directions.

For the metabolic derangement during catabolic diseases two predominant mechanisms have been postulated: (1) the afferent nervous system which is stimulated via a variety of receptors (e.g. pain receptors near the injury, and baroreceptors and chemoreceptors responding to changes in pressure and chemical content of blood) and (2) polypeptide cytokines (Goldstein \& Elwyn 1989). The signals of the afferent nervous system are processed in the hypothalamus which stimulates production of catabolic hormones (cortisol, glucagon, adrenaline and noradrenaline) via both the sympathetic nervous system and increased pituitary hormone secretion. The importance of the cytokines becomes more and more obvious in medical research. In 1930 Sir David 


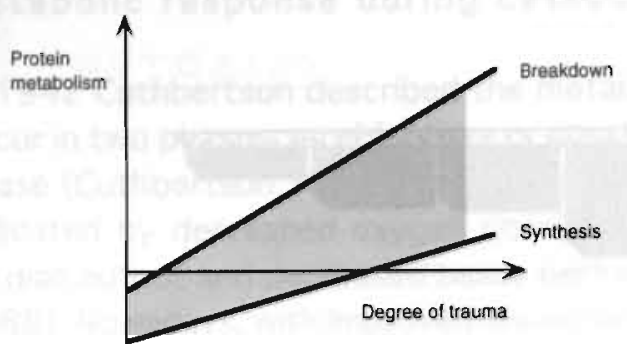

(a) Fasted state

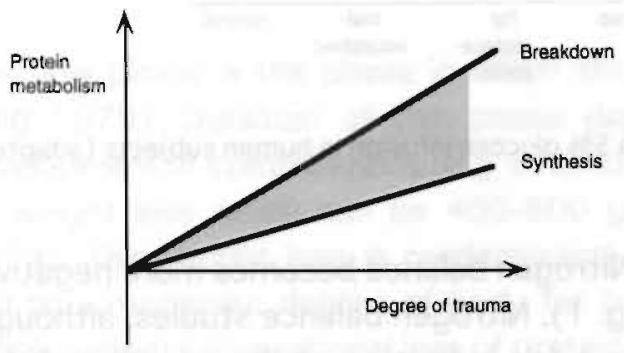

(b) Normal food intake

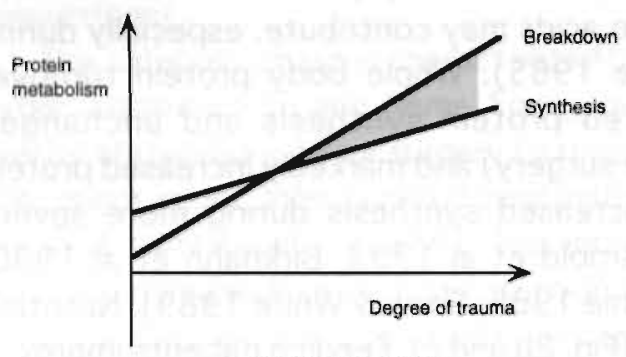

(c) Enhanced lood intake
Figure 2. Concept of adaptations in whole body protein turnover to different degrees of trauma and nutritional status (adapted from Claque et al 1983).

Cuthbertson stated (Cuthbertson 1930): 'Just as histamine and allied compounds appear to play such a large part in the production of shock, so some allied compounds formed from the breaking-up of the cellular debris in the fractured or injured area may cause a disturbance of the normal balance of the body cells resulting in an imbalance between anabolism and catabolism'. Later, factors derived from white blood cells, the so-called leukocyte endogenous mediator (LEM), were postulated as these allied compounds (Wannemacher et al 1975). Studies with LEM injected into rats showed characteristic metabolic changes (e.g. increased amino acid oxidation and increased liver protein synthesis) observed during catabolic diseases (Yang et al 1983). The active compounds of LEM appeared to be cytokines of which numerous variants (e.g. tumour necrosis factor, interleukin-1, interleukin-6) are now known to play a role in the metabolic derangement during several types of disease (Bistrian et al 1992, Dinarello 1984, Welbourn \& Young 1992). 


\section{Muscle wasting}

Net protein loss during the catabolic phase is for a large part the result of wasting of muscle protein and was first suggested in 1930 by Cuthbertson (Cuthbertson 1930, Cuthbertson 1932). From the quantity of nitrogen loss and the simultaneously excreted phosphorus and sulfur he concluded that this could not be derived from the injured leg of his patients only and that a general loss of muscle protein must be present (Cuthbertson 1930). Later this suggestion was confirmed by negative amino acid balances across skeletal muscle during catabolic diseases (Aulick \& Wilmore 1979, Duff et al 1979, Woolf et al 1979). With increasing severity of trauma or with sepsis a larger net efflux of amino acids from muscle is observed (Wolfe et al 1989). Part of these changes could, however, also be induced by decreases in intracellular concentrations of amino acids. Direct measurement of muscle wasting as changes in muscle weight or total muscle protein is difficult to perform in patients. However in animal models (mainly rats) decreased muscle weight or protein content have repeatedly been reported (Chance et al 1991, Jepson et al 1986, Odessey \& Parr 1982, Wusteman et al 1990).

Net loss of muscle protein is the result of an imbalance between protein synthesis and degradation. Many studies measuring protein synthesis rates have been performed in both human patients and animals. In catabolic rat models most studies report decreased (Emery et al 1984b, Frayn \& Maycock 1979, Hasselgren et al 1984, Jepson et al 1986, Wusteman et al 1990) or unchanged (Clark et al 1984, Emery \& Ghusain-Choueiri 1994, Hasselgren et al 1986, Odessey \& Parr 1982, Preedy et al 1988, Sakamoto et al 1983) protein synthesis rates. Increased synthesis rates have been reported in rats with burn injury (Pomposelli et al 1985, Shangraw \& Turinsky 1984). Results are contradictory probably due to variation in techniques used, severity of the insult, time of sampling after the insult and probably, the most important factor, food intake. Changes in food intake influence protein synthesis rates in muscle to a substantial degree. In different studies rats are either fed, fasted or sometimes intravenously fed. Most insults, however, influence food intake but not many studies have included pair fed control rats. Human studies in catabolic patients have been performed less frequently, but generally a decrease in muscle protein synthesis has been measured (Emery et al 1984a, Essén et al 1992). Also some indirect indications of decreased synthesis rates in muscle have been obtained (Rennie et al 1984, Wernerman et al 1986).

Several attempts have been made to measure muscle protein degradation rates during catabolic diseases. In vitro measurements indicate mainly increased degradation rates (Clark et al 1984, Hasselgren et al 1984, Hasselgren et al 1986), but also decreased (Odessey \& Parr 1982) or unchanged rates (Frayn \& Maycock 1979) have been reported. Methods to measure degradation rates in vivo all have major limitations (Barret \& Gelfand 1989, Sugden \& Fuller 1991). 
The most reliable method, in which both synthesis and degradation of individual tissues are estimated using amino acid tracer exchange rates, has been applied to humans and larger animals only because of potential problems with catherization and blood flow measurements in smaller animals.

\section{Muscle weakness and fatiguability}

After major surgery many patients complain, sometimes for months, of tiredness (Anonymous 1979). Patients undergoing moderate surgery show exercise intolerance up to 2 weeks following operation (Carswell \& Walker 1977). Major surgery induced postoperative fatigue for at least 30 days postoperatively as assessed using a questionnaire (Christensen et al 1985). Despite complaints of muscle weakness, muscular performance was not assessed in the postoperative state before 1979 (Anonymous 1979). Later, the group of Jeejeebhoy reported increased muscle fatiguability and an altered pattern of muscle contraction and relaxation in response to malnutrition using electrical stimulation of the adductor pollicis muscle (Jeejeebhoy 1986, Lopes et al 1982). Parenteral nutrition reversed these effects. Zeiderman and colleagues (Zeiderman et al 1990) observed a decreased muscle efficiency (level of energy expenditure for a given work load) in postsurgical patients, although no alterations in fatiguability of the adductor pollicis muscle was found.

In a recent paper it has been suggested that the cause of acute weakness in intensive care unit patients could be a combination of polyneuropathy and disturbances in function or structure of muscle per se (Chad \& Lacomis 1994). Results from a study of Tomera indicated that disturbances in second messengers (CAMP, inositol triphosphate) leading to increases of cytosolic calcium may be involved in muscular dysfunction (Tomera 1991). From exercise physiology studies a relation between muscle endurance performance and muscle mitochondrial density or activity has been established (Dudley et al 1987, Howald et al 1985, Takahashi \& Hood 1993). Impaired mitochondrial function and abnormal morphology, reported to occur in skeletal muscle of catabolic rats (Schumer et al 1971), furnish a possible mechanism involved in the muscle weakness during and following critical illness.

\section{The role of glutamine}

Glutamine is the most abundant amino acid in the body. It has the highest concentration of all amino acids in plasma $(0.5$ to $0.9 \mathrm{mM})$ and it constitutes about $40 \%$ of the free amino acid pool in human skeletal muscle (Vinnars et al 1975). Glutamine is a non-essential amino acid and can be synthesized in a reaction catalyzed by the enzyme glutamine synthase: 


$$
\text { glutamate }+\mathrm{ATP}+\mathrm{NH}_{3}-->\text { glutamine }+\mathrm{ADP}+\mathrm{P}_{\mathrm{f}}
$$

Activities of the enzyme have been reported to be high in brain, liver and kidney (Rowe 1985). Although a lower activity is present in skeletal muscle, it is evident that skeletal muscle represents a significant source of glutamine formation due to its large mass. Glutamine and alanine together represent $50 \%$ of the amino acids released from muscle in the postabsorptive state (Krebs 1980). Muscle is, however, not the only tissue important for glutamine supply. Also lung (Ardawi 1990, Ardawi 1991b) and to a smaller extent adipose tissue (Elia 1993) may provide glutamine.

Glutamine breakdown has mainly been described in the kidney, liver and intestinal mucosa. But also in muscle measurable activities of glutaminase have been observed (Ardawi \& Majzoub 1991, Kelso et al 1989). A major part of these activities may, however, be located in endothelial or infiltrating cells such as macrophages (Kelso et al 1989). Two main enzymes are involved in the breakdown of glutamine; phosphate dependent glutaminase and glutamine transaminase (Cooper 1988, Meister 1984). In the reaction catalyzed by glutaminase, glutamine is broken down to glutamate which can be further degraded to the TCA-cycle intermediate $\alpha$-ketoglutarate. Two types of glutamine transaminase are known to occur in rat tissues; glutamine transaminase $L$ and glutamine transaminase $\mathrm{K}$. The $\alpha$-ketoglutaramate produced by transamination of glutamine can subsequently be hydrolyzed by $\omega$-amidase to $\alpha$-ketoglutarate and ammonia (Meister 1984).

Sir Hans Krebs concluded in 1980 that most amino acids have multiple functions, but glutamine appears to be the most versatile (Krebs 1980). One of the first metabolic functions of glutamine that has been described is supply of ammonia to the kidney for regulation of the acid-base balance. Glutamine also acts as a precursor for synthesis of nucleotides such as ATP, purines and pyrimidines (Bulus et al 1989). Glutamine is consumed by rapidly dividing cells. This became apparent from in vitro culture of cell lines and tissues in which proliferation was enhanced by addition of glutamine. Rapidly dividing cells such as enterocytes, lymphocytes and macrophages use glutamine probably for both energy and as metabolic precursor necessary for cell replication (Lacey \& Wilmore 1990).

During catabolic diseases glutamine concentrations decrease markedly in skeletal muscle. This decrease has been described for the first time in patients following uncomplicated operation (Vinnars et al 1975). Later the decrease has been observed under many catabolic situations in both patients (Askanazi et al 1980, Fürst et al 1977) and animal studies (Ardawi \& Majzoub 1991, Ardawi 1988, Wusteman et al 1990). The glutamine pool stays depleted for a prolonged period after the insult as indicated by decreased concentrations up to 30 days after elective surgery (Petersson et al 1992). 
During catabolic stress the release of glutamine from both skeletal muscle (Bulus et al 1989, Deutz et al 1992, Rennie et al 1986, Souba \& Austgen 1990) and lung is increased (Ardawi 1991b, Plumley et al 1990). The increased release from muscle has been suggested (Hundal et al 1990, Rennie et al 1986) to be the result of an altered distribution of sodium, leading to net efflux of glutamine by the sodium dependent glutamine transporter (system $\mathrm{N}^{m}$ ). The reduction of the intracellular glutamine pool can only partly account for the increased efflux from muscle going on for days during severe illness. This implies an enhanced production of glutamine most likely from both net protein breakdown and de novo synthesis. Increased synthesis rates of glutamine have been suggested during catabolic states (Ardawi 1988, Lacey \& Wilmore 1990, Yoshida et al 1991). The extra glutamine supplied in this way is used by other tissues (Fig. 3). During acidosis glutamine can be used by the kidney to obtain extra ammonia to bind and excrete $\mathrm{H}^{+}$-ions. Following trauma glutamine can be used for wound repair (Caldwell 1989). Probably a large amount of glutamine is used by lymphocytes, especially during rapid proliferation in response to an immune challenge (Ardawi \& Newsholme 1983). Most likely the increased uptake of glutamine by spleen and liver is the result of extra utilization of glutamine by immune cells in these situations.

When increased glutamine production does not match increased utilization a shortage of glutamine may occur and lead to impaired wound repair and functioning of the immune system. Especially in critically ill patients or patients already depleted before the catabolic challenge a dramatic reduction in muscle mass may lead to an insufficient supply of extra glutamine. Glutamine uptake by the small intestine decreases following surgery (Deutz et al 1992) and during endotoxemia (Dudrick et al 1992). The small intestine extracts glutamine from arterial blood in a concentration dependent manner (Windmueller \& Speath 1974) and, therefore, a reduced availability and arterial level may be part of the decreased uptake of glutamine during severe illness. Glutamine is a major fuel for enterocytes and, therefore, it has been hypothesized that a shortage may lead to a damaged intestinal mucosa and subsequently bacterial translocation (Souba 1991, Wilmore et al 1988).

Due to numerous metabolic key functions and a potential shortage of glutamine, the amino acid is considered as conditionally essential in severe catabolic stress situations (Lacey \& Wilmore 1990). Many patients suffering from severe illness receive total parenteral nutrition (TPN). Unfortunately these formulas do not contain glutamine due to its low solubility and limited stability in solution. The existence of a link between the size of the glutamine pool in muscle and the rate of protein synthesis as reported by the group of Mike Rennie (MacLennan et al 1987, MacLennan et al 1988, Rennie et al 1986) have provided the rationale for therapeutic interventions to limit protein loss during catabolic diseases.

Many studies have been performed in which supplementation of glutamine 

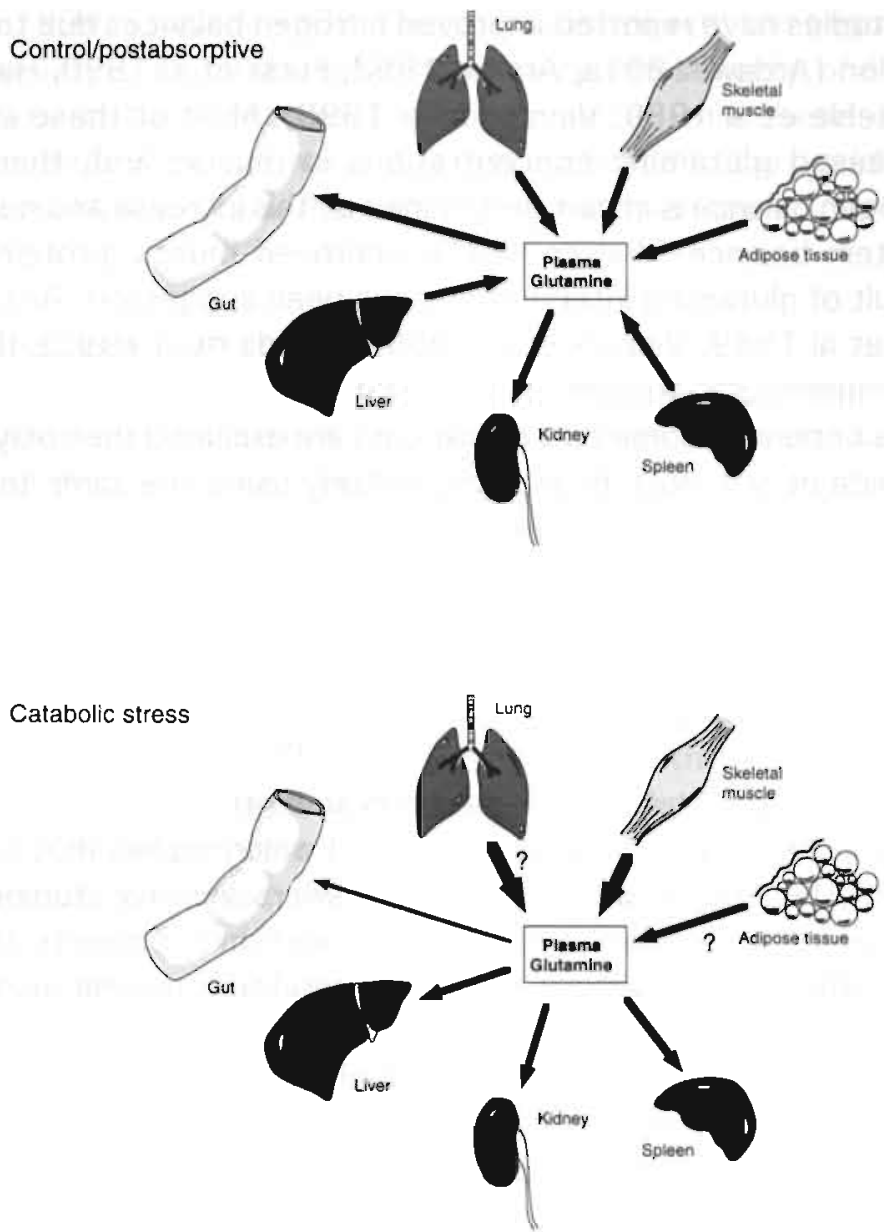

Figure 3. Glutamine fluxes between different tissues during the normai situation (top) and during catabolic stress (bottom). Thickness of the arrows indicate relative changes in comparison with the normal situation and do not give a quantitative impression of glutamine fluxes.

either as freshly prepared solutions of free glutamine or as dipeptides were studied. Several studies have shown that addition of glutamine to TPN can restore glutamine pools in muscle of postoperative patients (Fürst et al 1990, Hammarqvist et al 1989, Vinnars et al 1990, Wernerman et al 1989) although in most studies full restitution was not obtained. Roth and colleagues (Roth et al 1990) were unable to obtain an effect on the depleted muscle pool when infusing $40 \mathrm{~g}$ of alanyl-glutamine in patients with pancreatitis. In catabolic animal studies, glutamine supplemented TPN regimens have been reported to fully or partly restore glutamine pools in muscle (Ardawi \& Majzoub 1991, Wusteman \& Elia 1991, Yoshida et al 1992). In a study of Karner and colleagues (Karner et al 1989), however, no effect of intravenous glutamine administration on the depleted muscle pool was observed in septic dogs. 
Several studies have reported improved nitrogen balances due to glutamine supplementation (Ardawi 1991a, Ardawi 1992, Fürst et al 1990, Hammarqvist et al 1989, Stehle et al 1989, Vinnars et al 1990). Most of these studies also reported increased glutamine concentrations in muscle and, therefore, the improved nitrogen balance is in part determined by this increase and not reflecting improved protein balance (Walser 1991). Improved muscle protein synthesis rates as a result of glutamine intervention have been suggested (Ardawi 1991a, Hammarqvist et al 1989, Vinnars et al 1990, Yoshida et al 1992). If, however, studies using indirect measurements of in vivo protein synthesis (e.g. in vitro measurements or polyribosome concentrations) are excluded then only one study remains (Yoshida et al 1992). In addition, a study using the same technique as Yoshida and colleagues did not show an improvement in the muscle protein synthesis rates despite an increased glutamine pool (Wusteman \& Elia 1991).

\section{Catabolic animal models}

Severely ill patients exhibit a large variation in severity of disease, in metabolic responses and consequently in medical treatment which implies that large groups of patients should be studied to obtain reliable answers. Invasive studies or studies investigating for instance splanchnic tissue metabolism in patients are severely restricted for ethical and practical reasons. Therefore, several animal models have been developed to study the metabolic derangement in response to a catabolic challenge. In some studies pigs or dogs were infused with endotoxin or cytokines, but mainly rats were used. Rat models with standardized trauma (e.g. Jeevanandam et al 1993), burn injury (e.g. Ardawi 1988) and sepsis (Fink \& Heard 1990) have been used. Sepsis-like responses have been induced by endotoxin or cytokine administration, bacterial inoculum and cecal ligation and perforation. All these models show characteristics comparable to those observed in patients, but differences are also present. Disadvantages of most of these models are (1) a high variation in degree of morbidity and mortality and (2) the fact that an acute phase of illness results either in early death or full recovery within a few days.

To study nutritional interventions a model with a prolonged period of moderate illness or recovery is required. Goris and colleagues (Goris et al 1986) have used intraperitoneal injection of zymosan suspended in liquid paraffin to induce multiple organ failure in rats. The zymosan model has been repeatedly used (Mainous et al 1991, Schrimer et al 1988, Steinberg et al 1989, Von Asmuth et al 1990) because with a single injection a prolonged illness was induced lasting up to 14 days. Zymosan is a cell wall extract prepared from yeast (Saccharomyces cerevisiae) and a potent activator of the alternate pathway of complement. The major components of zymosan are ß-1,3 glucan, a polymer of glucose, and mannan. Both are known to have neutrophil and macrophage activating capability 
(Ainsworth 1994, Sawyer 1993). The main problem with the originally described model, however, is a high variation in mortality and severity of illness between different experiments. The research described in this thesis is based on a modification of the zymosan model. Key improvements to the model have provided a moderate mortality rate and a smaller biological variation.

\section{Outline and aims of the thesis}

From the many metabolic changes and adaptations occurring during catabolic diseases, the dramatic loss of muscle mass and prolonged muscle weakness are the main areas of investigation in this thesis. Ethically it is not feasible to study muscle metabolism by taking repeated muscle biopsies in patients under these circumstances and, therefore, a rat model was used.

Wasting of muscle mass is the result of a loss of muscle protein. Both protein wasting or deposition are determined by the net balance between protein synthesis and degradation. Therefore, preferably both these aspects of protein turnover should be measured when studying muscle protein wasting. However, no established in vivo method to measure both features is available for rats. The first aim of the study, therefore, was to investigate whether amino acid tracer kinetics, more and more used in larger animals and man, can also be utilized to estimate protein synthesis and degradation rates in rat skeletal muscle (chapter 2).

An ultimate goal of the studies was to investigate the influence of nutritional (and possibly pharmaceutical) intervention. To perform nutritional interventions an animal model with a prolonged period of moderate illness or recovery is required. No rat model expressing such etiology due to a simple challenge has, however, been described in the literature. The second aim, therefore, was to develop a rat model showing, in addition to an acute phase of severe iilness, a prolonged period of moderate illness or recovery with signs of muscle wasting and weakness. The model finally used is a modification of the zymosan model which has originally been described by Goris and colleagues (Goris et al 1986). In chapter 3 the modified model and changes in amino acid and protein metabolism are described focusing primarily on changes in skeletal muscle.

A third aim was to explore possible metabolic mechanisms important in the course or cause of muscle wasting and weakness. Oxidation rates of branched chain amino acids (BCAA) are increased during catabolic diseases. Skeletal muscle plays a significant role in the breakdown of BCAA and, therefore, activities of the rate limiting enzyme in the degradative pathway of BCAA are studied in muscle of the catabolic rats (chapter 4). Changes in muscle energy metabolism (concentrations of high energy phosphates, tricarboxylic acid cycle intermediates and other metabolites involved in muscle energy metabolism) are described in chapter 5 . In chapter 6 derangements in mitochondrial metabolism are studied 
because of its potential role in the etiology of muscle weakness and fatiguability. The effect of changes in mitochondrial density (capacity for oxidative energy generation) on energy metabolism is studied during electrical in situ stimulation (chapter 7).

The non-essential amino acid glutamine which is predominantly synthesized in muscle is nowadays considered to become essential in situations of severe illness (Lacey \& Wilmore 1990). The last and fourth aim of this research project was to obtain insight in the role of glutamine during catabolism and the effect of nutritional supplementation of this amino acid. Derangements in muscle glutamine in the catabolic rat model and the relation with protein synthesis rates are described in chapter 3 . In chapter 8 the effect of enteral glutamine administration, using a protein source rich in glutamine, on the main metabolic derangements described in the preceding chapters is studied. The intention of this study was to explore the effect of this intervention strategy on the degree of critical illness and on parameters of muscle wasting resulting from severe illness.

\section{References}

- Ainsworth AJ (1994). A B-glucan inhibitable zymosan receptor on channel catfish neutrophil. Vet Immun Immunopathol. 41: 141-152.

- Anonymous (1979). Postoperative fatigue. Lancet 1: 84-85.

- Ardawi MSM and Newsholme EA (1983). Glutamine metabolism in lymphocytes of the rat. Biochem J 212: 835-842.

- Ardawi MSM (1988). Skeletal muscle glutamine production in thermally injured rats. Clin Sci 74: 165-172.

- Ardawi MSM (1990). Glutamine-synthesizing activity in lungs of fed, starved, acidotic, diabetic, injured and septic rats. Biochem J 270: 829-832.

- Ardawi MSM (1991a). Effect of glutamine-enriched total parenteral nutrition on septic rats. Clin Sci 81: 215-222.

- Ardawi MSM (1991b). Glutamine and alanine metabolism in lungs of septic rats. Clin Sci 81 : 603-609.

- Ardawi MS and Majzoub MF (1991). Glutamine metabolism in skeletal muscle of septic rats. Metabolism 40: 155-164.

- Ardawi MSM (1992). Effects of epidermal growth factor and glutamine-supplemented parenteral nutrition on small bowel of septic rats. Clin Sci 82: 573-580.

- Arnold J, Campbell IT, Samuels TA, Devlin JC, Green CJ, Hipkin LJ, Macdonald IA, Scrimgeour CM, Smith K and Rennie MJ (1993). Increased whole body protein breakdown predominates over increased whole body protein synthesis in multiple organ failure. Clin Sci 84: 655-661.

- Askanazi J, Carpentier YA, Michelsen CB, Elwyn DH, Fürst P, Kantrowitz LR, Gump FE and Kinney JM (1980). Muscle and plasma amino acids following injury. Ann Surg 192: 78-85.

- Aulick ML and Wilmore DW (1979). Increased peripheral amino acid release following burn injury. Surgery 85: 560-565.

- Barret EJ and Gelfand RA (1989). The in vivo study of cardiac and skeletal muscle protein turnover. Diabetes/Metabolism Reviews 5: 133-148.

- Birkhahn RH, Long CL, Fitkin D, Geiger JW and Blakemore WS (1980). Effects of major skeletal muscle trauma on whole body protein turnover in man measured by $L-\left[1,{ }^{14} \mathrm{C}\right]$-leucine. Surgery 88: 294-299. 
- Bistrian BR, Schwartz J and Istfan NW (1992). Cytokines, muscle proteolysis, and the catabolic response to infection and inflammation. Proc Soc Exp Biol Med 200: 233-239.

- Black PR, Brooks DC, Bessey PQ Wolfe RR and Wilmore DW (1982). Mechanisms of insulin resistance following injury. Ann Surg 196: 420-435.

- Bulus N, Cersosimo E, Ghishan F and Abumrad NN (1989). Physiological importance of glutamine. Metabolism 38(supp| 1): 1-5.

- Caldwell MD (1989). Local glutamine metabolism in wounds and inflammation. Metabolism 38(suppl 1): 34-39.

- Carswell SH and Walker WF (1977). Exercise tolerance in surgical patients. In: Nutritional aspects of care in the critically ill (Richards JR and Kinney LH, eds.). Edinburgh, Churchill Livingstone: 161-176.

- Chad DA and Lacomis D (1994). Critically ill patients with newly acquired weakness: the clinicopathological spectrum. Ann Neurol 35: 257-259.

- Chance WT, Cao L, Zhang F, Foley-Nelson T and Fisher JE (1991). Clenbuterol treatment increases muscle mass and protein content of tumor-bearing rats maintained on total parenteral nutrition. JPEN 15: 530-535.

- Christensen T, Hougård $F$ and Kehlet $H$ (1985). Influence of pre- and intra-operative factors on the occurrence of postoperative fatigue. $\mathrm{Br} J$ Surg 72: 63-65.

- Clague MB, Keir MJ, Wright PD and Johnston IDA (1983). The effect of nutrition and trauma on whole-body protein metabolism in man. Clin Sci 65: 165-175.

- Clark AS, Kelly RA and Mitch WE (1984). Systemic response to thermal injury in rats. J Clin Invest 74: 888-897.

- Cooper AJL (1988). Glutamine aminotransferases and $\omega$-amidases. In: Glutamine and glutamate in mammals (Kvamme E, eds.) vol 1. Florida: 33-52.

- Cuthbertson DP (1930). The disturbance of metabolism produced by bony and non-bony injury, with notes on certain abnormal conditions of bone. Biochem J 24: 1244-1263.

- Cuthbertson DP (1932). Observations on the disturbance of metabolism produced by injury to the limb. Q J Med 1: 233-246.

- Cuthbertson DP (1942). Post-shock metabolic response. Lancet 1: 433-437.

- Deutz NEP, Reijven PLM, Athanasas G and Soeters PB (1992). Post-operative changes in hepatic, intestinal, splenic and muscle fluxes of amino acids and ammonia in pigs. Clin Sci 83: 607-614.

- Dinarello CA (1984). Interleukin-1 and the pathogenesis of the acute phase response. New Eng J Med 311: 1413-1418.

- Dudley GA, Tullson PC and Terjung RL (1987). Influence of mitochondrial content on the sensitivity of respiratory control. J Biol Chem 262: 9109-9114.

- Dudrick PS, Salloum RM, Copeland EM and Souba WW (1992). The early response of the jejunal brush border glutamine transporter to endotoxemia. J Surg Res 52: 372-377.

- Duff JH, Viidik T, Marchuk JB, Holliday RL, Finley RJ, Groves AC and Woolf LI (1979). Femoral arteriovenous amino acid differences in septic patients. Surgery 85: 344-348.

- Elia M (1993). Glutamine metabolism in human adipose tissue in vivo. Clin Nutr 12: 51-53.

- Elwyn DH (1987). Protein metabolism and requirements in the critically ill patient. Crit Care Clin 3: 57-69.

- Emery PW, Edwards RHT, Rennie MJ, Souhami RL and Halliday D (1984a). Protein synthesis in muscle measured in vivo in cachectic patients with cancer. Brit Med Journal 289: 584-586.

- Emery PW, Lovell L and Rennie MJ (1984b). Protein synthesis measured in vivo in muscle and liver of cachectic tumor-bearing rats. Canc Res 44: 2779-2784.

- Emery PW and Ghusain-Choueiri A (1994). Effect of surgical trauma on muscle protein synthesis in the rat. Brit J Surg 81: 539-542.

- Essén P, McNurlan MA, Wernerman J, Vinnars E and Garlick PJ (1992). Uncomplicated surgery, but not general anesthesia decreases muscle protein synthesis. Am J Physiol 262: E253E260.

- Fink MP and Heard SO (1990). Current research review. Laboratory models of sepsis and 
septic shock. J Surg Res 49: 186-196.

- Frayn KN and Maycock PF (1979). Regulation of protein metabolism by a physiological concentration of insulin in mouse soleus and extensor digitorum longus muscles. Biochem $\mathrm{J}$ 184: 323-330.

- Fürst P, Bergström J, Kinney JM and Vinnars E (1977). Nutrition in postoperative catabolism. In: Nutritional aspects of care in the critically ill 3 (Richards JR and Kinney JM, eds.). New York, Churchill Livingstone: $389-410$.

- Fürst P, Albers S and Stehle P (1990). Glutamine-containing dipeptides in parenteral nutrition. JPEN 14: 118S-124S.

- Goldstein SA and Elwyn DH (1989). The effect of injury and sepsis on fuel utilization. Annu Rev Nutr 9: 445-473.

- Goris RJA, Boekholtz WKF, Van Bebber IPT, Nuytinck JKS and Schilling PHM (1986). Multiple Organ Failure and sepsis without bacteria. An experimental model. Arch Surg 121: 897-901.

- Hammarqvist F, Wernerman J, Ali R, Von der Decken A and Vinnars E (1989). Addition of glutamine to total parenteral nutrition after elective abdominal surgery spares free glutamine in muscle, counteracts the fall in muscle protein synthesis and improves nitrogen balance. Ann Surg 209: 455-461.

- Hasselgren P-O, Jagenburg R, Karlström L, Pedersen P and Seeman T (1984). Changes of protein metabolism in liver and skeletal muscle following trauma complicated by sepsis. $J$ Trauma 24: 224-228.

- Hasselgren P-O, Talamini M, James H and Fisher JE (1986). Protein metabolism in different types of skeletal muscle during early and late sepsis in rats. Arch Surg 121: 918-923.

- Howald H, Hoppeler H, Claassen H, Mathieu O and Straub R (1985). Influences of endurance training on the ultrastructural composition of the different muscle fiber types in humans. Pflügers Arch 403: 369-376.

- Hundal HS, Babij P, Watt PW, Ward MR and Rennie MJ (1990). Glutamine transport and metabolism in denervated rat skeletal muscle. Am J Physiol 259: E1 48-E154.

- Jeejeebhoy KN (1986). Muscle function and nutrition. Gut 27: 25-39.

- Jeevanandam M, Ali MR, Holaday NJ, Weis JK and Petersen SR (1993). Relative nutritional efficacy of arginine and ornithine salts of alpha-ketoisocaproic acid in traumatized rats. Am J Clin Nutr 57: 889-896.

- Jepson MM, Pell JM, Bates PC and Millward DJ (1986). The effect of endotoxaemia on protein metabolism in skeletal muscle and liver of fed and fasted rats. Biochem J 235: 329-336.

- Karner J, Roth E, Ollenschläger G, Fürst P, Simmel A and Karner J (1989). Glutamine-containing dipeptides as infusion substrates in the septic state. Surgery 106: 893-900.

- Kelso TB, Shear CR and Max SR (1989). Enzymes of glutamine metabolism in inflammation associated with skeletal muscle hypertrophy. Am J Physiol 257: E883-E894.

- Kinney JM and Felig P (1979). The metabolic response to injury and infection. In: Endocrinology (DeGroot LJ, eds.) vol 3. New York, Grune \& Stratton, Inc.: 1963-1985.

- Kinney JM, Fürst P, Elwyn DH and Carpentier YA (1988). The intensive care patient. In: Nutrition and metabolism in patient care (Kinney JM, Jeejeebhoy KN, Hill GL and Owen OE, eds.). Philadelphia, Saunders: 656-671.

- Krebs H (1980). Glutamine metabolism in the animal body. In: Glutamine: metabolism, enzymology and regulation (Mora J and Palacios R, eds.). New York, 319-329.

- Lacey JM and Wilmore DW (1990). Is glutamine a conditionally essential amino acid? Nutr Rev 48: 297-309.

- Long CL, Spencer JL, Kinney JM and Geiger JW (1971). Carbohydrate metabolism in man: effect of elective operations and major injury. J Appl Physiol 31: 110-116.

- Long CL, Jeevanandam M, Kim BM and Kinney JM (1977). Whole body protein synthesis and catabolism in septic man. Am J Clin Nutr 30: 1340-1344.

- Lopes J, Rusel DM, Whitwell J and Jeejeeboy KN (1982). Skeletal muscle function in malnutrition. Am J Clin Nutr 36: 602-610.

- MacLennan PA, Brown RA and Rennie MJ (1987). A positive relationship between protein 
synthetic rate and intracellular glutamine concentration in perfused rat skeletal muscle. FEBS letters 215: 187-191.

- MacLennan PA, Smith K, Weryk B, Watt PW and Rennie MJ (1988). Inhibition of protein breakdown by glutamine in perfused rat skeletal muscle. FEBS letters 237: 133-136.

- Mainous MR, Tso P, Berg RD and Dietch EA (1991). Studies of the route, magnitude, and time course of bacterial translocation in a model of systemic inflammation. Arch Surg 126: 33-37.

- Meister A (1984). Enzymology of glutamine. In: Glutamine metabolism in mammalian tissues (Häussinger D and Sies H, eds.). Berlin, Heidelberg, Springer-Verlag: 3-15.

- Odessey R and Parr B (1982). Effect of insulin and leucine on protein turnover in rat soleus muscle after burn injury. Metabolism 31: 82-87.

- Petersson B, Vinnars E, Waller S-O and Wernerman J (1992). Long-term changes in muscle free amino acid levels after elective abdominal surgery. Br J Surg 79: 212-216.

- Plumley DA, Souba WW, Hautamaki D, Martin TD, Flyn TC, Rout R and Copeland EM (1990). Accelerated lung amino acid release in hyperdynamic septic surgical patients. Arch Surg 125: 57-61.

- Pomposelli JJ, Palombo JD, Hamawy KJ, Bistrian BR, Blackburn GL and Moldawer LL (1985). Comparison of different techniques for estimating rates of protein synthesis in vivo in healthy and bacteraemic rats. Biochem J 226: 37-42.

- Preedy VR, Paska L, Sugden PH, Schofield PS and Sugden MC (1988). The effect of surgical stress and short-time fasting on protein synthesis in vivo in diverse tissues of the mature rat. Biochem J 250: 179-188.

- Rennie MJ, Bennegärd K, Edén E and Lundholm K (1984). Urinary excretion and efflux from the leg of 3-methylhistidine before and after major surgical operation. Metabolism 33: 250256.

- Rennie MJ (1985). Muscle protein turnover and the wasting to injury and disease. Brit Med Bul 41:257-264.

- Rennie MJ, Babij P, Taylor PM, Hundal HS, MacLennan P, Watt PW, Jepson MM and Millward DJ (1986). Characteristics of a glutamine carrier in skeletal muscle have important consequences for nitrogen loss in injury, infection and chronic disease. Lancet 2: 1008-1012.

- Roth E, Karner J and Ollenschlager G (1990). Glutamine: an anabolic effector? JPEN 14: 130S$136 \mathrm{~S}$.

- Rowe B (1985). Glutamine synthase from muscle. Methods in Enzymology 113: 199-212.

- Sakamoto A, Moldawer LL, Palombo JD, Desai SP, Bistrian BR and Blackburn GL (1983). Alterations in tyrosine and protein kinetics produced by injury and branched chain amino acid administration in rats. Clin Sci 64: 312-331.

- Sawyer RT (1993). Intravenous zymosan-A challenge induces an alveolar inflammatory response. Inflammation 17: 273-281.

- Schrimer WJ, Schrimer JM, Naff GB and Fry DE (1988). Systemic complement activation produces hemodynamic changes characteristic of sepsis. Arch Surg 123: 316-321.

- Schumer W, Erve PR and Obernolte RP (1971). Endotoxemic effect on cardiac and skeletal muscle mitochondria. Surg Gynecol and Obstetrics 133: 433-436.

- Shangraw RE and Turinsky J (1984). Altered protein kinetics in vivo after single-limb burn injury. Biochem J 223: 747-753.

- Shaw JHF and Wolfe RR (1987). Fatty acid and glycerol kinetics in septic patients and in patients with gastrointestinal cancer. Ann Surg 205: 368-376.

- Shaw JHF and Wolfe RR (1989). An integrated analysis of glucose, fat, and protein metabolism in severely traumatized patients. Ann Surg 209: 63-72.

- Souba WW and Austgen TR (1990). Interorgan glutamine flow following surgery and infection. JPEN 14: 90S-93S.

- Souba WW (1991). Glutamine: a key substrate for the splanchnic bed. Annu Rev Nutr 11: 285-308.

- Stehle P, Mertes N, Puchstein C, Zander J, Albers S, Lawin P and Fürst P (1989). Effect of parenteral glutamine dipeptide supplements on muscle glutamine loss and nitrogen balance 
after major injury. Lancet 1: 231-233.

- Steinberg S, Flynn W, Kelly K, Bitzer L, Sharma P, Gutierrez G, Baxter J, Lalka D, Sands A, VanLiew J, Hasset J, Price R, Beam T and Flint L (1989). Development of a bacteria-independent model of the multiple organ failure syndrome. Arch Surg 124: 1390-1395.

- Sugden PH and Fuller SJ (1991). Review article. Regulation of protein turnover in skeletal and cardiac muscle. Biochern J 273: 21-37.

- Takahashi M and Hood DA (1993). Chronic stimulation-induced changes in mitochondria and performance in rat skeletal muscle. J Appl Physiol 74: 934-941.

- Tomera JF (1991). The effect of burn trauma on adenosine $3^{\prime}: 5^{\prime}$ cyclic monophosphate, inositol triphosphate and contraction in mouse gastrocnemius muscle. J Burn Care Rehabil 12: 485497.

- Vinnars E, Bergström J and Fürst P (1975). Influence of the postoperative state on the intracellular free amino acids in human muscle tissue. Ann Surg 182: 665-671.

- Vinnars E, Hammerqvist F, Von der Decken A and Wernerman J (1990). Role of glutamine and its analogs in posttraumatic muscle protein and amino acid metabolism. JPEN 14: 125S1295 .

- Von Asmuth EJU, Maessen JG, Van der Linden CJ and Buurman WA (1990). Tumor necrosis factor alpha (TNF- $\alpha$ ) and interleukin 6 in a zymosan-induced shock model. Scand. J Immunol 32: 313-319.

- Walser M (1991). Misinterpretation of nitrogen balances when glutamine stores fall or are replenished. Am J Clin Nutr 53: 1337-1338.

- Wannemacher RW, Pekarek RS, Klainer AS, Bartelloni PJ, Dupont HL, Hornick RB and Beisel WR (1975). Detection of a leukocytic endogenous mediator-like mediator of serum amino acid and zinc depression during various infectious illnesses. Infect Immun 11: 873-875.

- Welbourn CRB and Young Y (1992). Endotoxin, septic shock and acute lung injury - neutrophils, macrophages and inflammatory mediators. Br J Surg 79: 998-1003.

- Wernerman J, Von der Decken A and Vinnars E (1986). Protein synthesis in skeletal muscle in relation to nitrogen balance after abdominal surgery: the effect of total parenteral nutrition. JPEN 10: 578-582.

- Wernerman J, Hammerqvist F, Ali MR and Vinnars E (1989). Glutamine and ornithine- $\alpha-$ ketoglutarate but not branched-chain amino acids reduce the loss of muscle glutamine after surgical trauma. Metabolism 38: 63-66.

- Wilmore DW, Black PR and Muhlbacher F (1983). Injured man: trauma and sepsis. In: Nutritional support of the seriously ill patients (Winters RW and Greene HL, eds.). London, Academic Press, Inc.: 33-52.

- Wilmore DW, Smith RJ, O'Dwyer ST, Jacobs DO, Ziegler TR and Wang X-D (1988). The gut: A central organ after surgical stress. Surgery 104: 917-923.

- Windmueller HG and Speath AE (1974). Uptake and metabolism of plasma glutamine by the small intestine. J Biol Chem 249: 5070-5079.

- Wolfe RR, Jahoor F and Hartl WH (1989). Protein and amino acid metabolism after injury. Diabetes Metabolism Reviews 5: 149-164.

- Woolf LI, Groves AC and Duff JH (1979). Amino acid metabolism in dogs with E. colibacteremic shock. Surgery 85: 212-218.

- Wusteman M, Wight DGD and Elia M (1990). Protein metabolism after injury with turpentine: a rat model for clinical trauma. Am J Physiol 259: E763-E769.

- Wusteman M and Elia M (1991). Effect of glutamine infusion on glutamine concentration and protein synthetic rate in rat muscle. JPEN 15: 521-525.

- Yang RD, Moldawer LL, Sakamoto A, Keenan RA, Matthews DE, Young VR, Wannemacher RW, Blackburn GL and Bistrian BR (1983). Leukocyte endogenous mediator alters protein dynamics in rats. Metabolism 32: 654-660.

- Yoshida S, Lanza-Jacoby S and Stein TP (1991). Leucine and glutamine metabolism in septic rats. Biochem J 276: 405-409.

- Yoshida S, Leskiw MJ, Schluter MD, Bush KT, Nagale RG, Lanza-Jacoby S and Stein TP (1992). 
Effect of total parenteral nutrition, systemic sepsis, and glutamine on gut mucosa in rats. Am J Physiol 263: E368-E373.

- Zeiderman MR, Welchew EA and Clark RG (1990). Changes in cardiorespiratory and muscle function associated with development of postoperative fatigue. $\mathrm{Br}$ J Surg 77: 576-580. 


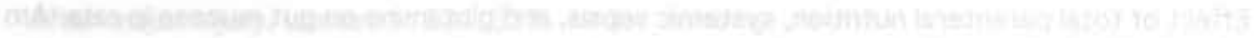

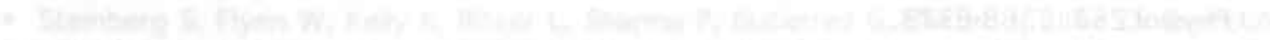

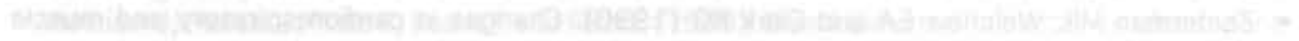

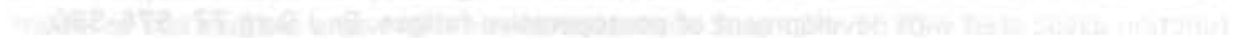




\section{Tracer kinetics are of limited value for measuring in vivo protein synthesis and degradation rates in muscle of anesthetized rats.}

Olav E. Rooyackers and Anton J.M. Wagenmakers. Department of Human Biology, University of Limburg, Maastricht, The Netherlands.

\section{Abstract}

1. Measuring amino acid kinetics using muscle exchange rates of labeled phenylalanine and leucine have been successfully used to estimate in vivo protein synthesis and degradation rates in human forearm and hind-limb of large laboratory animals. No good method to measure protein breakdown in muscle of small laboratory animals is available and, therefore, we investigated whether this technique can be applied to rats.

2. Using $\left[{ }^{3} \mathrm{H}\right]$ phenylalanine exchange measurements, protein synthesis and degradation rates were measured in muscle of fed and 2 day starved rats. Protein synthesis rates obtained in this way were compared with rates measured with the phenylalanine flooding dose ter.hnique in sham operated fed and fasted rats and in awake fed rats.

3. Using the $\left[{ }^{3} \mathrm{H}\right]$ phenylalanine exchange method, protein synthesis rates in 2 day starved rats were increased to $292 \%$ and protein degradation rates to $217 \%$ of the values obtained in fed rats. However, due to a high variation these changes were not statistically significant. Results obtained with the flooding dose technique indicate that 2 days starvation reduced protein synthesis rates to $61 \%$ of the fed value.

4. We conclude that due to the high variation and the contradictory results, $\left[{ }^{3} \mathrm{H}\right]$ phenylalanine exchange measurements as applied in this study are of limited value to estimate in vivo protein synthesis and degradation rates of individual tissues in rats. 


\section{Introduction}

Muscle protein wasting is a common feature observed in many diseases and has repeatedly been reported to be a major complication in patients with trauma and sepsis. To investigate the mechanism of muscle wasting preferably both protein synthesis and protein degradation should be measured in vivo. For measuring protein synthesis alone incorporation of labeled amino acids into tissue protein following a primed continuous infusion or a flooding dose are generally accepted methods (Barret \& Gelfand 1989, Sugden \& Fuller 1991). Few techniques (difference between muscle growth rate and protein synthesis rate, loss of amino acid tracer from prelabeled protein, 3-methylhistidine efflux and exchange rates of amino acid tracers) are available, however, to estimate in vivo protein degradation rates (Barret \& Gelfand 1989, Rennie 1985, Sugden \& Fuller 1991). Exchange rates of certain amino acid tracers across individual tissues seem reliable for estimating both protein synthesis and degradation in large animals (dogs and lambs) and human subjects (Barret et al 1987, Bennet et al 1990, Cheng et al 1985, Cheng et al 1987, Gelfand \& Barret 1987, Gelfand et al 1988, Louard et al 1990, Oddy \& Lindsay 1986). Many animal models to study metabolic derangements accompanied by muscle protein wasting during diseased states have been developed in rats and have created a need for a method to measure protein degradation rates in small animals. Sugden and Fuller (Sugden \& Fuller 1991 ) suggested potential technical problems in small animals with catheterization and plasma flow measurements necessary to apply the tracer exchange method. Both these techniques have been adapted for usage in rats by members of our research group (Dejong et al 1992). In this study we, therefore, investigated whether $\left[{ }^{3} \mathrm{H}\right]$ phenylalanine exchange measurements can be used in rats to simultaneously estimate rates of protein degradation and synthesis in muscle tissue.

Using $\left[{ }^{3} \mathrm{H}\right]$ phenylalanine exchanges across hindquarter, we estimated protein synthesis and degradation rates in muscle of fed and 2 day starved rats. Protein synthesis rates obtained in this way were compared with rates obtained with the flooding dose technique applied under the same circumstances (sham operation) and in non operated fed rats. Five groups of rats were studied; two fed and two fasted groups for measuring protein synthesis with one of the two techniques $\left(\left[{ }^{3} \mathrm{H}\right]\right.$ phenylalanine exchange or flooding dose) under anesthesia and surgery (needed to perform the exchange measurements) and one fed group for measuring protein synthesis with the flooding dose technique in the awake fed control animal. 


\section{Methods}

Principle of the [3H]phenylalanine exchange measurements (Barret et al 1987, Louard et al 1990)

For an amino acid with a constant intracellular concentration the net uptake or release is the difference between production and utilization. For phenylalanine, which is neither synthesized nor degraded in skeletal muscle, at steady state the net balance across muscle tissue is the difference between protein synthesis and degradation and therefore:

(1) release $=$ uptake - net balance, protein degradation $=$ protein synthesis - net balance

According to the Fick principle net balances can be calculated from the arteriovenous difference of phenylalanine [Phe] and the plasma flow:

(2) net balance $=\left([\text { Phe }]_{\mathrm{a}}-[\mathrm{Phe}]_{\mathrm{v}}\right) \times$ flow

where $[\mathrm{Phe}]_{\mathrm{a}}$ is the phenylalanine concentration in the artery and $[\mathrm{Phe}]_{v}$ is the phenylalanine concentration in the vein.

Protein synthesis can be estimated by measuring the net uptake of phenylalanine from the artery:

(3) protein synthesis $=E R \times[P h e]_{a} \times$ flow

The extraction rate (ER) for labeled phenylalanine is the arteriovenous difference in radioactivity divided by the arterial radioactivity (all in $\mathrm{dpm} / \mathrm{ml}$ ).

The rate of protein degradation across the hindquarter is estimated from the dilution of the specific activity of phenylalanine by unlabelled phenylalanine released from tissue protein due to protein degradation. This can be calculated from equations 1-3:

(4) protein degradation

$$
\begin{aligned}
& =\left(E R \times[P h e]_{a} \times \text { flow }\right)-\left(\left([\mathrm{Phe}]_{\mathrm{a}}-[\mathrm{Phe}]_{\mathrm{v}}\right) \times \text { flow }\right) \\
& =\text { flow } \times[\mathrm{Phe}]_{v} \times\left(1-\mathrm{SA}_{\mathrm{v}} / \mathrm{SA}_{a}\right)
\end{aligned}
$$

In which SA is the specific activity of phenylalanine (dpm/nmol).

These calculations do not take into account the reutilization of phenylalanine derived from protein breakdown and therefore synthesis and degradation rates are minimal estimations.

These assumptions and calculations are valid only in a steady state during isotopic equilibrium of $\mathrm{L}-\left[4{ }^{3} \mathrm{H}\right]$ phenylalanine in plasma. A primed constant infusion with a 
priming bolus of $0.55 \mu \mathrm{Ci}(18 \mathrm{pmol}) / 100 \mathrm{~g}$ body weight followed by an infusion of $0.44 \mu \mathrm{Ci}(15 \mathrm{pmol}) / 100 \mathrm{~g}$ body weight per hour results in a plateau reached within $30 \mathrm{~min}$ in 250-300 g rats (Fig. 1).

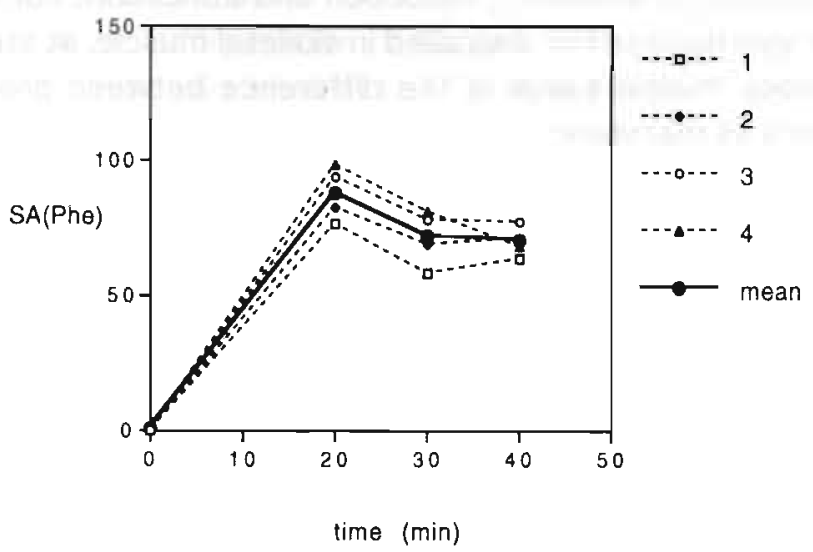

Figure 1. Specific activity $(\mathrm{dpm} / \mathrm{nmol})$ of $\left[{ }^{3} \mathrm{H}\right]$ phenylalanine during a primed continuous infusion of L-[4- $\left.{ }^{3} \mathrm{H}\right]$ phenylalanine $(0.55 \mu \mathrm{Ci}$ and $18 \mathrm{pmol} / 100 \mathrm{~g}$ body weight as a bolus followed by a continuous infusion of $0.44 \mu \mathrm{Ci}$ and $15 \mathrm{pmol} / 100 \mathrm{~g}$ body weight per hour) into a jugular vein catheter. Approximately $400 \mu$ l of blood was sampled from a carotic artery catheter just before starting of the infusion and at 20,30 and 40 min during the infusion in 4 anesthetized rats. The specific activities were measured as described in the methods.

\section{Experiments}

All experiments were performed using male Wistar rats (250-300 g, Winkelmann, Borchen, Germany), individually housed under standard conditions ( $12 \mathrm{~h}$ lightdark cycle) and fed standard lab chow and water ad libitum.

On day 0 rats were randomly assigned to one of the following groups (5-6 rats/ group);

A: fed, $\left[{ }^{3} \mathrm{H}\right]$ phenylalanine exchange measurements

B: 2 days fasted, $\left[{ }^{3} \mathrm{H}\right]$ phenylalanine exchange measurements

C: fed, $\left[{ }^{3} \mathrm{H}\right]$ phenylalanine flooding dose technique, sham operated

D: 2 days fasted, $\left[{ }^{3} \mathrm{H}\right]$ phenylalanine flooding dose technique, sham operated

E: fed, $\left[{ }^{3} \mathrm{H}\right]$ phenylalanine flooding dose technique, non restrained awake rats

After a 4 day acclimatization period, food was taken away from the rats of the fasted groups ( $B$ and $D$ ) in the morning. Experiments were performed 48 to 54 hours later. Food was taken away from the fed rats just before the start of the measurements and these rats were, therefore, fasted for 0-6 hours. 


\section{Procedures groups $A$ and $B$}

Fed and 2 day starved rats were anesthetized using ether. Rectal temperature was monitored and maintained at or close to pre-anesthesia levels using a heating blanket. The right carotic artery and the left jugular vein were cannulated with PE-50 catheters. The inferior caval vein and the abdominal aorta (just above the bifurcation) were cannulated with a 25-gauge needle fitted to silastic tubing (Silastic Medical Grade Tubing $0.051 \mathrm{~cm} \mathrm{ID,} 0.094 \mathrm{~cm} \mathrm{OD)}$ ) and cemented in place with cyanoacrylate adhesive.

After positioning of the catheters, $L-\left[4-{ }^{3} \mathrm{H}\right]$ phenylalanine was infused $(0.55 \mu \mathrm{Cl}$ and $18 \mathrm{pmol} / 100 \mathrm{~g}$ body weight as a bolus followed by a continuous infusion of $0.44 \mu \mathrm{Ci}$ and $15 \mathrm{pmol} / 100 \mathrm{~g}$ body weight per hour) into the jugular vein until steady state (30 $\mathrm{min})$. For flow blood determination, para-aminohippuric acid $(\mathrm{PAH} ; 5 \mathrm{mM}$, iso-osmotic, $\mathrm{pH} 7.4$ ) infusion in the aortic catheter was started 10 minutes after positioning of the catheters. A priming dose of $0.15 \mathrm{ml} / 100 \mathrm{~g}$ body weight of a $50 \mathrm{mM}$ PAH solution was followed by continuous infusion of a $5 \mathrm{mM}$ PAH solution at a rate of $1.5 \mathrm{ml} / \mathrm{h}$ (Dejong et al 1992). Approximately 30 min after the $\left[{ }^{3} \mathrm{H}\right]$ phenylalanine infusion was started blood samples were obtained by slowly aspiring blood $( \pm 800 \mu \mathrm{l})$, first from the carotic artery and immediately thereafter from the inferior caval vein. The blood samples were kept on ice in heparinized cups until further processing (maximal $3 \mathrm{~min}$ ). Part of the blood sample was deproteinized with perchloric acid (PCA) for PAH measurements. Of the remainder, plasma was separated by centrifugation and used for determination of the specific activity of phenylalanine. $100 \mu$ Plasma was deproteinized with sulfosalicylic acid for amino acid analysis. Processed samples were stored at $-80^{\circ} \mathrm{C}$ until analysis.

\section{Procedures group $C$ and $D$}

Fed and 2 day starved rats were sham operated and catheters placed as described for group A and B. Ten min after positioning of the catheters an infusion of PAH (see above) into the aortic catheter was started. Five min later a flooding dose of L-[4- $\left.{ }^{3} \mathrm{H}\right]$ phenylalanine $(150 \mathrm{mM} ; 40 \mu \mathrm{Ci} / \mathrm{ml} ; 1 \mathrm{ml} / 100 \mathrm{~g}$ body weight) was injected into the jugular vein as described before (Garlick et al 1980). Muscle (gastrocnemius) was sampled $15 \mathrm{~min}$ later, rapidly frozen in liquid nitrogen using a precooled pair of tongs and stored at $-80^{\circ} \mathrm{C}$ until analysis of $\left[{ }^{3} \mathrm{H}\right]$ phenylalanine incorporation into protein. Due to the laparotomy necessary to insert the catheters the flooding dose had to be administered intravenously instead of intraperitoneally. No difference from the intraperitoneal administration is to be expected because of the comparable fractional synthesis rates obtained with both techniques (Garlick et al 1980, Jepson et al 1986).

\section{Procedure group $E$}

Fed control rats were given an intraperitoneal injection with a flooding dose of $L$ $\left[4-{ }^{3} \mathrm{H}\right]$ phenylalanine ( $150 \mathrm{mM} ; 20 \mu \mathrm{Ci} / \mathrm{ml} ; 2 \mathrm{ml} / 100 \mathrm{~g}$ body weight) as described 
before (Jepson et al 1986). Muscle was sampled after $15 \mathrm{~min}$, rapidly frozen in liquid nitrogen using a precooled pair of tongs and stored at $-80^{\circ} \mathrm{C}$ until analysis.

\section{Measurements}

Plasma amino acid concentrations were determined by HPLC (Van Eijk et al 1988). For PAH-determination in whole blood a modification of the method used by Brun was used (Brun 1951, Dejong et al 1992). Plasma PAH concentration was calculated from whole blood PAH concentrations using the hematocrit. Plasma flow was calculated as follows (Dejong et al 1992, Katz \& Bergman 1969):

$$
\text { Flow }=\frac{1}{[\mathrm{PAH}]_{\mathrm{V}}-[\mathrm{PAH}]_{\mathrm{A}}} \times \frac{100}{\text { body weight }}\left[\mathrm{ml} \cdot \mathrm{min}^{-1} \cdot 100 \mathrm{~g} \text { body weight }{ }^{\mathrm{t}}\right]
$$

In which $I$ is the infusion rate of $\mathrm{PAH}(\mu \mathrm{mol} / \mathrm{min})$, and $[\mathrm{PAH}]_{V . A}$ are the concentrations of $\mathrm{PAH}$ in venous (V) and arterial (A) blood. The specific activity of phenylalanine $(\mathrm{dpm} / \mathrm{nmol})$ in the deproteinized plasma was determined using a modification of the method described by Suzuki and Yagi (Garlick et al 1980, Suzuki \& Yagi 1974). Phenylalanine was converted to ß-phenylethylamine with tyrosine decarboxylase and pyridoxal phosphate and extracted using chloroform/ heptane. Both concentration and radioactivity were determined to calculate specific activity:

$$
\mathrm{SA}=\text { radioactivity }(\mathrm{dpm} / \mathrm{ml}) / \text { concentration }(\mathrm{nmol} / \mathrm{ml})
$$

Concentrations of ATP, ADP, AMP, creatine phosphate and creatine were measured in PCA ( $1 \mathrm{M}$ ) extracts of muscle tissue of the experimental groups $C$ and $E$ using enzymatic methods (Harris et al 1974). These methods were adapted for a centifugal analyzer (COBAS-BIO, Roche Diagnostics).

\section{Calculations}

For calculating net balance and protein synthesis and degradation rates equations described above have been used. When using the flooding dose technique, fractional protein synthesis rates (FSR) were calculated from the specific activity of phenylalanine in the intracellular amino acid pool (precursor pool) and of the protein-bound phenylalanine in muscle (Garlick et al 1980, Jepson et al 1986):

$$
\mathrm{FSR}=\frac{\mathrm{SA}_{\text {bound }}}{\mathrm{SA}_{\text {precursor }}} \times \frac{1}{\text { time }} \times 100[\% / \text { day }]
$$

For the intraperitoneally administered flooding dose as applied to group $\mathrm{E}$ the SA of the precursor pool was multiplied by 0.9 to correct for the longer period to reach isotope equilibrium in the intracellular pool as suggested before (Jepson et al 1986). 
Statistical analysis of differences between groups was performed using the nonparametric Mann-Whitney U-test. Significance was set at $p<0.05$. All values are given as mean (range).

\section{Results}

Body weight was significantly decreased in 2 day starved rats in comparison with fed control rats (258 (range: $242-266$ ) vs 304 (range: $292-314$ ) gram). Since not for all animals plasma flows were available, mean flows per group were used for calculation instead of individual flows. Also plasma flow values from another study closely comparable to the present one (same breed and age of rats both fed and $48 \mathrm{~h}$ fasted) were used. Plasma flow rates were not different between the fasted and fed rats $(1.92 \pm 0.54$ (SEM; $n=15)$ vs $2.11 \pm 0.68($ SEM; $n=11)$ $\mathrm{ml}^{\mathrm{min}} \mathrm{mi}^{-1} .100 \mathrm{~g} \mathrm{body}$ weight $\left.^{-1}\right)$.

Using $\left[{ }^{3} \mathrm{H}\right]$ phenylalanine exchange measurements protein synthesis rates in 2 day starved rats were increased to $292 \%$ and protein degradation rates to $213 \%$ of the fed value (Table 1). Due to the high variation these changes were not statistically significant. Net balance of phenylalanine across muscle was not different from zero in both fed and 2 day starved rats (Table 1). Protein synthesis rates measured with the flooding dose technique in the sham operated rats were decreased in the starved rats to $61 \%$ of the value obtained in fed rats (Table 1). Protein synthesis rates measured in muscle of the awake fed rats were significantly higher $(65 \%)$ than in the anesthetized sham operated fed rats (Table 1 ).

Concentrations of ATP and ADP were significantly decreased in muscle of sham operated fed rats in comparison with awake fed rats (Table 2). No differences were observed in concentrations of AMP, creatine phosphate and the sum of creatine and creatine phosphate (Table 2).

Table 1 . Protein synthesis and degradation rates. Values are given as mean (range) of 5-6 rats. *: significantly different from the fed group; \#:significantly different from the fed, sham operated, flooding dose group.

\section{Group $A$ and $B$}

net balance ( $\mathrm{nmol}$ Pheimin per $100 \mathrm{~g}$ bodyweight) degradation ( $\mathrm{nmol}$ Phe/min per $100 \mathrm{~g}$ bodyweight) synthesis (nmol Phe/min per $100 \mathrm{~g}$ bodyweight)

\section{Group C and D}

protein synthesis (\%/day)

Group E

protein synthesis (\%/day)

\section{fasted}

fed

$\begin{array}{rlrl}-10.8 & (-24.9-10.9) & -7.5 & (-36.1-9.5) \\ 49.3 & (16.9-73.9) & 22.7 & (13.6-32.7) \\ 26.5 & (5.8-60.1) & 9.1 & (-14.7-26.4) \\ & & & \\ 4.6 & & & \\ 4.6-5.2) & 7.5 & (5.5-9.4)\end{array}$


Tabie 2. Concentrations ( $\mu \mathrm{mol} / \mathrm{g}$ wet weight) of intracellular muscle metabolites of control (group E) and sham operated (group C) rats. Values are given as mean (range) of 5 rats. *: significantly different from the control group.

$\begin{array}{lllll}\text { ATP } & 5.23^{*}(4.36-6.26) & 6.45 & (6.14-6.77) \\ \text { ADP } & 0.67 *(0.53-0.78) & 0.83 & (0.75-0.95) \\ \text { AMP } & 0.09 & (0.07-0.14) & 0.07 & (0.05-0.08) \\ \text { creatine phosphate } & 17.7 & (14.5-22.2) & 17.7 & (13.4-19.8) \\ \text { creatine + creatine phosphate } & 27.6 & (23.1-35.5) & 32.0 & (29.8-33.1)\end{array}$

\section{Discussion}

Changes in protein content of muscle are the result of the net balance between protein synthesis and degradation rates and, therefore, preferably both should be measured when investigating mechanisms of protein deposition or wasting. In vivo estimations of both protein synthesis and degradation rates obtained with exchange measurements using amino acid tracers have been successfully used in human subjects and large laboratory animals (Barret et al 1987, Bennet et al 1990, Cheng et al 1985, Cheng et al 1987, Gelfand \& Barret 1987, Gelfand et al 1988, Louard et al 1990, Oddy \& Lindsay 1986). Thompson and colleagues (Thompson et al 1989) have used the technique to measure protein turnover in human forearm. The protein synthesis rate they obtained was in the same quantitative range as rates obtained with other techniques and they concluded that phenylalanine tracer kinetics, therefore, are valid to measure protein turnover in human muscle. Barret and colleagues (Barret et al 1987) concluded from their results that the technique can be used for estimating in vivo protein turnover in specific muscle beds of anesthetized dogs. In small laboratory animals, such as rats and mice, incorporation of labeled amino acids is generally accepted for measuring in vivo protein synthesis rates, but no good method is available to measure protein degradation rates in vivo (Barret \& Gelfand 1989, Sugden \& Fuller 1991). Sugden and Fuller (Sugden \& Fuller 1991) suggested that tracer exchange measurements may be applicable only to larger animals and human subjects because of potential technical problems with catheterization and plasma flow measurements in small animals. Both these techniques have been adapted for usage in rats by members of our research group (Dejong et al 1992). Here 
we investigated whether $\mathrm{L}-\left[4{ }^{3} \mathrm{H}\right]$ phenylalanine exchange measurements can be used to estimate in vivo protein synthesis and degradation rates in rat skeletal muscle.

Using $\left[{ }^{3} \mathrm{H}\right]$ phenylalanine exchanges mean protein synthesis rates were aimost three-fold higher in fasted rats than in fed rats. However, this increase was not statistically significant due to a large variation between individual animals. Also net balance and protein degradation values showed a high variation. Starvation resulted in a reduction in protein synthesis rates when measured with the flooding dose technique in sham operated rats. The effect of starvation on protein synthesis rates in rat muscle has been measured with different techniques in the past; primed constant infusion in vivo (Millward et al 1976), incubated muscle (Li \& Goldberg 1976, Li et al 1979), perfused hindquarter (Goodman et al 1981) and in vivo flooding dose (Baillie et al 1988, Jepson et al 1986, Preedy et al 1988 , Preedy \& Sugden 1989). In all these studies starvation has been reported to cause a reduction in protein synthesis rates. Cheng and colleagues (Cheng et al 1987) utilizing $\left[1-{ }^{13} \mathrm{C},{ }^{15} \mathrm{~N}\right]$ leucine exchange measurements observed decreased protein synthesis rates of the forearm muscle of fasted human subjects. The three fold increase in apparent protein synthesis rates calculated here from $\left[{ }^{3} \mathrm{H}\right]$ phenylalanine exchange measurements in 2 day starved rats is in contradiction to these findings.

Calculations of protein synthesis and degradation rates using $\left[{ }^{3} \mathrm{H}\right]$ phenylalanine exchange measurements were based on only one sampling point in this study because not more blood can be obtained from rats without the risk of hypovolemia. Protein synthesis rates measured with the flooding dose technique were mean values of a 15 min incorporation period and, therefore, variation in time due to for instance depth of anesthesia will have a larger influence on values obtained with the exchange measurements (Table 1 ). The surgical procedure required to apply the $\left[{ }^{3} \mathrm{H}\right]$ phenylalanine flux measurements in this study may have had an effect on muscle metabolism as indicated by decreased protein synthesis rates measured with the flooding dose technique in anesthetized and sham operated fed rats and decreased concentrations of ATP and ADP.

The controversial effect of starvation on protein synthesis rates, the large variation in values obtained, the effect of the required procedure on protein synthesis rates measured with the flooding dose technique, and the decreased concentrations of ATP and ADP in muscle indicate that $\left[{ }^{3} \mathrm{H}\right]$ phenylalanine tracer kinetics as performed in this study do not reliably estimate in vivo protein turnover rates of rat muscle.

\section{Acknowledgement}

We thank Cees Dejong for performing the surgery and Mick Deutz and Hans van Eijk for measuring amino acid concentrations. 


\section{References}

- Baillie AGS, Maltin CA and Garlick. PJ (1988). The effect of fasting and insulin infusion on muscle protein synthesis in immature and adult rats. Proc Nutr Soc 47: 114A.

- Barret EJ, Revkin $\mathrm{JH}_{3}$ Young LH, Zaret BL, Jacob R and Gelfand RA (1987). An isotopic method for measurement of muscle protein synthesis and degradation in vivo. Biochem J 245: 223228.

- Barret EJ and Gelfand RA (1989). The in vivo study of cardiac and skeletal muscle protein turnover. Diabetes/Metabolism Reviews 5: 133-148.

- Bennet WM, Connacher AA, Scrimgeour CM and Rennie MJ (1990). The effect amino acid infusion on leg protein turnover assessed by $\mathrm{L}-\left[{ }^{15} \mathrm{~N}\right]$ phenylalanine and $\mathrm{L}-\left[1-{ }^{13} \mathrm{C}\right]$ leucine exchange. Eur J Clin Invest 20: 41-50.

- Brun C (1951). A rapid method for the determination of para-aminohippuric acid in kidney function tests. J Lab Clin Med 37: 955-958.

- Cheng KN, Dworzak F, Ford GC, Rennie MJ and Halliday D (1985). Direct determination of leucine metabolism and protein breakdown in humans using the $\mathrm{L}-\left[1-{ }^{13} \mathrm{C},{ }^{15} \mathrm{~N}\right]$-leucine and the forearm model. Eur J Clin Invest 15: 349-354.

- Cheng KN, Pacy PJ, Dworzak F, Ford GC and Halliday D (1987). Influence of fasting on leucine and muscle protein metabolism across the human forearm determined using $\mathrm{L}-\left[1-{ }^{13} \mathrm{C},{ }^{15} \mathrm{~N}\right]$ leucine as a tracer. Clin Sci 73: 241-246.

- Dejong CHC, Kampman MT, Deutz NEP and Soeters PB (1992). Altered glutamine metabolism in rat portal drained viscera and hindquarter during hyperammonia. Gastroenterology 102: 936-948.

- Garlick PJ, McNurlan MA and Preedy VR (1980). A rapid and convenient technique for measuring the rate of protein synthesis in tissue by injection of $\left[{ }^{3} \mathrm{H}\right]$-phenylalanine. Biochem J 192: 719 723.

- Gelfand RA and Barret EJ (1987). Effect of physiologic hyperinsulinemia on skeletal muscle protein synthesis and breakdown in man. J Clin Invest 80: 1-6.

- Gelfand RA, Glickman MG, Castellino P, Louard RJ and Defronzo RA (1988). Measurement of $\mathrm{L}-\left[1-{ }^{14} \mathrm{C}\right]$ leucine kinetics in splanchnicus and leg tissue in humans. Effect of amino acid infusion. Diabetes 37: 1365-1372.

- Goodman MN, McElaney MA and Rudermen NB (1981). Adaptation to prolonged starvation in the rat: curtailment of skeletal muscle proteolysis. Am J Physiol 241: E321-E327.

- Harris RC, Hultman E and Nordesjö LO (1974). Glycogen, glycolytic intermediates and high energy phosphates determined in biopsy samples of musculus quadriceps femoris of man at rest. Methods and variances of values. Scand J Clin Lab Invest 33: 109-120.

- Jepson MM, Pell JM, Bates PC and Millward DJ (1986). The effect of endotoxaemia on protein metabolism in skeletal muscle and liver of fed and fasted rats. Biochem J 235: 329-336.

- Katz ML and Bergman EN (1969). Simultaneous measurements of hepatic and portal blood flow in the sheep and dog. Am J Physiol 216: 946-952.

- Li JB and Goldberg AL (1976). Effects of food deprivation on protein synthesis and degradation in rat skeletal muscles. Am J Physiol 231: 441-448.

- Li JB, Higgins JE and Jefferson LS (1979). Changes in protein turnover in skeletal muscle in response to fasting. Am J Physiol 236: E222-E228.

- Louard RJ, Barret EJ and Gelfand RA (1990). Effect of infused branched-chain amino acids on muscle and whole-body amino acid metabolism in man. Clin Sci 79: 457-466.

- Millward DJ, Garlick PJ, Nnanyelugo DO and Waterlow JC (1976). The relative importance of muscle protein synthesis and breakdown in the regulation of muscle mass. Biochem $\mathrm{J} 156$ : 185-188.

- Oddy VH and Lindsay DB (1986). Determination of rates of protein synthesis, gain and degradation in intact hind-limb muscle of lambs. Biochem J 233: 417-425.

- Preedy VR, Paska L, Sugden PH, Schofield PS and Sugden MC (1988). The effect of surgical 
stress and short-time fasting on protein synthesis in vivo in diverse tissues of the mature rat. Biochem J 250: 179-188.

- Preedy VR and Sugden PH (1989). The effect of fasting or hypoxia on rates of protein synthesis in vivo in subcellular fractions of rat heart and gastrocnemius muscle. Biochem J 257: 519527.

- Rennie MJ (1985). Muscle protein turnover and the wasting to injury and disease. Brit Med Bul 41: 257-264.

- Sugden PH and Fuller SJ (1991). Review article. Regulation of protein turnover in skeletal and cardiac muscle. Biochem J 273: 21-37.

- Suzuki $O$ and Yagi K (1976). A fluorometric assay for B-phenylethylamine in rat brain. Anal Biochem 75: 192-200.

- Thompson GN, Pacy PJ, Meritt H, Ford GC, Read MA, Cheng KN and Halliday D (1989). Rapid measurement of whole body and forearm protein turnover using a $\left[{ }^{2} \mathrm{H}_{\mathrm{s}}\right]$ phenylalanine model. Am J Physiol 256: E631-E639.

- Van Eijk HMH, Van der Heijden MAH, Van Berlo CLH and Soeters PB (1988). Fully automated liquid-chromatographic determination of amino acids. Clin Chem 34: 2510-251 3. 


\section{Prolonged changes in protein and amino acid metabolism after zymosan treatment in rats.}

Olav E. Rooyackers, Wim H.M. Saris, Peter B. Soeters* and Anton J.M. Wagenmakers. Departments of Human Biology and *Surgery, University of Limburg, Maastricht, The Netherlands.

Clinical Science (1994) 87(5): 619-626.

\section{Abstract}

1. Intraperitoneal injections of zymosan were given to rats, according to a modified procedure, in order to create a pattern of illness with an acute critical phase for $36 \mathrm{~h}$ followed by a prolonged recovery phase lasting for at least 10 days. Changes in amino acid and protein metabolism were studied in both phases.

2. Differences between this modified and the original zymosan model are a lower mortality (16\%) which is limited to the first 36 critical hours and absence of signs of severe illness during the prolonged recovery phase.

3. Wasting of muscle protein and decreased protein synthesis rates in muscle were observed during the acute phase of illness. Liver size and liver protein synthesis rates were increased during the same period. The decrease in the total amount of muscle protein and the increase in liver weight were still present 12 days after zymosan treatment, despite a normalization of protein synthesis rates. Large decreases were observed in the concentrations of the conditionally essential amino acids glutamine and arginine in muscle during 6 days. Decreases in plasma glutamine and arginine 12 days after zymosan indicated that the rats were still not fully recovered on this day.

4. We conclude that injection of a single dose of zymosan in rats leads to metabolic derangements both during the acute phase of critical illness and during the prolonged recovery phase. The model seems suited for investigating the biochemical mechanisms behind these metabolic derangements and for studying therapeutic and nutritional interventions during recovery from critical illness. 


\section{Introduction}

During severe illness such as sepsis and trauma a complex metabolic derangement often leads to a protracted course in an intensive care unit. Loss of muscle mass and changes in the concentrations of amino acids and other metabolites are characteristic features in this period. Repeated tissue sampling for research purposes is restricted in critically ill patients for ethical reasons. Therefore, several animal models have been developed to investigate these metabolic derangements. However, the few animal models (cecal ligation and puncture, burn injury and repeated endotoxin administration) suitable to investigate the long term metabolic derangements as frequently seen in man all have important limitations. With cecal ligation and puncture (CLP) (Ardawi \& Majzoub 1991, Wichterman et al 1980) and burn injury (Ardawi 1988, Fong et al 1991) invasive techniques notably anesthesia and surgery are required to induce the catabolic state. Both models are also characterized by high mortality rates. Endotoxin administration, results in a short lived metabolic response due to rapid clearance of endotoxin, unless multiple injections or constant infusions are used (Jepson et al 1986). Prolonged or repeated administration, however, leads to endotoxin tolerance.

Goris and colleagues (Goris et al 1986, Van Bebber et al 1989) described a rat model for long term illness with clinical signs of sepsis and multiple organ failure existing for a period of 14 days. Illness in this model was induced by an aseptic intraperitoneal injection with zymosan suspended in liquid paraffin. Zymosan, which is a glucopolysaccharide from the cell wall of yeast, is a potent activator of the alternative pathway of complement (Schrimer et al 1988) and of macrophages (Steinberg et al 1989). A disadvantage of this model is a high mortality rate and a large variability in severeness of disease and mortality. Here we describe a modification of the zymosan model. This modified model showed a reproducible pattern of illness starting with an acute phase of critical illness with limited mortality rates which was followed by a prolonged recovery phase without mortality and signs of severe illness. In this modified model protein synthesis rates in muscle, liver and small intestinal mucosa and concentrations of amino acids in muscle and plasma have been measured up to 12 days after zymosan treatment.

\section{Methods}

Male Lewis rats (180-270 g), supplied by the central laboratory animal facilities of the University of Limburg, were individually housed and kept in a controlled environment ( 12 hour light cycle, $21-22^{\circ} \mathrm{C}$ and $50-60 \%$ humidity). Rats were fed a standard lab chow (SRM-A 2010, Hope Farms, The Netherlands) containing (wt/wt) approximately $25 \%$ protein, $6.5 \%$ fat and $39.5 \%$ carbohydrates. The rats were allowed to acclimatize for one week. The experiments were approved 
by the animal experimental committee of the University of Limburg.

Rats were given an aseptic intraperitoneal injection of zymosan $(50 \mathrm{mg}$ per $100 \mathrm{~g}$ body weight) suspended in liquid paraffin $(25 \mathrm{mg} / \mathrm{ml})$. The zymosan (Sigma Chemical Company) was sterilized by $\gamma$ radiation ( \pm 12000 rad). Suspensions were prepared in small portions using $25 \mathrm{ml}$ aliquots of sterilized liquid paraffin (Merck). An OMNI 1000 homogenizer (OMNI international) was used to provide a homogeneous suspension of zymosan in paraffin after which the suspension was sterilized by incubation at $100^{\circ} \mathrm{C}$ (water bath) for $90 \mathrm{~min}$.

Food intake is reduced after zymosan administration and therefore, paraffin injected control rats were pair fed. Pair feeding was performed in three periods during the day to ensure that the pair fed rats would not eat all the food at once and would subsequently be starving the remainder of the day. The three periods were from $8.00 \mathrm{am}$ till $3.00 \mathrm{pm}$, from $3.00 \mathrm{pm}$ till $10.00 \mathrm{pm}$, and from $10.00 \mathrm{pm}$ till $8.00 \mathrm{am}$.

Protein synthesis rates (muscle, liver and jejunal mucosa), tissue weights and concentrations of protein (muscle and liver) and amino acids (plasma and muscle) were measured $16 \mathrm{~h}$ and 2, 4, and 6 days after treatment with zymosan suspended in paraffin or paraffin only (pair fed). A control group with free access to rat chow and no paraffin injections was also included in the study. These rats were studied on day 3 to make them closely comparable to all the other experimental groups. In an additional experiment (experiment 2) tissue weights (muscle and liver) and concentrations of the amino acids glutamate (Glu), glutamine (Gln) and arginine (Arg) (plasma and muscle) were measured 12 days after treatment in zymosan injected, pair fed, and ad libitum fed rats. In both experiments groups were matched for age and initial body weight. During the experiment food intake and body weights were determined daily. On the day of the experiment the rats were starved from $8.00 \mathrm{am}$ till $12.00 \mathrm{am}$. Pair feeding was performed at $7.00 \mathrm{am}$ on this day. Protein synthesis rate measurements and sampling of tissues and blood were performed between 12.00 am and 2.00 $\mathrm{pm}$.

To measure protein synthesis rates the phenylalanine flooding dose technique as described by Jepson and colleagues (Jepson et al 1986) was used. Rats were injected intraperitoneally with a large dose of $\mathrm{L}-\left[4-{ }^{3} \mathrm{H}\right]$ phenylalanine $(150 \mu \mathrm{mol}$ of phenylalanine and $20 \mu \mathrm{Ci}$ of labelled phenylalanine $/ \mathrm{ml} ; 2 \mathrm{ml} / 100 \mathrm{~g}$ body weight). After $15 \mathrm{~min}$ the rats were killed by cervical dislocation and mixed blood was collected after decapitation. Gastrocnemius muscle, liver and jejunum were collected within $3 \mathrm{~min}$ after cervical dislocation. Muscle and liver were weighed and frozen in liquid nitrogen using a precooled pair of tongs. The jejunum was transferred to ice cold water and rinsed with ice cold water. The mucosa was separated from the seromuscular layer by scraping with a ice cold glass slide and frozen in liquid nitrogen using a precooled pair of tongs.

For measuring the incorporation of $\left[{ }^{3} \mathrm{H}\right]$ phenylalanine into tissue protein the method described by Garlick and colleagues was used (Garlick et al 1980). The 
same samples were used to measure protein concentration using the Lowry method (Lowry et al 1951). Fractional protein synthesis rates (FSR) were calculated from the specific activity $(\mathrm{SA} ; \mathrm{dpm} / \mathrm{nmol})$ of $\left[{ }^{3} \mathrm{H}\right]$ phenylalanine in the precursor pool (intracellular phenylalanine) and the SA of protein bound $\left[{ }^{3} \mathrm{H}\right]$ phenylalanine. To calculate the fractional protein synthesis rates in muscle the SA of intracellular phenylalanine was multiplied by 0.9 as described by Jepson and colleagues (Jepson et al 1986) because plateau labelling of the precursor pool in muscle is reached after 2 or 3 min only. For liver this correction factor was 1.0 (Jepson et al 1986). It was assumed that the correction factor for small intestine also is 1.0 .

$$
F S R=\frac{S A_{\text {protein bound }}}{S A_{\text {precursor }} \times \text { time }(\text { days })} \times 100 \%
$$

In a pilot experiment it was shown that no difference existed between zymosan treated and control rats in the time to reach plateau labelling (1-2 min) and the maintenance of the plateau for at least $20 \mathrm{~min}$ in blood after a flooding dose of $\left[{ }^{3} \mathrm{H}\right]$ phenylalanine.

Free amino acids in muscle and plasma were measured by HPLC (Van Eijk et al 1988). Plasma was deproteinized with sulfosalicylic acid. Intracellular amino acids in muscle were extracted using a $5 \%$ sulfosalicylic acid solution with norvaline $(0.5 \mathrm{mM})$ as an internal standard. Concentrations of glutamate, glutamine and arginine in muscle and plasma from experiment 2 were measured using enzymatic assays as described before (Gäde 1990, Lund 1990).

All measurements were done in duplicate, except for muscle protein synthesis rates which were done in triplicate. Values are given as mean (range). The MannWhitney U-test was used to determine statistically significant differences between the zymosan treated and pair fed rats at one time point and between the zymosan treated and the ad libitum fed control rats. Significance was set at $p<0.05$.

\section{Results}

\section{The rat model}

All rats injected with zymosan showed signs of severe illness including lethargy, anorexia, diarrhoea, and loss of hemorrhagic fluid from nose and eyes during two days after zymosan administration. The peritoneal cavity yielded remnants of paraffin and adhesions between abdominal organs were found 2, 4, 6 and 12 days after zymosan treatment. The liver was pale and had adhesions with the diaphragm and stomach. The pair fed rats (injected with paraffin only) and the ad libitum fed rats showed none of these abnormalities. Sixteen percent of the zymosan treated animals died during the first $36 \mathrm{~h}$ after injection. No animals died hereafter. Due to the induction of the illness food intake was dramatically reduced. Intake was reduced to $0.5 \mathrm{~g} /$ day on day one and two after which it 


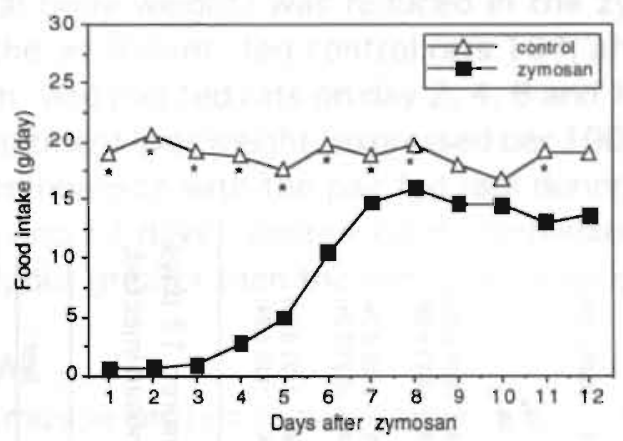

Figure 1. Food intake ( $\mathrm{g} /$ day) of control and zymosan treated rats. Values of experiment 2 are given in which rats were studied for 12 days after zymosan treatment. The rats in experiment 1 follow the same pattern of food intake for the 6 days that they were studied. *: Significantly different from control at $p<0.05$.

slowly increased to $70-80 \%$ of the normal intake between day 7 and 12 after zymosan treatment (Fig. 1).

The initial body weights were not significantly different between the experimental groups in both experiments (Table 1 and 2). The rats from experiment 2, however, had higher initial body weights in comparison with those of experiment 1. Due to the treatment both the pair fed and the zymosan treated rats lost weight in comparison with the fed control rats (Fig. 2). A decrease in weight was seen during the first 4 days, followed by a small increase. No catchup growth was observed. The reduction in body weight in the pair fed group was larger than in the zymosan treated rats. Muscle (gastrocnemius) weight (expressed

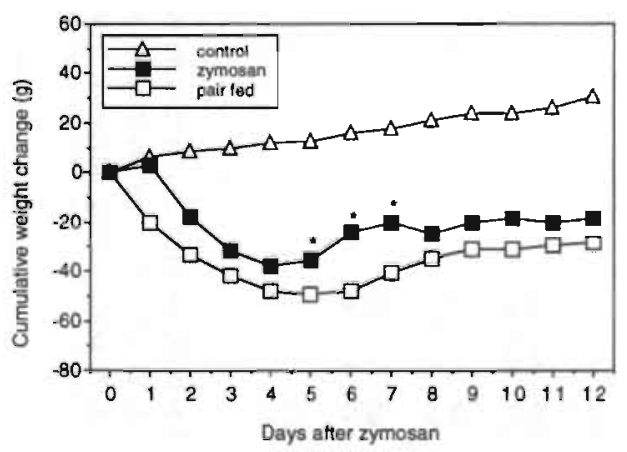

Figure 2. Cumulative changes in body weight $(\mathrm{g})$ of control, pair fed and zymosan treated rats. Values of experiment 2 are given in which rats were studied for 12 days after zymosan treatment. The rats in experiment 1 follow the same pattern of cumulative weight change for the 6 days that they were studied. Rats were injected with either zymosan suspended in paraffin or with paraffin only (pair fed). Control rats were not injected. Changes were calculated from initial body weight and body weights attained every morning during the experiment. All numbers of the zymosan treated and the pair fed rats were significantly different from those of the control rats, except on day 0 for both experimental groups and on day 1 for the pair fed rats. *: Significant difference between zymosan treated and pair fed rats at $p<0.05$. 
Table 1 . Initial body weight, gastrocnemius weight, protein content, total protein, and dry/wet weight ratio $16 \mathrm{~h}$, and 2, 4 and 6 days (d) after treatment. Values are given as mean (range) of 6-8 rats. Con: ad libitum fed control; zym: zymosan injected; pf: pair fed rats. *: significantly different from control; \#: significantly different from pair fed. ': Values of ad libitum fed rats are obtained at day 3 to make them closely comparable to all other groups. Because growing rats are used these numbers should be slightly smaller for the younger rats and larger for the older rats. na: not analyzed.

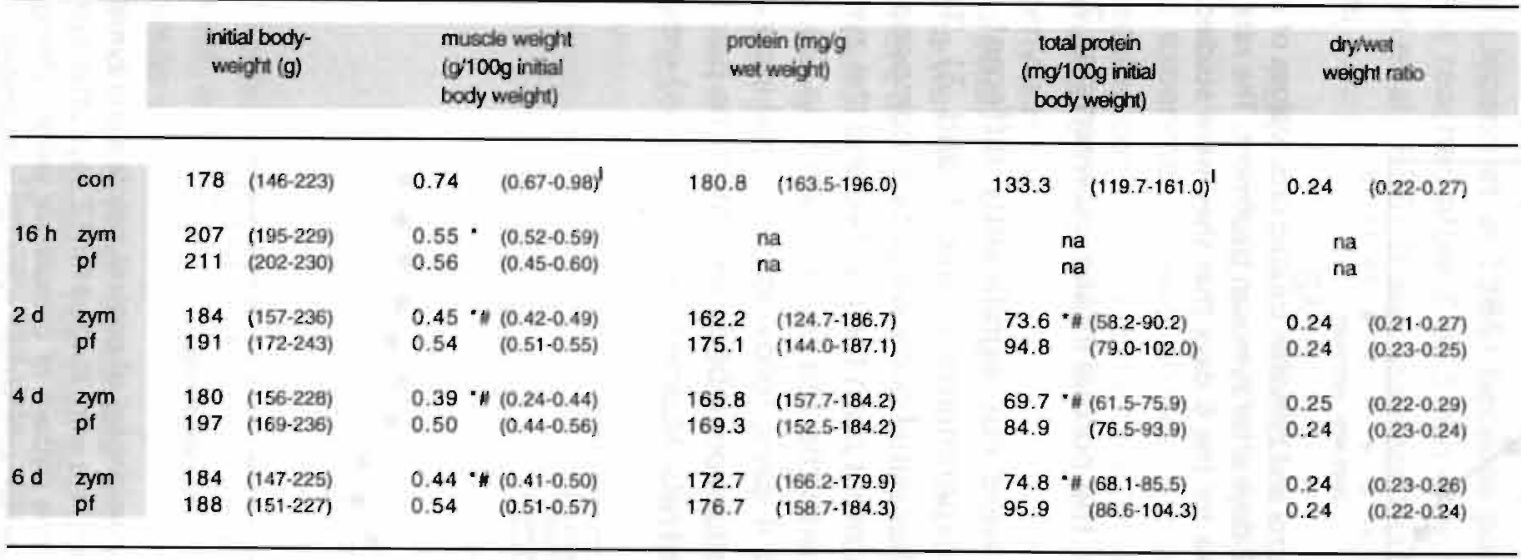

Table 2. Initial body weight, gastrocnemius weight, gastrocnemius protein and liver weight measured 12 days after treatment. Values are given as mean (range) of 6-8 rats. Con: ad libitum fed control; zym: zymosan injected; pf: pair fed rats. *: significantly different from control; \#: significantly different from pair fed.

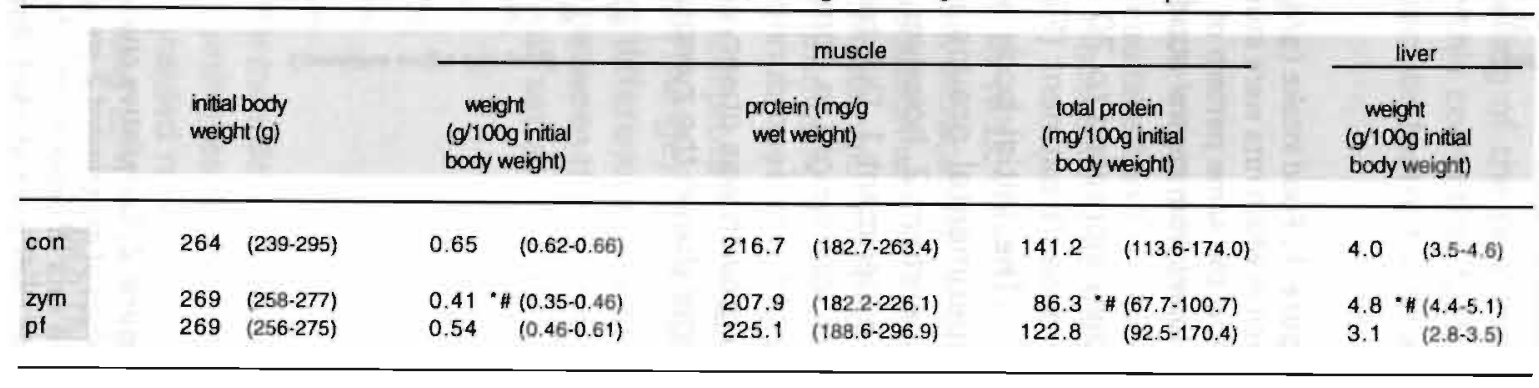


per $100 \mathrm{~g}$ of initial body weight) was reduced in the zymosan treated rats in comparison with the ad libitum fed control rats $16 \mathrm{~h}$ after treatment and with both the ad libitum and pair fed rats on day 2, 4, 6 and 12 (Table 1 and 2). Due to the zymosan treatment liver weight (expressed per $100 \mathrm{~g}$ of initial body weight) was increased in comparison with the pair fed rats during the whole experiment ( $16 \mathrm{~h}$ and $2,4,6$, and 12 days), decreased in comparison with the fed controls on $16 \mathrm{~h}$ and day 2 , but greater than the fed controls on day 12 (Table 2 and 3 ).

\section{Protein metabolism}

No differences in muscle protein concentration and dry/wet weight ratio were observed in the zymosan treated rats in comparison with the ad libitum and pair fed control rats (Table 1 ). Total muscle protein content (expressed per $100 \mathrm{~g}$ of initial body weight) was decreased in the zymosan treated rats 2, 4, 6, and 12 days after treatment in comparison with the ad libitum and pair fed control rats (Table 1 and 2). Total liver protein content (expressed per $100 \mathrm{~g}$ of initial body weight) was significantly decreased in the zymosan treated group in comparison with the fed control rats $16 \mathrm{~h}$ and 2 and 4 days after treatment, but was increased compared to the pair fed group on day 2, 4 and 6 (Table 3).

Table 3. Liver weight, protein content and total protein 16h, and 2, 4 and 6 days (d) after treatment. Values are given as mean (range) of 6-8 rats. Con: ad libitum fed control; zym: zymosan injected; pf: pair fed rats. *: significantly different from control; \#: significantly different from pair fed. ': Values of ad libitum fed rats are obtained at day 3 to make them closely comparable to all other groups. Because growing rats are used these numbers should be slightly smaller for the younger rats and larger for the older rats.

$\begin{array}{ccc}\text { liver weight } & \text { protein }(\mathrm{mg} / \mathrm{g} \text { wet } & \text { total protein } \\ (\mathrm{g} / 100 \mathrm{~g} \text { initial } & \text { weight }) & \text { ( } \mathrm{mg} / 100 \mathrm{~g} \text { initial } \\ \text { body weight) } & & \text { body weight) }\end{array}$

\begin{tabular}{|c|c|c|c|c|c|c|c|}
\hline & con & 5.2 & $(4.2-6.0)^{1}$ & 194.8 & (186.3-208.7) & 1008 & $(830-1135)^{\prime}$ \\
\hline \multirow[t]{2}{*}{$16 \mathrm{~h}$} & zym & $3.7 *$ & $(3.4-3.9)$ & 202.4 & $\#(187.7-218.0)$ & $744 *$ & $(642-828)$ \\
\hline & pf & 3.1 & $(3.0-3.2)$ & 224.9 & (215.3-231.3) & 700 & (666-729) \\
\hline \multirow{2}{*}{$2 d$} & zym & $3.9 *$ & $(3.8-4.3)$ & 187.3 & $\#(174.7-196.4)$ & $738^{*}$ & $(679-778)$ \\
\hline & pf & 2.9 & $(2.4-3.2)$ & 205.3 & $(182.0-218.3)$ & 589 & $(517-636)$ \\
\hline \multirow[t]{2}{*}{$4 d$} & zym & $4.8 \#$ & $(4.6-5.2)$ & 168.5 & * (125.4-189.5) & $811^{*}$ & H (606-949) \\
\hline & pí & 3.3 & $(2.8-3.6)$ & 180.6 & (166.5-195.9) & 592 & $(504-650)$ \\
\hline & zym & $5.1 \#$ & $(4.6-5.8)$ & 176.9 & $(132.7-199.3)$ & $895 \hbar$ & (718-998) \\
\hline & pf & 4.0 & $(3.2-4.4)$ & 173.5 & $(165.4-186.8)$ & 687 & (552-757) \\
\hline
\end{tabular}


Fractional protein synthesis rates in muscle were decreased in the zymosan treated rats in comparison with the pair fed and fed control rats $16 \mathrm{~h}$ after treatment (Table 4). On day 2 and 4 after treatment protein synthesis rates were decreased in muscle of the zymosan treated rats in comparison with the fed control rats. No difference, however, was seen at these time points between the zymosan treated and pair fed rats. Liver protein synthesis rates of the zymosan treated rats were increased $16 \mathrm{~h}, 2$ days, and 4 days after treatment in comparison with the pair fed rats (Table 4). In comparison with the fed controls an increase was seen 2 days after treatment. Fractional protein synthesis rates of the mucosal layer of the jejunum were decreased in the zymosan treated rats on day 6 in comparison with both control groups (Table 4).

Table 4. Fractional protein synthesis rates (\%/day) of gastrocnemius, liver, and mucosal layer of the jejunum $16 \mathrm{~h}$, and 2, 4 and 6 days (d) after treatment. Values are given as mean (range) of 6-8 rats. Con: ad libitum fed control; zym: zymosan injected; pf: pair fed rats. *: significantly different from control; \#: significantly different from pair fed.

\begin{tabular}{|c|c|c|c|c|c|c|c|}
\hline & & \multicolumn{2}{|c|}{ muscle } & \multicolumn{2}{|c|}{ liver } & \multicolumn{2}{|c|}{ mucosa } \\
\hline & con & 8.2 & $(6.8-9.8)$ & 78.7 & $(66.7-102.6)$ & 83.1 & $(67.9-91.6)$ \\
\hline \multirow[t]{2}{*}{$16 \mathrm{~h}$} & zym & $5.3 * \hbar$ & $(4.3-6.5)$ & $74.1 \#$ & $(60.1-87.7)$ & 105.2 & $(67.2-142.7)$ \\
\hline & pf & 9.5 & $(7.5-10.5)$ & 53.4 & $(46.3-58.4)$ & 92.5 & $(38.7 \cdot 145.4)$ \\
\hline \multirow[t]{2}{*}{$2 d$} & zym & $5.1^{*}$ & $(3.4-6.8)$ & $113.5^{*}$ & $(78.8-143.9)$ & 74.2 & $(60.6-87.8)$ \\
\hline & pf & 5.7 & $(3.7-8.0)$ & 77.4 & $(59.6-99.5)$ & 78.4 & $(67.9-87.1)$ \\
\hline \multirow[t]{2}{*}{$4 d$} & zym & $5.8 *$ & $(4.2-9.2)$ & $88.6 \#$ & $(73.7-100.4)$ & 72.9 & $(61.9-88.4)$ \\
\hline & pf & 5.7 & $(3.8-7.2)$ & 72.9 & $(58.8-85.2)$ & 78.2 & $(59.8-99.9)$ \\
\hline \multirow[t]{2}{*}{$6 \mathrm{~d}$} & zym & 6.9 & $(5.6-8.1)$ & 81.9 & $(67.2-99.1)$ & 66.1 & \# (52.4-77.0) \\
\hline & pf & 6.5 & $(3.9-8.1)$ & 70.0 & (55.8-88.9) & 85.5 & (59.3-98.4) \\
\hline
\end{tabular}

\section{Amino acid metabolism}

Both in plasma (Table 5) and muscle (Table 6) the sum of the amino acid concentrations was decreased on 2, 4, and 6 days after zymosan treatment in comparison with one or both of the control groups. The concentrations of phenylalanine and tyrosine are not included because these are higher than the physiological values due to the flooding dose of phenylalanine given for measuring the protein synthesis rates. Most essential amino acids (threonine, methionine, tryptophane, lysine, valine, leucine, isoleucine) were decreased in concentration in plasma 2, 4, and 6 days after treatment (Table 5). Of the non-essential amino acids plasma concentrations of glutamate and glutamine were decreased on day 6 and 12 and of arginine on day 4, 6 and 12 after zymosan treatment (Table 5 
and 7). In muscle, of the essential amino acids, threonine was decreased 2, 4, 6 days after treatment, lysine on day 2 and 4 , and the sum of the branched chain amino acids (valine, leucine and isoleucine) on day 4 and 6 (Table 6 ). Of the nonessential both the concentrations of glutamine and arginine were decreased respectively on day 2 and 6 , and on day 2,4 , and 6 . No differences in concentrations of glutamate, glutamine and arginine were observed in muscle 12 days after treatment (Table 7).

Table 5. Plasma concentrations of amino acids $(\mu \mathrm{mol} / \mathrm{l}) 2,4$ and 6 days after treatment. Values are given as mean (range) of 6-8 rats. *: significantly different from control; \#: significantly different from pair fed.

\begin{tabular}{|c|c|c|c|c|c|c|c|c|c|c|}
\hline \multirow{2}{*}{$\begin{array}{l}\text { amino } \\
\text { acid }\end{array}$} & \multicolumn{3}{|c|}{2 days } & \multicolumn{3}{|c|}{4 days } & \multicolumn{3}{|c|}{6 days } & \multirow[t]{2}{*}{ control } \\
\hline & zymosan & & pair-fed & zymosan & & pair-led & zymosan & & pair-fed & \\
\hline Gh & 635 & & $\begin{array}{c}754 \\
\end{array}$ & 664 & & 648 & $\begin{array}{c}552 \\
(361-670)\end{array}$ & $\#$ & 740 & $\begin{array}{c}637 \\
(500-683)\end{array}$ \\
\hline Arg & $\begin{array}{c}133 \\
(85-210)\end{array}$ & & $\begin{array}{c}160 \\
(116-207)\end{array}$ & $\begin{array}{c}81 \\
(73-89)\end{array}$ & "\# & $\begin{array}{c}171 \\
(136-212)\end{array}$ & $\begin{array}{c}74 \\
(55.107)\end{array}$ & '" & $\begin{array}{c}152 \\
(100-200)\end{array}$ & $\begin{array}{c}146 \\
\text { (112-185) }\end{array}$ \\
\hline Val & $\begin{array}{c}175 \\
(130-232)\end{array}$ & & $\begin{array}{c}183 \\
(117.222)\end{array}$ & $\begin{array}{c}104 \\
(91 \cdot 110)\end{array}$ & " & $\begin{array}{c}163 \\
(126-192)\end{array}$ & $\begin{array}{c}114 \\
(98-139)\end{array}$ & " & $\begin{array}{c}183 \\
(137 \cdot 219)\end{array}$ & $\begin{array}{c}158 \\
(112-188)\end{array}$ \\
\hline lie & $\begin{array}{c}71 \\
(56-91)\end{array}$ & & $\begin{array}{c}81 \\
(51 \cdot 108)\end{array}$ & $\begin{array}{c}44 \\
(40-48)\end{array}$ & " & $\begin{array}{c}52 \\
(39-63)\end{array}$ & $\begin{array}{c}41 \\
(36-46)\end{array}$ & " & $\begin{array}{c}63 \\
(49-75)\end{array}$ & $\begin{array}{c}63 \\
(49-72)\end{array}$ \\
\hline Leu & 124 & & 127 & 70 & 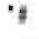 & 98 & 69 & "\# & 104 & 102 \\
\hline BCAA & $\begin{array}{c}(97-167) \\
369 \\
(283-482)\end{array}$ & & $\begin{array}{c}(82-172) \\
390 \\
(250-495)\end{array}$ & $\begin{array}{c}(61-77) \\
219 \\
(193-234)\end{array}$ & $" z$ & $\begin{array}{c}(67-12) \\
313 \\
(232-374)\end{array}$ & $\begin{array}{c}(59-83) \\
225 \\
(193-268)\end{array}$ & • & $\begin{array}{c}(84-124) \\
351 \\
(270-410)\end{array}$ & $\begin{array}{c}(75-121) \\
323 \\
(236-381)\end{array}$ \\
\hline Thr & $\begin{array}{c}177 \\
(125-306)\end{array}$ & $\nexists$ & $\begin{array}{c}266 \\
(184-320)\end{array}$ & $\begin{array}{c}100 \\
(85-119 !\end{array}$ & $" \#$ & $\begin{array}{c}263 \\
(229-310)\end{array}$ & $\begin{array}{c}174 \\
(122-253)\end{array}$ & t & $\begin{array}{c}230 \\
(194-265)\end{array}$ & $\begin{array}{c}208 \\
(155-232)\end{array}$ \\
\hline Met & $\begin{array}{c}44 \\
(35-52)\end{array}$ & & $\begin{array}{c}46 \\
(36-59)\end{array}$ & $\begin{array}{c}27 \\
(23-30)\end{array}$ & ' & $\begin{array}{c}45 \\
(38-56)\end{array}$ & $\begin{array}{c}21 \\
(18-25)\end{array}$ & 'है & $\begin{array}{c}38 \\
(28-48)\end{array}$ & $\begin{array}{c}39 \\
(30-47)\end{array}$ \\
\hline Tाp & $\begin{array}{c}56 \\
(44-77)\end{array}$ & $\#$ & $\begin{array}{c}69 \\
{[51-89]}\end{array}$ & $\begin{array}{c}34 \\
(26-45)\end{array}$ & 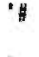 & $\begin{array}{c}80 \\
(62.101)\end{array}$ & $\begin{array}{c}42 \\
(32-56)\end{array}$ & 'if & $\begin{array}{c}61 \\
(43-73)\end{array}$ & $\begin{array}{c}59 \\
{[42-69)}\end{array}$ \\
\hline Lys & $\begin{array}{c}329 \\
(274-427)\end{array}$ & $\#$ & $\begin{array}{c}421 \\
(323 \cdot 517)\end{array}$ & $\begin{array}{c}269 \\
(176-352)\end{array}$ & ' & $\begin{array}{c}326 \\
(203-415)\end{array}$ & $\begin{array}{c}347 \\
(330-559)\end{array}$ & & $\begin{array}{c}342 \\
(246-476)\end{array}$ & $\begin{array}{c}372 \\
(324-423)\end{array}$ \\
\hline Glu & $\begin{array}{c}103 \\
(58-166)\end{array}$ & & $\begin{array}{c}113 \\
(60-170)\end{array}$ & $\begin{array}{c}94 \\
(70-125)\end{array}$ & & $\begin{array}{c}82 \\
(73-93)\end{array}$ & $\begin{array}{l}70 \\
(60-79)\end{array}$ & $" \sharp$ & $\begin{array}{c}90 \\
(68-115)\end{array}$ & $\begin{array}{c}124 \\
(81 \cdot 196)\end{array}$ \\
\hline Ala & $\begin{array}{c}344 \\
(227-603)\end{array}$ & & $\begin{array}{c}307 \\
(237-427)\end{array}$ & $\begin{array}{c}276 \\
(224-314)\end{array}$ & & $\begin{array}{c}359 \\
(283-510)\end{array}$ & $\begin{array}{c}208 \\
(182-242)\end{array}$ & & $\begin{array}{c}347 \\
(290-397)\end{array}$ & $\begin{array}{c}242 \\
(197 \cdot 270)\end{array}$ \\
\hline Asก & $\begin{array}{c}58 \\
(48 \cdot 75)\end{array}$ & " & $\begin{array}{c}64 \\
(50-78)\end{array}$ & $\begin{array}{c}33 \\
(22-41)\end{array}$ & ; & $\begin{array}{c}47 \\
(41 \cdot 59)\end{array}$ & $\begin{array}{c}31 \\
(24-33)\end{array}$ & $\cdot$ & $\begin{array}{c}40 \\
(23-62)\end{array}$ & $\begin{array}{c}40 \\
(30-50)\end{array}$ \\
\hline Ser & $\begin{array}{c}255 \\
(201-395)\end{array}$ & \# & $\begin{array}{c}316 \\
(246-418)\end{array}$ & $\begin{array}{c}192 \\
(152-267)\end{array}$ & 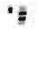 & $\begin{array}{c}352 \\
(316-434)\end{array}$ & $\begin{array}{c}221 \\
(140-376)\end{array}$ & ; & $\begin{array}{c}381 \\
(327-422)\end{array}$ & $\begin{array}{c}262 \\
(210-302)\end{array}$ \\
\hline Gly & $\begin{array}{c}342 \\
(194594)\end{array}$ & & $\begin{array}{c}361 \\
(256-439)\end{array}$ & $\begin{array}{c}3018 \\
\{279-373\}\end{array}$ & 11 & $\begin{array}{c}492 \\
(439-604)\end{array}$ & $\begin{array}{c}238 \\
(214257)\end{array}$ & 's & $\begin{array}{c}477 \\
(376-5 m)\end{array}$ & $\begin{array}{c}395 \\
(333-483)\end{array}$ \\
\hline His & $\begin{array}{c}73 \\
(45-97)\end{array}$ & & $\begin{array}{c}63 \\
(46-88)\end{array}$ & $\begin{array}{c}60 \\
(55-66)\end{array}$ & & $\begin{array}{c}67 \\
(59-79)\end{array}$ & $\begin{array}{c}52 \\
(40-57)\end{array}$ & i & $\begin{array}{c}65 \\
(51-76)\end{array}$ & $\begin{array}{c}60 \\
(47 \cdot 73)\end{array}$ \\
\hline Cit & $\begin{array}{c}72 \\
(49-105)\end{array}$ & & $\begin{array}{c}81 \\
(59-102)\end{array}$ & $\begin{array}{c}75 \\
(57-84)\end{array}$ & & $\begin{array}{c}78 \\
(65.94)\end{array}$ & $\begin{array}{c}90 \\
(73-126)\end{array}$ & & $\begin{array}{c}98 \\
(74-134)\end{array}$ & $\begin{array}{c}82 \\
(60-106)\end{array}$ \\
\hline Tau & $\begin{array}{c}126 \\
{[65-253]}\end{array}$ & ' & $\begin{array}{c}156 \\
(124-182)\end{array}$ & $\begin{array}{c}147 \\
(80-285)\end{array}$ & & $\begin{array}{c}223 \\
(136-392)\end{array}$ & $\begin{array}{c}108 \\
(79-162)\end{array}$ & ' & $\begin{array}{c}288 \\
(224-376)\end{array}$ & $\begin{array}{c}210 \\
(136-274)\end{array}$ \\
\hline Sum & $\begin{array}{c}2932 \\
(2674-3387)\end{array}$ & 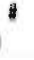 & $\begin{array}{c}3567 \\
(2898-4167)\end{array}$ & $\begin{array}{c}2580 \\
(2381.2689)\end{array}$ & " & $\begin{array}{c}3525 \\
\text { (2983-4431) }\end{array}$ & $\begin{array}{c}2471 \\
(2175 \cdot 2680)\end{array}$ & "\# & $\begin{array}{c}3697 \\
(3001-4189)\end{array}$ & $\begin{array}{c}3194 \\
(2508-3660)\end{array}$ \\
\hline
\end{tabular}


Table 6. Gastrocnemius concentrations of amino acids (nmol/g wet weight) 2, 4 and 6 days after treatment. Values are given as mean (range) of 6-8 rats. *: significantly different from control; \#: significantly different from pair fed.

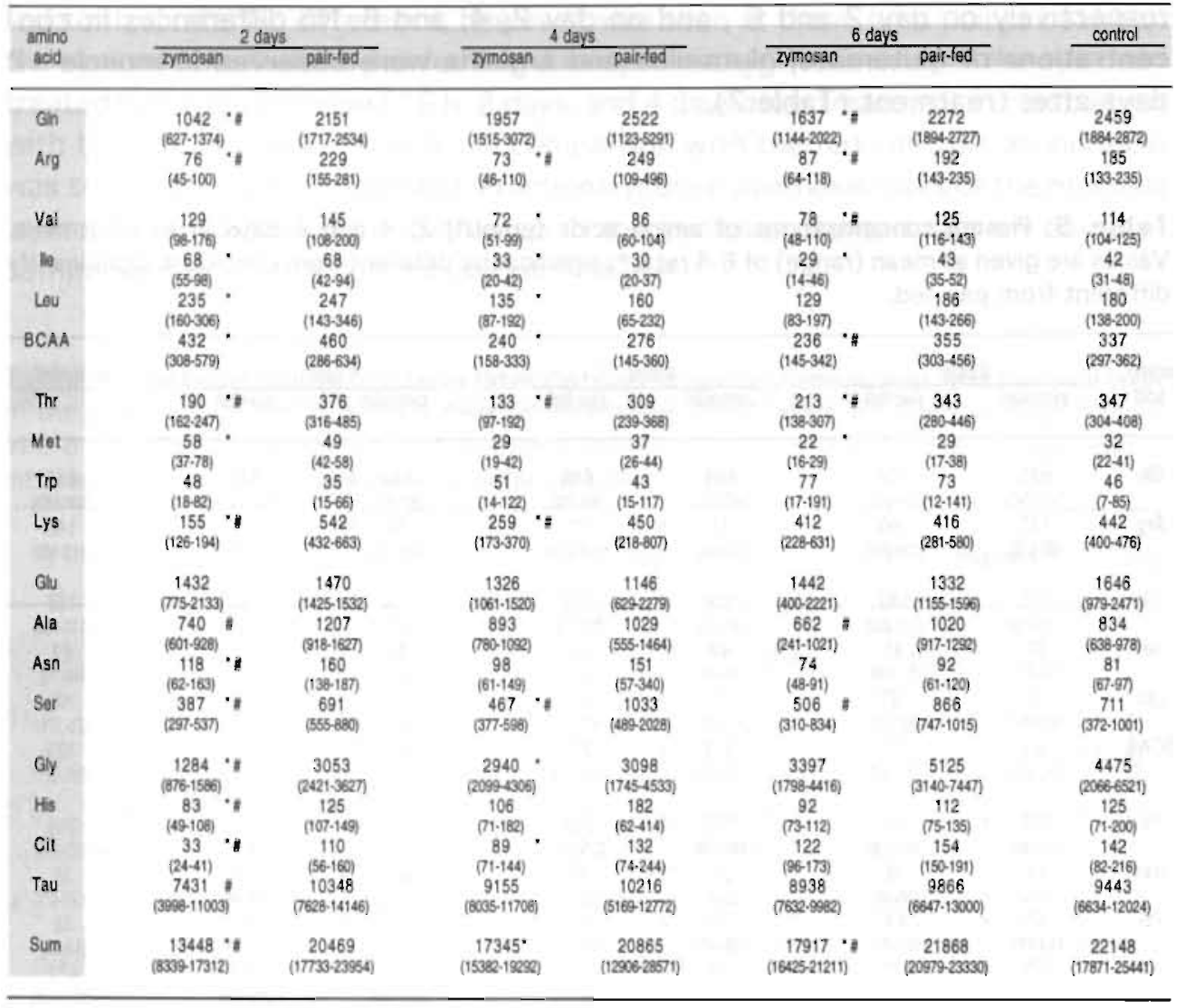

Table 7. Gastrocnemius and plasma concentrations of Glu, Gln and Arg measured 12 days after treatment. Values are given as mean (range) of 6-8 rats. Con: ad libitum fed control; zym: zymosan injected; pf: pair fed rats. *: significantly different from control; \#: significantly different from pair fed.

\begin{tabular}{|c|c|c|c|c|c|c|c|c|c|c|c|c|}
\hline & \multicolumn{6}{|c|}{ muscle } & \multicolumn{6}{|c|}{ plasma } \\
\hline & \multicolumn{2}{|c|}{$\begin{array}{l}\text { Glu (umolvg } \\
\text { wel vroight) }\end{array}$} & \multicolumn{2}{|c|}{ Ginfumoly } & \multicolumn{2}{|c|}{$\begin{array}{l}\text { Arg (nmolg } \\
\text { wht weight) }\end{array}$} & \multicolumn{2}{|c|}{$\begin{array}{c}\text { Gu } \\
\text { (umoli) }\end{array}$} & \multicolumn{2}{|c|}{$\underset{\text { (umoil) }}{\mathrm{Gh}}$} & \multicolumn{2}{|c|}{$\begin{array}{l}\text { Avg } \\
\text { (umoln) }\end{array}$} \\
\hline con & 2.5 & $(2.2-3.0)$ & 3.4 & $(2,7-4.4)$ & 259 & $(161-360)$ & 174 & $(130-219)$ & 727 & $(588-810)$ & 201 & $\{188-220\}$ \\
\hline zym & 2.1 & $(1.9-2.9)$ & 3.3 & $(2,9-4.0)$ & 333 & $(212-402)$ & 89 & $(69-97)$ & 545 & $*(493-594)$ & 125 & $\cdot *(104.148)$ \\
\hline pt & 2.31 & $(2.0-2.6)$ & 3.4 & $(3.3-4.2)$ & 368 & (247-568) & 127 & $(108-165)$ & 692 & (561-915) & 190 & $(160-231)$ \\
\hline
\end{tabular}




\section{Discussion}

Many animal models have been developed to study the metabolic response to trauma and sepsis (for review see Fink \& Heard 1990). However, most models only show an acute severe and short lived period of illness. A simple intraperitoneal injection with zymosan suspended in paraffin, as used here, provided a model for studying both an acute phase of critical illness and a prolonged recovery phase.

Zymosan treatment has been used in several studies as a model for critical illness and multiple organ failure. Goris and colleagues who introduced the model in rats described a triphasic illness (Goris et al 1986, Van Bebber et al 1989). The first three days clinical signs of critical illness were observed such as lethargy, anorexia, hyperventilation, diarrhoea and loss of hemorrhagic fluid from nose and eyes. A stable intermediate period was then followed by the development of a second phase of severe illness with signs of multiple organ failure between 7 and 14 days after zymosan treatment. Steinberg and colleagues (Steinberg et al 1989) described histopathological changes in lung, liver and kidney 7 days after zymosan administration from which they concluded that injection of zymosan in rats created a model for multiple organ failure.

Several pilot experiments performed in our laboratory showed that the model as described by Goris and colleagues (Goris et al 1986, Van Bebber et al 1989) led to varying degrees of illness and variable mortality rates in repeated experiments. Much effort, therefore, has been put into improvement of the reproducibility of the model. The procedure to prepare the zymosan suspension has been modified (see methods) and the dose of zymosan was reduced to half the dose administered by Goris. This resulted in a decrease of acute mortality to $16 \%$ ( $35 \%$ in the studies of Goris), whereafter no additional rats died (another $15 \%$ in the studies of Goris). This modified model has led to a reproducible pattern of illness in six different experiments performed in our laboratory over the last two years with a total of 132 rats. Rats showed signs of severe illness during two to three days after which they slowly recovered as indicated by increasing food intake and gain of body weight. During the phase of severe illness characteristic changes in protein metabolism with muscle protein wasting, decreased muscle protein synthesis rates, increased liver weight and enhanced liver protein synthesis rates were observed. Although the rats did not show signs of critical illness anymore between day 6 and 12 changes in food intake, body weight, tissue weight and protein (day 6 and 12), concentrations of glutamine and arginine in plasma ( 6 and 12 days) and muscle ( 6 days) and mucosal protein synthesis rates ( 6 days) indicate that the zymosan treated rats were not fully recovered. There were, however, no signs of severe illness or multiple organ failure during this period in the modified model.

Muscle mass was found to be decreased on day 2, 4, 6 and 12 after zymosan treatment and since both the dry/wet weight ratio and the protein concentrations in the gastrocnemius muscle at these time points were unchanged, this suggests 
that the net loss was due to a reduction in muscle tissue. Both the pair fed and the zymosan treated rats lost muscle tissue, however, in the pair fed rats this was in proportion to the decreased body weight due to the semi starvation. The larger loss in the zymosan injected rats indicates that the wasting of muscle is the result of net protein catabolism induced by severe illness. If this protein wasting applies to the whole skeletal muscle compartment of the rat then the smaller loss of body weight in the zymosan treated rats in comparison with the pair fed rats may be the result of increased water retention in the zymosan treated rats. in critically ill patients water is often sequestered as nonfunctional extracellular fluid (Jacobson 1986).

Muscle wasting is a common feature during severe illness in humans and is often, at least in part, the result of decreased protein synthesis rates (Rennie \& Harrison 1984). In most animal models of sepsis and critical illness wasting of muscle mass is accompanied by reduced protein synthesis rates (Emery et al 1984, Jepson et al 1986, Wusteman et al 1990). In the zymosan injected rats muscle protein synthesis rates were reduced $16 \mathrm{~h}$ after treatment in comparison with the pair fed animals. Also altered protein breakdown rates may contribute to the changes in protein content but these were not measured because no good method for in vivo measurements is available in rats. The difference in total muscle protein content between zymosan injected and pair fed rats did not increase further after day 2.

In contrast to muscle, liver protein synthesis rates were increased not only in the critical phase but also on day 4 . Increases in total liver protein content and liver protein synthesis rates have also been observed in rats treated with endotoxin and turpentine (Jepson et al 1986, Wusteman et al 1990). This response in part may be a reflection of the increased synthesis rate of (retained) acute phase and endogenous proteins in liver.

Decreased concentrations of branched chain amino acids (BCAA) in plasma and muscle were seen 4 and 6 days after zymosan treatment in comparison with pair fed and fed controls. During severe illness a reduction in plasma BCAA concentration has been observed (Freund et al 1979, Fürst 1983). In a study of Stinnett and colleagues decreased plasma and intracellular muscle concentrations of BCAA have been reported in both patients and animals with severe burn injury (Stinnett et al 1982). Enhanced whole body and muscle oxidation rates of BCAA, reported during sepsis, burn injury and trauma (Jahoor et al 1989, Tischler \& Fagan 1983) may be the cause of these reduced concentrations.

Concentrations of the non-essential amino acid glutamine in muscle were reduced in comparison with the pair fed and fed control rats until 6 days after zymosan treatment. Plasma concentrations of glutamine were maintained until 6 days after zymosan treatment and reduced on day 12 after treatment. Decreased concentrations of glutamine in muscle have been repeatedly reported in critically ill patients (Askanazi et al 1980, Fürst et al 1977) and in animal models (Ardawi \& Majzoub 1991, Ardawi 1988, Wusteman et al 1990). Glutamine 
levels in human muscle stay low during a prolonged period (30 days) in contrast to changes in concentrations of other amino acids (Petersson et al 1992). Glutamine has more metabolic functions than any other amino acid (Krebs 1980) and is, therefore, suggested to become essential during severe illness (Lacey \& Wilmore 1990).

A positive correlation has been reported between concentrations of glutamine and protein synthesis rates in muscle both in vivo (Jepson et al 1988) and in vitro (MacLennan et al 1987). Rennie and colleagues hypothesized that a fall in muscle glutamine concentration is causally related to muscle wasting in patients (Rennie et al 1986). No such correlation ( $p=0.49$ ) was found in the zymosan treated rats (Fig. 3 ) due to the normalization of protein synthesis rates on day 6 in the zymosan treated rats in combination with reduced muscle concentrations of glutamine. Wusteman and colleagues observed a similar discripancy between changes in protein synthesis rate and glutamine concentration in muscle of dietary restricted rats and also came to the conclusion that this relation is not a universal one (Wusteman et al 1990).

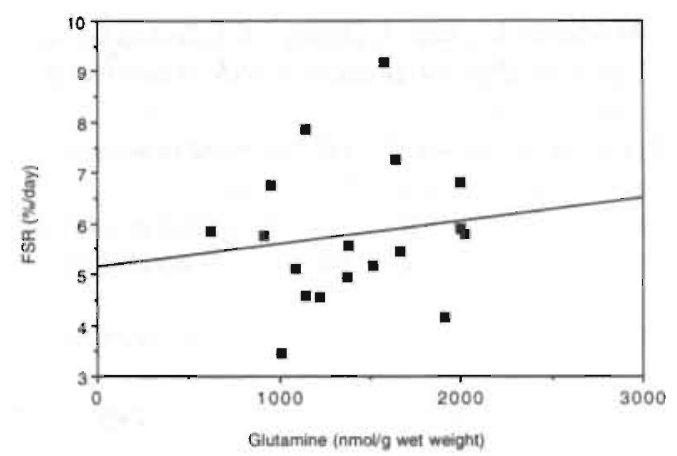

Figure 3. Relationship $\left(y=5.1+0.0004 x ; R^{2}=0.028 ; p=0.49\right)$ between muscle concentrations of glutamine and muscle fractional protein synthesis rates from the zymosan treated rats measured on day 2, 4 and 6. The Spearman rank correlation was used for statistical analysis.

Concentrations of arginine were decreased in muscle 2 and 6 days after zymosan treatment. Plasma concentrations, however, were reduced on day 4, 6 and 12. Arginine has also been suggested as an indispensable dietary amino acid in clinical conditions such as starvation, injury or stress due to its metabolic functions during growth, wound healing and tumor cell killing (Barbul 1986). The decreased concentrations of arginine in the zymosan treated rats both in plasma and muscle, therefore, may lead to an impaired recovery.

We conclude that injection of a single dose of zymosan in rats leads to metabolic derangements both during the acute phase of critical illness and during the prolonged recovery phase. The model seems suited for investigating the biochemical mechanisms behind these metabolic derangements and for studying therapeutic and nutritional interventions during recovery from critical illness. 


\section{Acknowledgement}

We thank Mick Deutz and Hans van Eijk for performing the amino acid analysis.

\section{References}

- Ardawi MSM (1988). Skeletal muscle glutamine production in thermally injured rats. Clin Sci 74: $16 \mathfrak{1} \cdot 172$.

- Ardawi MS and Majzoub MF (1991). Glutamine metabolism in skeletal muscle of septic rats. M:tabolism 40: 155-164.

- Askanazi J, Carpentier YA, Michelsen CB, Elwyn DH, Fürst P, Kantrowitz LR, Gump FE and Kinney JM (1980). Muscle and plasma amino acids following injury. Ann Surg 192: 78-85.

- Barbul A (1986). Arginine: biochemistry, physiology, and therapeutic implications. JPEN 10: 227-238.

- Emery PW, Lovell L and Rennie MJ (1984). Protein synthesis measured in vivo in muscle and liver of cachectic tumor-bearing rats. Canc Res 44: 2779-2784.

- Fink MP and Heard SO (1990). Current research review. Laboratory models of sepsis and septic shock. J Surg Res 49: 186-196.

- Fong Y, Minei JP, Marano A, Moldawer LL, Wei H, Shires iii GT, Shires GT and Lowry SF (1991). Skeletal muscle amino acid and myofibrillar protein mRNA response to thermal injury and infection. Am J Physiol 261: R536-R542.

- Freund H, Atamian S, Holroyde J and Fischer JE (1979). Plasma amino acids as predictors of the severity and outcome of sepsis. Ann Surg 190: 571-567.

- Fürst P, Bergström J, Kinney JM and Vinnars E (1977). Nutrition in postoperative catabolism. In: Nutritional aspects of care in the critically ill 3 (Richards JR and Kinney JM, eds.). New York, Churchill Livingstone: $389-410$.

- Fürst P (1983). Intracellular muscle free amino acids - their measurement and function. Proc Nutr Soc 42: 451-462.

- Gäde G (1990). Arginine and arginine phosphate. In: Methods of enzymatic analysis (Bergmeyer HU, eds.). 8. Weinheim, VCH Publicers: 425-431.

- Garlick PJ, McNurlan MA and Preedy VR (1980). A rapid and convenient technique for measuring the rate of protein synthesis in tissue by injection of $[3 \mathrm{H}]$-phenylalanine. Biochem $\mathrm{J} \mathrm{192:}$ 719-723.

- Goris RJA, Boekholtz WKF, Van Bebber IPT, Nuytinck JKS and Schilling PHM (1986). Multiple Organ Failure and sepsis without bacteria. An experimental model. Arch Surg 121: 897-901.

- Jacobson HR (1986). Fluid and electrolyte problems in surgery, trauma, and burns. In: Fluid and electrolytes (Kokko JP and Tannen RL, eds.). Philadelphia, W.B. Saunders Company: 791816.

- Jahoor F, Shangraw RE, Miyoshi H, Wallfish H, Herndon DN and Wolfe RR (1989). Role of insulin and glucose oxidation in mediating the protein catabolism of burns and sepsis. Am J Physiol 257: E323-E331.

- Jepson MM, Pell JM, Bates PC and Millward DJ (1986). The effect of endotoxaemia on protein metabolism in skeletal muscle and liver of fed and fasted rats. Biochem J 235: 329-336.

- Jepson MM, Bates PC, Broadbent P, Pell JM and Millward DJ (1988). Relationship between glutamine concentration and protein synthesis in rat skeletal muscle. Am J Physiol 255: E166E172.

- Krebs H (1980). Glutamine metabolism in the animal body. In: Glutamine: metabolism, enzymology and regulation (Mora J and Palacios R, eds.). New York, 319-329.

- Lacey JM and Wilmore DW (1990). Is glutamine a conditionally essential amino acid? Nutr Rev 48: 297-309. 
- Lowry OH, Rosebrough NJ, Farr AL and Randall RJ (1951). Protein measurement with the Folin phenol reagent. J Biol Chem 193: 265-275.

- Lund P (1990). L-glutamine and L-glutamate. In: Methods of enzymatic analysis (Bergmeyer HU, eds.). 8. Weinheim, VCH Publicers: 357-363.

- MacLennan PA, Brown RA and Rennie MJ (1987). A positive relationship between protein synthetic rate and intracellular glutamine concentration in perfused rat skeletal muscle. FEBS letters 215: 187-191.

- Petersson B, Vinnars E, Waller S-O and Wernerman J (1992). Long-term changes in muscle free amino acid levels after elective abdominal surgery. Br J Surg 79: 212-216.

- Rennie MJ and Harrison R (1984). Effect of injury, disease and malnutrition on protein metabolism in man. Unanswered questions. The Lancet 1: 323-325.

- Rennie MJ, Babij P, Taylor PM, Hundal HS, MacLennan P, Watt PW, Jepson MM and Millward DJ (1986). Characteristics of a glutamine carrier in skeletal muscle have important consequences for nitrogen loss in injury, infection and chronic disease. The Lancet 2: 1008-1012.

- Schrimer WJ, Schrimer JM, Naff GB and Fry DE (1988). Systemic complement activation produces hemodynamic changes characteristic of sepsis. Arch Surg 123: 316-321.

- Steinberg S, Flynn W, Kelly K, Bitzer L, Sharma P, Gutierrez G, Baxter J, Laiha D, Sands A, VanLiew J, Hasset J, Price R, Beam T and Flint L (1989). Development of a bacteria-independent model of the multiple organ failure syndrome. Arch Surg 124: 1390-1395.

- Stinnett JD, Alexander JW, Watanabe C, MacMillan BG, Fischer JE, Morris MJ, Trocki O, Miskell $P$, Edwards $L$ and James $H$ (1982). Plasma and skeletal muscle amino acids following severe burn injury in patients and experimental animals. Ann Surg 195: 75-89.

- Tischler ME and Fagan JM (1983). Response to trauma of protein, amino acid, and carbohydrate metabolism in injured and uninjured rat skeletal muscles. Metabolism 32: 853-867.

- Van Bebber IPT, Boekholz WKF, Goris RJA, Schillings PHM, Dinges HP, Bahrami S, Redi H and Schlag G (1989). Neutrophil function and lipid peroxidation in a rat model of Multiple Organ Failure. J Surg Res 47: 471-475.

- Van Eijk HMH, Van der Heijden MAH, Van Berlo CH and Soeters PB (1988). Fully automated liquid-chromatographic determination of amino acids. Clin Chem 34: 2510-2513.

- Wichterman KA, Baue AE and Chaudry IH (1980). Sepsis and septic shock - A review of laboratory models and a proposal. J Surg Res 29: 189-201.

- Wusteman M, Wight DGD and Elia M (1990). Protein metabolism after injury with turpentine: a rat model for clinical trauma. Am J Physiol 259: E763-E769. 


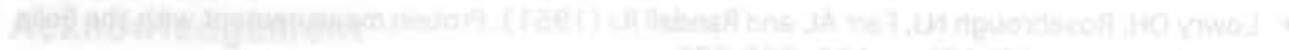

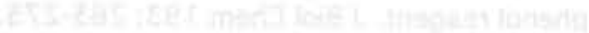

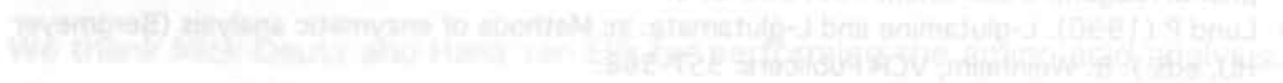

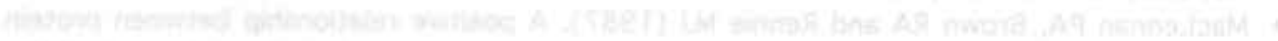

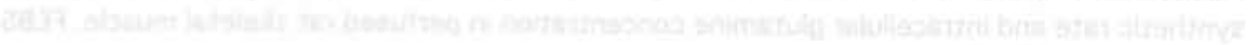
Q

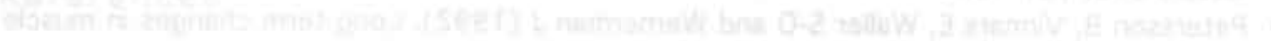

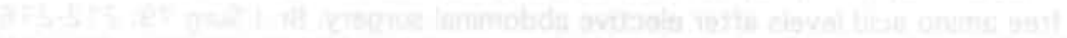

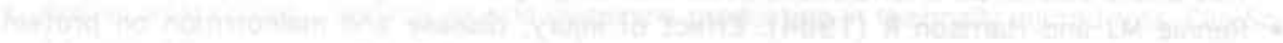

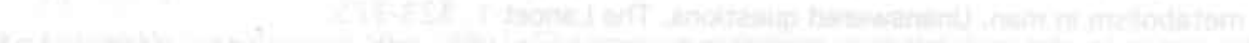

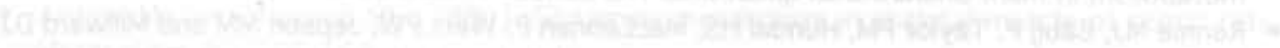

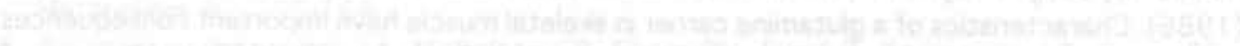

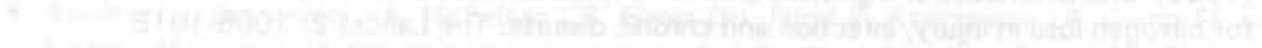

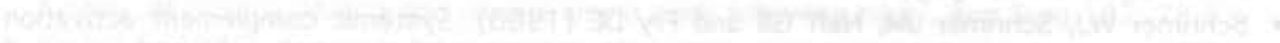

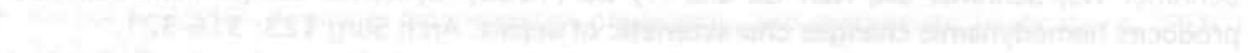

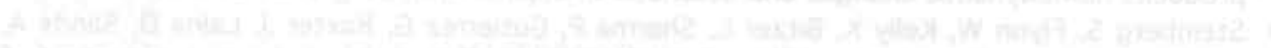

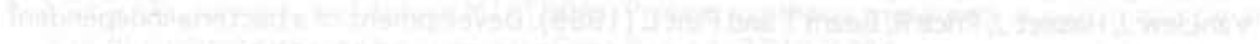

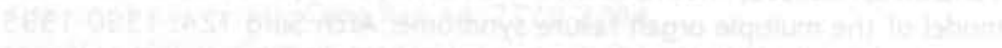

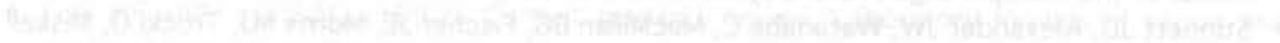

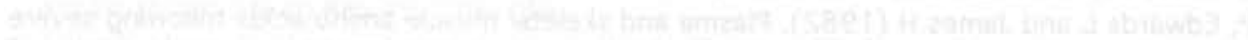

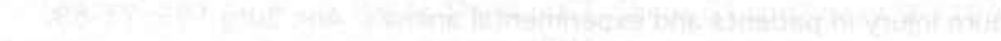

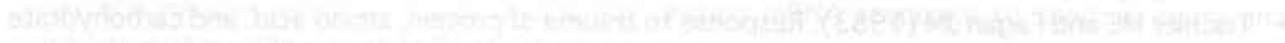
The

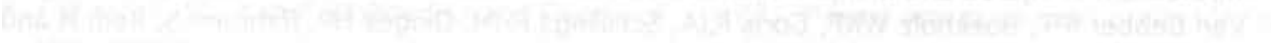

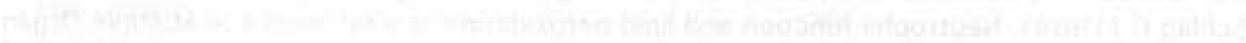

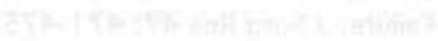

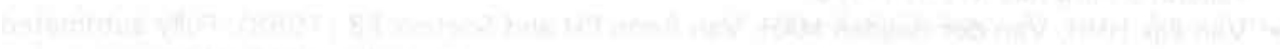

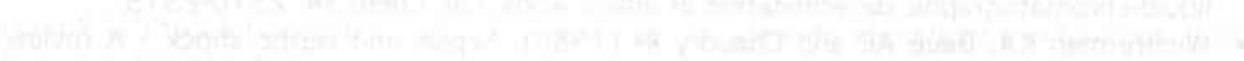

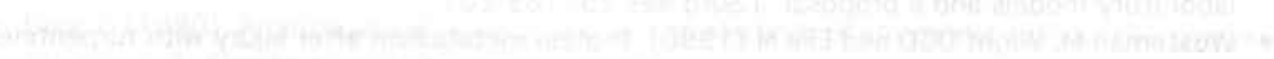




\section{Prolonged activation of the branched chain $\alpha$-keto acid dehydrogenase complex in muscle of zymosan treated}

\section{rats.}

Olav E. Rooyackers, Joan M.G. Senden, Peter B. Soeters*, Wim H.M. Saris, and Anton J.M. Wagenmakers. Departments of Human Biology and *Surgery, University of Limburg, Maastricht, The Netherlands.

European Journal of Clinical Investigation (accepted for publication)

\section{Abstract}

1. Whole body oxidation rates of branched chain amino acids (BCAA) are increased during catabolic diseases. A significant role for muscle in this feature has been suggested and, therefore, activities of the rate limiting enzyme in the degradative pathway of the BCAA in muscle were investigated in a catabolic rat model (intraperitoneal zymosan injection).

2. Both actual and total activities of the branched chain $\alpha$-keto acid dehydrogenase complex (BC-complex) were measured in skeletal muscle of zymosan treated rats and compared with values measured in pair fed and ad libitum fed controls.

3. The actual activity and the percentage of the enzyme in the active form were increased 2 and 6 days after the zymosan challenge. Total activity of the BC-complex and the activities of mitochondrial marker enzymes were reduced 2 days after zymosan treatment.

4. We conclude that zymosan treatment leads to (1) a reduction of the mitochondrial content in skeletal muscle and (2) a prolonged activation of the $\mathrm{BC}$-complex in muscle which may explain enhanced oxidation of BCAA during catabolic diseases. 


\section{Introduction}

Increased oxidation rates of branched chain amino acids (BCAA) have been repeatedly reported (Duff et al 1979, Goodlad \& Clark 1980, Goodlad et al 1981, Jahoor et al 1989, Odessey \& Parr 1982, Pomposelli et al 1985, Tischler \& Fagan 1983, Woolf et al 1979, Yoshida et al 1991) to be part of the metabolic response during catabolic diseases (e.g. sepsis, trauma and cancer). This increased oxidation together with the observation that BCAA stimulate protein synthesis and reduce protein breakdown in muscle in vitro (Li \& Odessey 1986), have led to many therapeutic trials in which BCAA enriched nutritional regimens were studied in patients with sepsis and trauma. Some of the early studies reported a positive effect on nitrogen balance in a small number of patients (Cerra et al 1984, Echenique et al 1984), but no positive effects have been observed in more recent, better controlled clinical trials (Von Meyenfeldt et al 1990).

Recently we described a catabolic rat model showing an acute phase of critical illness for 2 days followed by prolonged recovery after an intraperitoneal injection with zymosan (chapter 3 ). The model is characterized by severe muscle wasting during the acute phase. During the following recovery phase no signs of critical illness are observed anymore but several changes (e.g. decreased muscle protein mass, decreased concentrations of muscle glutamine and increased liver size) indicate that the rats are not fully recovered 6 days after the zymosan challenge. Also concentrations of plasma and muscle BCAA are reduced in the recovery period.

The branched chain $\alpha$-keto acid dehydrogenase complex (BC-complex) is the rate limiting enzyme in the degradative pathway of BCAA in muscle. In the present study we investigated whether the activity of this enzyme is enhanced in muscle of zymosan treated rats, in an attempt to provide a mechanism for the increased oxidation of BCAA during critical illness. The activity of the BC-complex is regulated by a phosphorylation/dephosphorylation cycle with phosphorylation causing inactivation. Therefore, both actual and total activities of the BC-complex were determined. Measurements were performed $16 \mathrm{~h}, 2$ days and 6 days after treatment to investigate both acute and long term effects.

To investigate whether changes in total activity of the BC-complex were related to changes in mitochondrial content, activities of two other mitochondrial enzymes (cytochrome $c$ oxidase and citrate synthase) were measured. The activities of these latter enzymes represent maximal activities and can be used, therefore, as indicators of mitochondrial content in muscle. 


\section{Methods}

Male SPF Lewis rats of approximately $200 \mathrm{~g}$ were supplied by the central laboratory animal facilities of the University of Limburg. The rats were individually housed and kept in a controlled environment (12 h light cycle, $21-22{ }^{\circ} \mathrm{C}$ and $50-60 \%$ humidity). Rats were fed a standard lab chow (SRM-A, Hope Farms, The Netherlands) containing (wt/wt) approximately $28 \%$ protein, $7 \%$ fat, $54 \%$ carbohydrates, $4 \%$ fibres and $7 \%$ minerals with a trace element and vitamin supplement. The rats were allowed to acclimatize for one week. The experiments were approved by the animal experimental committee of the University of Limburg.

Previously we have reported concentrations of amino acids and protein synthesis rates in zymosan treated rats (chapter 3 ). The same rats were used for the measurements described in this chapter.

Rats were injected intraperitoneally with zymosan ( $50 \mathrm{mg}$ per $100 \mathrm{~g}$ body weight) suspended in liquid paraffin $(25 \mathrm{mg} / \mathrm{ml})$. Zymosan administration reduced food intake and, therefore, the paraffin-injected control rats were pair fed. Pair feeding was performed in three periods during $24 \mathrm{~h}$ (from 8:00 am till 3:00 $p$, 3:00 pm till 10:00 pm, and from 10:00 pm till 8:00 am) to ensure that the pair fed rats would not eat all the food at once and consequently would be starving for the remainder of the day. Also an ad libitum fed non-treated control group was included to study the effect of pair feeding. These rats were studied on day 3 to make them closely comparable to the other groups. All groups were matched for age and initial body weight. During the experiment food intake and body weight were determined daily.

On the day of the measurements pair feeding was performed at 7:00 am and food was withheld in all groups from 8:00 am till 12:00 am Sampling of muscle tissue and measurements of the $\mathrm{BC}$-complex activities were done between $12: 00$ am and 2:00 pm. Activities of the BC-complex, cytochrome $c$ oxidase and citrate synthase were measured in muscle of zymosan treated, pair fed, and ad libitum fed control rats $16 \mathrm{~h}$ and 2 , and 6 days after treatment.

Animals were killed by cervical dislocation and the gastrocnemius muscle was rapidly removed, weighed, and about $50 \mathrm{mg}$ of the muscle sample was transferred to ice cold SET-buffer ( $0.25 \mathrm{M}$ sucrose, $2 \mathrm{mM}$ EDTA and $10 \mathrm{mM}$ Tris/ $\mathrm{HCl} ; \mathrm{pH}=7.4$ ) for preparation of a homogenate to measure enzyme activities. Homogenates $(5 \%)$ of the fresh muscle samples were made in ice cold SETbuffer within 1 min after sampling, using a Teflon-glass Potter-Elvehjem homogenizer. Both the total activity and the actual activity of the BC-complex were immediately determined as described before (Wagenmakers et al 1991). The enzyme complex is active in the dephosphorylated form. To measure the actual activity, both kinase and phosphatase of the BC-complex were inhibited. This was attained by incubation with $5 \mathrm{mM}$ ADP (kinase inhibition) and with $50 \mathrm{mM} \mathrm{NaF}$ (phosphatase inhibition). For measuring total activity, only the kinase was inhibited and, therefore, all the enzyme dephosphorylated. Activities (in 
nmol.min $n^{-1} . g$ wet weight $\left.{ }^{-1}\right)$ were calcuiated from the ${ }^{14} \mathrm{CO}_{2}$ production during incubation with $\left[1-{ }^{14} \mathrm{C}\right]-4$-methyl-2-oxopentanoate ( $\alpha$-keto acid of leucine) for $10 \mathrm{~min}$ at $37^{\circ} \mathrm{C}$. The same homogenate was used to determine activities of cytochrome $c$ oxidase and citrate synthase. These enzymes were used as mitochondrial marker enzymes in order to obtain information regarding changes in mitochondrial content. Activities of cytochrome $c$ oxidase were measured as described before (Gohil et al 1981). Citrate synthase activities were measured as described by Shepherd and Garland (Shepherd \& Garland 1969) following 4 times freezing (liquid nitrogen) and thawing (water bath), and ultrasonicating of the sample.

All measurements were done in duplicate except for the actual activities of the $\mathrm{BC}$-complex which were done in triplicate. Values shown are mean (range). Statistical analysis of differences between zymosan treated and pair-fed animals and between the experimental groups and the ad libitum fed control rats were performed using the Mann-Whitney U-test. Significance was set at $P<0.05$.

\section{Results}

Following the zymosan challenge rats almost stopped eating for 2 days after which the intake gradually increased to approximately $80 \%$ of normal (Fig. 1). Both the zymosan injected and pair fed rats lost body weight for 3 days (Fig. 2). An increase in body weight was observed for the following 3 days, but no catch up growth was present.

The actual activity of BC-complex in muscle of the zymosan treated rats was increased $16 \mathrm{~h}$ after treatment in comparison with the fed control rats and

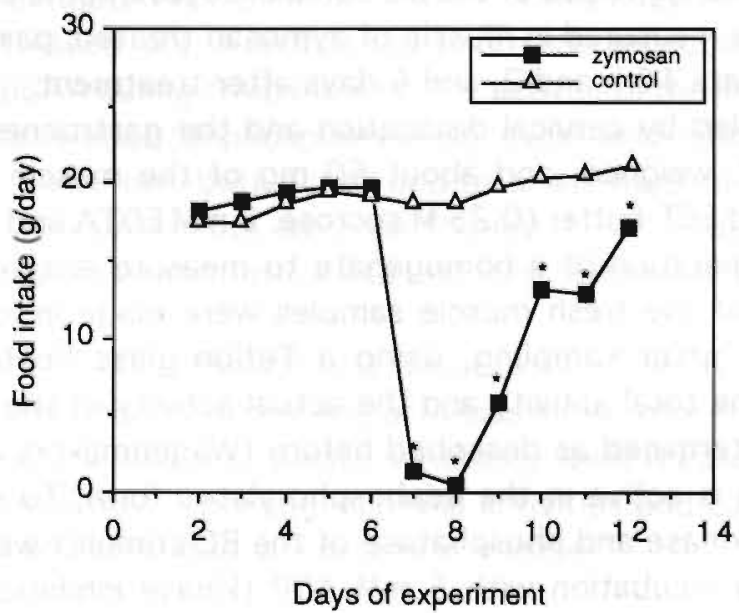

Figure 1. Food intake ( $\mathrm{g} /$ day) of control and zymosan treated rats. The zymosan challenge was given on day 6 of the experiment. *: Significantly different from control $(p<0.05)$. 


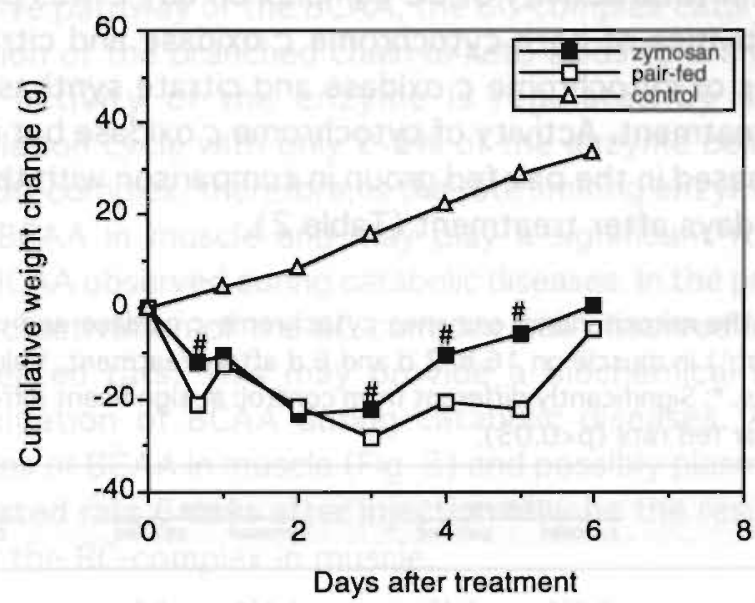

Figure 2. Cumulative changes in body weight ( $\mathrm{g}$ ) of control, pair fed and zymosan treated rats. Rats were injected with either zymosan suspended in paraffin or with paraffin only (pair fed). Control rats were not injected. Changes were calculated from initial body weight and body weights attained every morning during the experiment. All values of the zymosan treated and the pair fed rats were significantly different from those of the control rats, except on day 0. \#: Significant difference between zymosan treated and pair fed rats $(p<0.05)$.

on day 2 and 6 in comparison with both the fed and pair fed control rats (Table 1). The increased actual activity of the pair fed group $16 \mathrm{~h}$ after treatment was back to normal on day 2 and marginally decreased on day 6 (Table 1). The total activity of the $\mathrm{BC}$-complex (total amount of enzyme) was decreased in the zymosan treated animals $16 \mathrm{~h}$ and 2 days after treatment (Table 1). The percentage of the enzyme in the active form was increased in the zymosan treated rats $16 \mathrm{~h}$ after treatment in comparison with the fed control rats and on 2 and $6 \mathrm{~d}$ after treatment in comparison with both the pair fed and fed control rats (Table 1 ).

Table 1. Actual and total activity (nmol.min-'.g wet weight: $)$ and the percentage active form of the BC-complex in muscle on $16 \mathrm{~h}, 2 \mathrm{~d}$ and $6 \mathrm{~d}$ after treatment. Values are given as mean (range) of 6-8 rats. *: Significantly different from control; \#: significant difference between zymosan treated and par fed rats $(p<0.05)$.

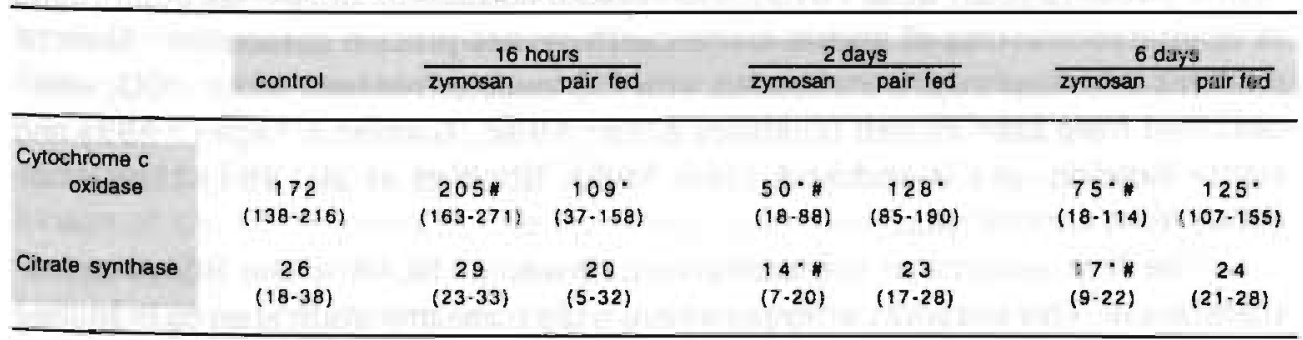


The reduction in total activity of $\mathrm{BC}$-complex on day 2 was paralleled by a decrease in the activities of both cytochrome $c$ oxidase and citrate synthase (Table 2). Activities of cytochrome $c$ oxidase and citrate synthase stayed low until 6 days after treatment. Activity of cytochrome $c$ oxidase but not of citrate synthase was decreased in the pair fed group in comparison with the fed control rats $16 \mathrm{~h}, 2$ and 6 days after treatment (Table 2).

Table 2. Activities of the mitochondrial enzymes cytochrome $c$ oxidase and citrate synthase ( $\mu$ mol.min $^{-1}$.g wet weight ${ }^{-1}$ ) in muscle on $16 \mathrm{~h}, 2 \mathrm{~d}$ and $6 \mathrm{~d}$ after treatment. Values are given as mean (range) of 6-8 rats. *: Significantly different from control; \#: significant difference between zymosan treated and par fed rats $(p<0.05)$.

\begin{tabular}{|c|c|c|c|c|c|c|c|}
\hline & \multirow[b]{2}{*}{ control } & \multicolumn{2}{|c|}{16 hours } & \multicolumn{2}{|c|}{2 days } & \multicolumn{2}{|c|}{6 days } \\
\hline & & zymosan & pair led & zymosan & pair led & 2ymosan & pair fed \\
\hline Actual activity & $\begin{array}{c}0.6 \\
(0.3-0.7)\end{array}$ & $\begin{array}{c}0.9 \cdot 3 \\
(0.6 \cdot 1.3)\end{array}$ & $\begin{array}{c}1.4^{\circ} \\
(0.8-2.2)\end{array}$ & $\begin{array}{c}1.1 \cdot \% \\
(0.7-1.9)\end{array}$ & $\begin{array}{c}0.6 \\
(0.3-1.1)\end{array}$ & $\begin{array}{c}1.2^{*} \\
(0.9-1.5)\end{array}$ & $\begin{array}{c}0.4^{*} \\
(0.2-0.5)\end{array}$ \\
\hline Total activity & $\begin{array}{c}31.2 \\
(15.2-38.4)\end{array}$ & $\begin{array}{c}19.9 \% \\
(16.9-27.4\}\end{array}$ & $\begin{array}{c}25.7 \\
(20.0 \cdot 37.8)\end{array}$ & $\begin{array}{c}14.9 . \\
(5.8-27.8)\end{array}$ & $\begin{array}{c}24.8 \\
(5.7-36.5)\end{array}$ & $\begin{array}{c}26.7 \\
(9.9-37.4)\end{array}$ & $\begin{array}{c}20.7 \\
(17.2-25.8)\end{array}$ \\
\hline$\%$ active form & $\begin{array}{c}2.1 \\
(0.9-3.8)\end{array}$ & $\begin{array}{c}4.5^{\circ} \\
(2.9-6.3)\end{array}$ & $\begin{array}{c}5.7^{\circ} \\
(3.7 .9 .8)\end{array}$ & $\begin{array}{c}9.2^{\circ} * \\
(5.1-18.2)\end{array}$ & $\begin{array}{c}2.9 \\
(1.2 .5 .4)\end{array}$ & $\begin{array}{c}5.0^{\circ} \\
(2.7-8.6)\end{array}$ & $\begin{array}{c}1.9 \\
(0.7-2.9)\end{array}$ \\
\hline
\end{tabular}

\section{Discussion}

Enhanced oxidation of BCAA has been reported to occur during severe catabolic diseases. In an animal model of sepsis in which rats were injected with live Escherichia coli bacteria, a 1.4 to 1.5 -fold increase in the oxidation rate of leucine has been observed (Pomposelli et al 1985, Yoshida et al 1991). Also in patients with sepsis and burn injury ${ }^{13} \mathrm{C}$-leucine oxidation was increased 2 to 2.6 fold (Jahoor et al 1989). Several studies have indicated that the increased oxidation of BCAA occurs mainly in skeletal muscle. Woolf and colleagues (Woolf et al 1979) measured arteriovenous differences of amino acids across the legs in a dog model with $E$. coli bacteremic shock. From an increased release of phenylalanine (indicating an increased protein breakdown rate) together with a decreased release of BCAA they concluded that BCAA are oxidized faster in muscle of animals with bacteremic shock. Similar results have been reported in septic patients (Duff et al 1979). Increased oxidation of BCAA has been found in incubated muscles of animal models with severe protein catabolism. Skeletal muscles and diaphragms incubated with ${ }^{14} \mathrm{C}$-leucine released more ${ }^{14} \mathrm{CO}_{2}$ when obtained from burn injured (Odessey \& Parr 1982, Tischler \& Fagan 1983) and tumor bearing rats (Goodlad \& Clark 1980, Goodlad et al 1981) than when taken from control rats.

The first enzyme in the oxidative pathway of BCAA is the BCAA aminotransferase. This enzyme catalyzes a reversible transamination step to branched chain $\alpha-k$ eto acids and is present in abundance in muscle. The second enzyme in 
the degradative pathway of the BCAA, the BC-complex catalyzes the irreversible decarboxylation of the branched chain $\alpha$-keto acids to branched chain acylCoA esters. The activity of the enzyme is regulated by a phosphorylation/ dephosphorylation cycle with only $2-3 \%$ of the enzyme being active in skeletal muscle. The $\mathrm{BC}$-complex, therefore, is the rate limiting enzyme in the degradative pathway of BCAA in muscle and may play a significant role in the increased oxidation of BCAA observed during catabolic diseases. In the present study modest but prolonged activation of the BC-complex was observed in skeletal muscle of zymosan injected rats. This may provide a biochemical mechanism for the increased oxidation of BCAA during catabolic diseases. Also the decreased concentrations of BCAA in muscle (Fig. 3 ) and possibly plasma (chapter 3 ) in the zymosan treated rats 6 days after injection may be the result of this prolonged activation of the $\mathrm{BC}$-complex in muscle.

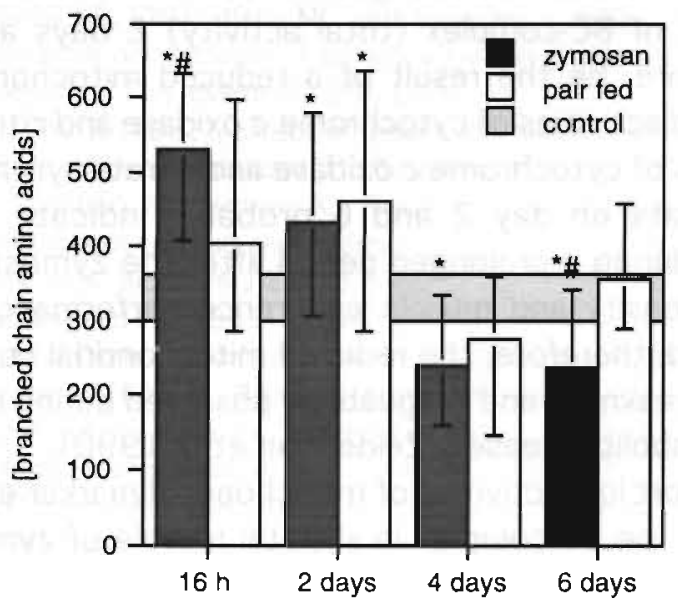

Time after treatment

Figure 3. Sum of branched chain amino acids (leucine, isoleucine and valine) concentrations in gastrocnemius muscle ( $\mathrm{nmol} / \mathrm{g}$ wet weight) of control, pair fed and zymosan treated rats. Values are given as mean (range) of 6-8 rats. *: Significantly different from control; \#: significant difference between zymosan treated and par fed rats. Data are adapted from chapter 3 in which the same rats have been used as in the present study.

Increased concentrations of BCAA were observed in rat muscle $16 \mathrm{~h}$ after zymosan treatment in comparison with pair fed and ad libitum fed rats (Fig. 3). This increase may lead to the observed activation of the $\mathrm{BC}$-complex. A correlation between concentrations of BCAA and activity of the BC-complex has been observed before (Block et al 1987a) and may be explained by inhibition of the kinase of the BC-complex by the branched chain $\alpha$-keto acids (Lau et al 1982). Net protein breakdown in muscle of the zymosan treated rats, indicated by a loss of muscle protein and decreased protein synthesis rates in the acute phase of illness (chapter 3 ) seems to be the cause for the increased concentrations of 
BCAA. However, an even greater activation of the BC-complex in muscle of the pair fed rats on $16 \mathrm{~h}$ in combination with normal BCAA concentrations (Fig. 3) indicate that other mechanisms must be involved. This could include increased concentrations of free ADP in muscle, which inhibit the kinase of the BC-complex (Lau et al 1982) or effects of cytokines or stress hormones. Both cytokines and glucocorticoids have been reported to activate the BC-complex when administered to rats (Block et al 1987b, Nawabi et al 1990). Zymosan is a potent activator of monocytes and macrophages (Steinberg et al 1989) and, therefore, enhanced production of cytokines is likely to occur in the zymosan treated rats. Von Asmuth and colleagues (Von Asmuth et al 1990) have reported increased circulatory levels of tumor necrosis factor (TNF) and interleukin- 6 several hours following zymosan injection in mice.

Both cytochrome $c$ oxidase and citrate synthase are mitochondrial marker enzymes and can be used to estimate changes in mitochondrial content of tissues. The decreased amount of BC-complex (total activity) 2 days after zymosan treatment may, therefore, be the result of a reduced mitochondrial content indicated by the reduced activities of cytochrome $c$ oxidase and citrate synthase. The decreased activities of cytochrome $c$ oxidase and citrate synthase in muscle of zymosan treated rats on day 2 and 6 probably indicate a diminished mitochondrial content during a prolonged period after the zymosan treatment. Muscle mitochondrial density and muscle endurance performance are related (Dudley et al 1987) and, therefore, the reduced mitochondrial content may be involved in the muscle weakness and fatiguability observed during recovery from surgery and severe catabolic diseases (Zeiderman et al 1990).

In summary we report low activities of mitochondrial marker enzymes and a prolonged activation of the $\mathrm{BC}$-complex in skeletal muscle of zymosan treated rats. This activation of the $\mathrm{BC}$-complex may supply a mechanism for increased BCAA oxidation during catabolic diseases.

\section{References}

- Block KP, Aftring RP, Mehars WB and Buse MG (1987a). Modulation of rat skeletal muscle branched chain $\alpha$-keto acid dehydrogenase in vivo. Effect of dietary protein and meal consumption. J Clin Invest 79: 1349-1358.

- Block KP, Richmond WB, Mehard WB and Buse MG (1987b). Glucocorticoid-mediated activation of muscle branched chain a. keto acid dehydrogenase in vivo. Am J Physiol 252: E396-E407.

- Cerra FB, Mazuski JE, Chute E, Nuwer N, Teasley K, Lysne J, Shronts EP and Konstantinides KN (1984). Branched chain metabolic support. A prospective, randomized, double-blind trial in surgical stress. Ann Surg 199: 286-291.

- Dudley GA. Tullson PC and Terjung RL (1987). Influence of mitochondrial content on the sensitivity of respiratory control. J Biol Chem 262: 9109-9114.

- Duff JH, Viidik T, Marchuk JB, Holliday RL, Finley RJ, Groves AC and Woolf LI (1979). Femoral arteriovenous amino acid differences in septic patients. Surgery 85: 344-348.

- Echenique MM, Bistrian BR, Moldawer LL, Palombo JD, Miller MM and Blackburn GL (1984). 
Improvement in amino acid use in the critically ill patient with parenteral formulas enriched with branched chain amino acids. Surg Gynecol Obstet 159: 233-241.

- Gohil K, Jones DA and Edwards RHT (1981). Analysis of muscle mitochondrial function with techniques applicable to needle biopsy samples. Clin Physiol 1: 195-207.

- Goodlad GAJ and Clark CM (1980). Leucine metabolism in skeletal muscle of the tumorbearing rats. Europ J Cancer 16: 1153-1162.

- Goodlad GAJ, Tee MK and Clarke CM (1981). Leucine oxidation andi protein degradation in the extensor digitorum longus and soleus of the tumor-bearing host. Biochem Med 26: 143-147.

- Jahoor F, Shangraw RE, Miyoshi H, Wallfish H, Herndon DN and Wolfe RR (1989). Role of insulin and glucose oxidation in mediating the protein catabolism of burns and sepsis. Am J Physiol 257: E323-E331.

- Lau KS, Fatania HR and Randle PJ (1982). Regulation of the branched chain 2-oxoacid dehydrogenase kinase reaction. FEBS Letters 144: 57-62.

- Li JB and Odessey R (1986). Regulation of protein turnover in heart and skeletal muscle by branched chain amino acids and keto acids. In: Problems and potential of branched chain amino acids in physiology and medicine (Odessey R, eds.). Amsterdam, Elsevier Science Publishers: 107-130.

- Nawabi MD, Block KP, Chakrabarti MC and Buse MG (1990). Administration of endotoxin, tumor necrosis factor or interleukin 1 to rats activates skeletal muscle branched chain $\alpha$-keto acid dehydrogenase. J Clin invest 85: 256-263.

- Odessey R and Parr B (1982). Effect of insulin and leucine on protein turnover in rat soleus muscle after burn injury. Metabolism 31: 82-87.

- Pomposelli JJ, Palombo JD, Hamawy KJ, Bistrian BR, Blackburn GL and Moldawer LL (1985). Comparison of different techniques for estimating rates of protein synthesis in vivo in healthy and bacteraemic rats. Biochem J 226: 37-42.

- Shepherd D and Garland PB (1969). Citrate synthase from rat liver. In: Methods in enzymology vol. 13. Citric Acid Cycle (Lowenstein JM, eds.). New York, Academic Press: 11-16.

- Steinberg S, Flynn W, Kelly K, Bitzer L, Sharma P, Gutierrez G, Baxter J, Lalha D, Sands A, VanLiew J, Hasset J, Price R, Beam T and Flint L (1989). Development of a bacteria-independent model of the multiple organ failure syndrome. Arch Surg 124: 1390-1395.

- Tischler ME and Fagan JM (1983). Response to trauma of protein, amino acid, and carbohydrate metabolism in injured and uninjured rat skeletal muscles. Metabolism 32: 853-867.

- Von Asmuth EJU, Maessen JG, Van der Linden C.J and Buurman WA (1990). Tumor necrosis factor alpha (TNF-a) and interleukin 6 in a zymosan-induced shock model. Scand J Immunol 32: 313-319.

- Von Meyenfeldt MF, Soeters PB, Vente JP, Van Berlo CLH, Roeflart MMJ, De Jong KP, Van der Linden CJ and Gouma DJ (1990). Effect of branched chain amino acid enrichment of total parenteral nutrition on nitrogen sparing and clinical outcome of sepsis and trauma: a prospective randomized double blind trail. Br J Surg 77: 924-929.

- Wagenmakers AJM, Beckers EJ, Brouns F, Kuiper H, Soeters PB, Van der Vusse GJ and Saris WHM (1991). Carbohydrate supplementation, glycogen depletion, and amino acid metabolism during exercise. Am J Physiol 260: E883-E890.

- Woolf LI, Groves AC and Duff JH (1979). Amino acid metabolism in dogs with E. colibacteremic shock. Surgery 85: 212-218.

- Yoshida S, Lanza-Jacoby S and Stein TP (1991). Leucine and glutamine metabolism in septic rats. Biochem J 276: 405-409.

- Zeiderman MR, Welchew EA and Clark RG (1990). Changes in cardiorespiratory and muscle function associated with development of postoperative fatigue. Br J Surg 77: 576-580. 


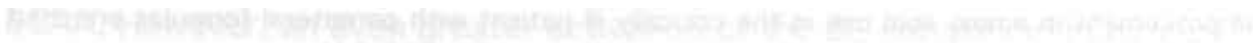

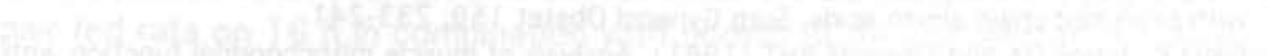

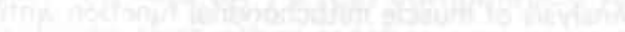

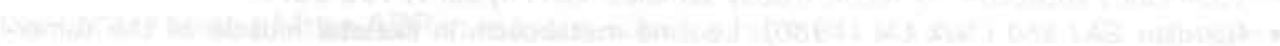

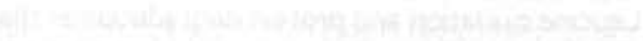




\section{CHAPTER}

\section{Derangement in energy metabolism in muscle of zymosan treated rats.}

Olav E. Rooyackers, Annemie P. Gijsen, Wim H.M. Saris, Peter B. Soeters* and Anton J.M. Wagenmakers. Departments of Human Biology and *Surgery, University of Limburg, Maastricht, The Netherlands.

Submitted for publication

\section{Abstract}

1. Critical illness and the following recovery are characterized by muscle weakness and exercise intolerance. Impaired cellular metabolism has been suggested to be involved in this feature. In this study we investigated the possibility of a derangement in energy metabolism in skeletal muscle of a catabolic rat model (zymosan injection) both during acute critical illness and recovery, by measuring changes in key metabolites.

2. Concentrations of high energy phosphates, tricarboxylic acid cycle intermediates, pyruvate, lactate and glycogen were measured in skeletal muscle of zymosan treated rats and compared with values measured in pair fed and ad libitum fed controls. Measurements were performed $16 \mathrm{~h}$, and 2, 4 and 6 days after treatment.

3. Concentrations of creatine phosphate were decreased in the zymosan treated rats 2 days after treatment. Modest decreases in concentrations of ATP, tricarboxylic acid cycle intermediates and pyruvate to approximately $80 \%$ of control values were observed in recovering rats 6 days after zymosan treatment.

4. We conclude that only modest changes in key metabolites of the energy metabolism (e.g. high energy phosphates and tricarboxylic acid cycle intermediates) were present in resting skeletal muscle of critically ill and recovering rats. 


\section{Introduction}

Complaints about tiredness and exercise intolerance of patients recovering from critical illness are most likely related to loss of muscle contractility and increased fatiguability (Anonymous 1979, Chad \& Lacomis 1994). In addition to loss of muscle mass, changes in cellular metabolism may be involved in the cause of muscle weakness. Impaired mitochondrial functioning has been suggested to occur in skeletal muscle during severe illness (Schumer et al 1971, Tavakoli \& Mela 1982) and could be related to muscle weakness by influencing energy metabolism. In this study we investigated whether concentrations of key metabolites in energy metabolism (e.g. high energy phosphates and intermediates of the tricarboxylic acid cycle) were decreased both during acute critical illness and the following recovery.

Zymosan injected rats were used as a model to investigate a potential derangement in muscle energy metabolism. Recently we described changes in protein and amino acid metabolism in muscle of zymosan treated rats during both critical illness and a prolonged recovery phase (chapter 3 ). The acute critical phase characterized by lethargy, anorexia and severe muscle wasting was observed during 2 days following the zymosan challenge. Thereafter, the rats slowly recovered during a period of at least 10 days without signs of severe illness. In addition to severe muscle wasting, activities of two mitochondrial marker enzymes (citrate synthase and cytochrome $c$ oxidase) were reduced in muscle of zymosan treated rats up to 6 days after injection, indicating a reduced mitochondrial density (chapter 4). In the present study concentrations of tricarboxylic acid (TCA) cycle intermediates, pyruvate, lactate, glycogen, high-energy phosphates and ammonia were, therefore, measured in muscle of zymosan treated and pair fed control rats $16 \mathrm{~h}$ and 2,4 , and 6 days after injection. Also concentrations of free ADP and free AMP were calculated because of their important role as modulators of glycolytic flux and mitochondrial oxidation (Newsholme \& Start 1973).

\section{Methods}

Male SPF Lewis rats ( $180-270 \mathrm{~g}$ ), supplied by the animal house of the University of Limburg, were individually housed and kept in a controlled environment (12 hour light cycle, $21-22^{\circ} \mathrm{C}$ and $50-60 \%$ humidity). Rats were fed a standard lab chow (SRM-A, Hope Farms, The Netherlands) containing (wt/wt) approximately $28 \%$ protein, $7 \%$ fat, $54 \%$ carbohydrates, $4 \%$ fibers and $7 \%$ minerals with a trace element and vitamin supplement. Rats were allowed to acclimatize to individual housing for one week. All experiments were approved by the Animal Experimental Committee of the University of Limburg.

Previously we have reported concentrations of amino acids and protein 
synthesis rates (chapter 3 ) and branched chain amino acid metabolism (chapter 4) in zymosan treated rats. The same rats were used for the measurements described in this chapter.

Critical illness was induced by intraperitoneal injection of zymosan $(50 \mathrm{mg}$ per $100 \mathrm{~g}$ body weight) suspended in sterile liquid paraffin $(25 \mathrm{mg} / \mathrm{ml})$ as described before (chapter 3 ). Food intake was substantially reduced after zymosan administration and, therefore, paraffin injected control rats were pair fed. Pair feeding was performed in three periods during the day (from 8.00 am till 3.00 $\mathrm{pm}, 3.00 \mathrm{pm}$ till $10.00 \mathrm{pm}$, and from $10.00 \mathrm{pm}$ till $8.00 \mathrm{am}$ ) to ensure that the pair fed rats would not eat all food offered at once and subsequently would be starved for the remainder of the day. Measurements were performed $16 \mathrm{~h}$ and 2 , 4 , and 6 days after treatment. Also a control group with free access to the rat chow and no paraffin injection was included in the study. All groups were matched for age and initial body weight. During the experiment food intake and body weight were determined daily.

On the day of the measurements pair feeding was performed at 7.00 am and food withheld from 8.00 am till $12.00 \mathrm{am}$. Sampling of muscle tissue was done between 12.00 am and $2.00 \mathrm{pm}$. Animals were killed by cervical dislocation and the gastrocnemius muscle was rapidly removed, weighed, freeze-clamped in liquid nitrogen and stored at $-80^{\circ} \mathrm{C}$ until analysis.

For metabolite determination muscle was homogenized in ice-cold $1 \mathrm{M}$ perchloric acid (1:5) with an OMNI 1000 mechanical homogenizer. The supernatant was neutralized with $2 \mathrm{M}$ potassium bicarbonate and used for measuring the following muscle metabolites:

- ATP, ADP, AMP, creatine phosphate, creatine, lactate and pyruvate as described by Harris and colleagues (Harris et al 1974).

Citrate, malate and succinate as described before in Methods of Enzymatic Analysis (Dagley 1974, Möllering 1974, Williamson 1974).

Ammonia as described before (Janssen et al 1988).

All these analyses were modified for a centrifugal analyzer (COBAS-BIO, Roche Diagnostica).

A small part (10-60 mg) of the frozen muscle was used to determine glycogen content. Free glucose was separated from glycogen by dissolving muscle in $1 \mathrm{M} \mathrm{NaOH}\left(37^{\circ} \mathrm{C}, 1\right.$ hour $)$ and precipitating glycogen with $96 \%$ ethanol $\left(80^{\circ} \mathrm{C}\right.$ for $10 \mathrm{~min}$ and then overnight at $4^{\circ} \mathrm{C}$ ). The glycogen pellet was hydrolyzed using $1 \mathrm{M} \mathrm{HCl}\left(100^{\circ} \mathrm{C}, 3\right.$ hours $) . \mathrm{HCl}$ was neutralized with a $\mathrm{KCl}$ saturated $\mathrm{KOH} /$ Tris $(2.1 \mathrm{M} / 0.12 \mathrm{M})$ buffer. Glucosyl units obtained from glycogen were determined using a glucose kit (Hexokinase method, Roche) for a centrifugal analyzer (COBASBIO, Roche Diagnostica).

Concentrations of free ADP and free AMP were calculated using concentrations of reactants and equilibrium constants of the near equilibrium reactions 
catalyzed by creatine kinase and adenylate kinase as described before (Dudley \& Terjung 1985, Dudley et al 1987). For these calculations free magnesium concentrations in muscle were assumed to be $1 \mathrm{mM}$ and not to be influenced by the treatments.

$$
\begin{aligned}
& {\left[\text { ADP }_{\mathrm{f}}\right]=\frac{[\mathrm{ATP}][\mathrm{Cr}]}{1.66 \times 10^{9}\left[\mathrm{H}^{*}\right][\mathrm{CrP}]}} \\
& {\left[\mathrm{AMP}_{\mathrm{f}}\right]=\frac{\left[\mathrm{ADP}_{\mathrm{t}}\right]^{2}}{1.05[\mathrm{ATP}]}}
\end{aligned}
$$

Concentration of hydrogen ions $\left[\mathrm{H}^{+}\right]$was obtained from the $\mathrm{pH}$, which was estimated from the relationship between $\mathrm{pH}$ and the sum of lactate and pyruvate concentrations (Dudley \& Terjung 1985, Sahlin et al 1975):

$$
\mathrm{pH}=7.06-0.226 \times \text { [lactate] } \times \text { [pyruvate] }
$$

Differences between pair fed and zymosan treated rats and between the experimental groups and ad libitum fed control group were analyzed for statistical significance using the Mann-Whitney U-test. Significance was set at $p<0.05$. All measurements were done in duplicate. Values are given as mean (range).

\section{Results}

Rats injected with zymosan showed both clinical (lethargy, anorexia, diarrhea) and metabolic (muscle wasting, decreased glutamine pools and enlarged liver) signs of critical illness (chapter 3 ). A mortality rate of $16 \%$ was observed in this study. All deaths occurred during the first $36 \mathrm{~h}$. Pair-fed and ad libitum fed control rats showed none of these signs. Details of the animal model including changes in food intake, body weight and protein synthesis rates have been described elsewhere (chapter 3 ).

\section{Concentrations of adenine nucleotides (Table 1)}

Concentrations of ATP and the sum of ATP, ADP and AMP were decreased in both pair fed and zymosan treated rats in comparison with ad libitum fed control rats $16 \mathrm{~h}$ after treatment. AMP concentrations were increased in both experimental groups after $16 \mathrm{~h}$.

Concentrations of ATP were decreased in muscle of zymosan treated rats on day 4 in comparison with both control groups and 6 days after treatment in comparison with ad libitum fed control rats. The sum of ATP, ADP and AMP was decreased on days 4 and 6 in comparison with ad libitum fed control rats.

Concentrations of free AMP were increased in zymosan challenged rats on day 2 in comparison with both ad libitum and pair fed control rats. Free ADP concentrations were similar in all groups. 
Table 1. Concentrations of ATP, ADP, AMP ( $\mu \mathrm{mol} / \mathrm{g}$ wet weight) and of free ADP and AMP (nmol/g wet weight) measured in muscle 16 hours (h) and 2, 4 and 6 days (d) after treatment. Values are given as mean (range) of 6-8 rats. Con: ad libitum fed control; zym: zymosan injected; pf: pair fed rats. *: Significantly different from control; \# significantly different from pair fed.

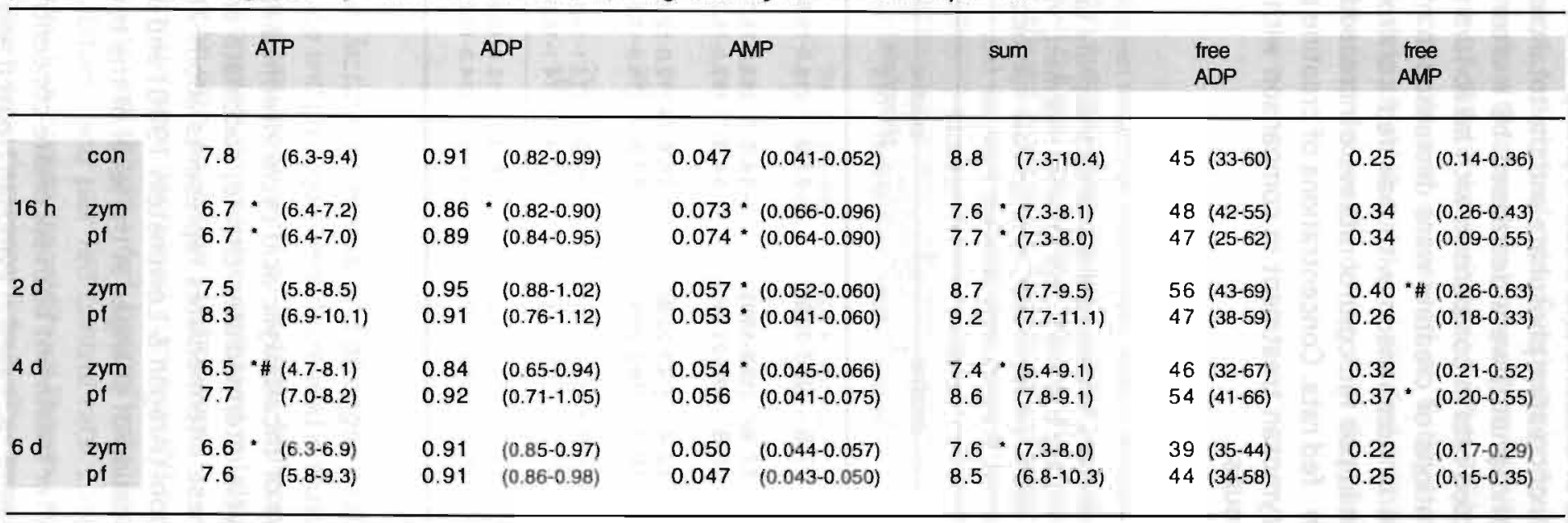




\section{Concentrations of creatine and creatine phosphate (Table 2)}

Concentrations of creatine phosphate and the total creatine pool (sum of creatine and creatine phosphate) were decreased $16 \mathrm{~h}$ after treatment in pair fed and zymosan injected rats in comparison with ad libitum fed control rats.

Concentrations of creatine were decreased in muscle of zymosan treated rats on day 4 in comparison with pair fed control rats. However, creatine concentrations in pair fed control rats were increased on this day in comparison with ad libitum fed rats. Concentrations of creatine phosphate were decreased 2 days after zymosan treatment in comparison with both ad libitum and pair fed control groups.

Table 2. Concentrations of creatine and creatine phosphate ( $\mu \mathrm{mol} / \mathrm{g}$ wet weight) measured in muscle 16 hours $(h)$ and 2,4 and 6 days (d) after treatment. Values are given as mean (range) of 6-8 rats. Con: ad libitum fed control; zym: zymosan injected; pf: pair fed rats. *: Significantly different from control; \# significantly different from pair fed.

\begin{tabular}{|c|c|c|c|c|c|c|c|}
\hline & \multirow[b]{2}{*}{ con } & \multicolumn{2}{|c|}{ creatine } & \multicolumn{2}{|c|}{$\begin{array}{l}\text { creatine } \\
\text { phosphate }\end{array}$} & \multicolumn{2}{|c|}{ sum } \\
\hline & & 17.5 & $(15.7-20,5)$ & 17.9 & $(16.5-19.6)$ & 35.4 & $(33.8-37.9)$ \\
\hline \multirow[t]{2}{*}{$16 \mathrm{~h}$} & zym & 17.4 & $(15.8-19.1)$ & $14.5^{\star}$ & $(13.2-15.7)$ & $31.9^{*}$ & $(30.5-33.2)$ \\
\hline & pf & 16.8 & $(9.3-21.0)$ & $14.3^{*}$ & $(12.6-15.7)$ & 31.1 * & $(23.4-35.3)$ \\
\hline \multirow[t]{2}{*}{$2 d$} & zym & 19.4 & $(14.7-22.8)$ & 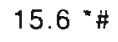 & $(12.0-18.6)$ & 35.0 & (26.6-38.8) \\
\hline & pi & 18.0 & $(16.2-20.1)$ & 17.8 & $(16.9-19.6)$ & 33.5 & $(20.1-39.0)$ \\
\hline \multirow[t]{2}{*}{$4 d$} & zym & $18.8 \#$ & $(14.6-21.1)$ & 15.9 & $(13.1-19.1)$ & 34.8 & $(27.7-37.4)$ \\
\hline & pi & $21.3^{*}$ & $(19.9-24.1)$ & 16.4 & $(14.1-18.9)$ & $37.6^{\circ}$ & $(34.3-39.9)$ \\
\hline \multirow[t]{2}{*}{$6 d$} & zym & 17.7 & $(15.9-18.9)$ & 18.3 & $(15.5-19.8)$ & 36.0 & $(32.8-38.6)$ \\
\hline & pf & 18.2 & $(16.2-19.9)$ & 17.6 & $(14.9-19.6)$ & 35.8 & $(32.4-37.2)$ \\
\hline
\end{tabular}

Concentrations of tricarboxylic acid cycle intermediates (Table 3)

Of the TCA cycle intermediates citrate, succinate and malate were measured. The sum of these intermediates represents about $70 \%$ of the total TCA cycle intermediate pool (Aragón \& Lowenstein 1980) and is, therefore, considered to be a good indication of changes in the level of the total TCA-cycle intermediate pool in muscle.

At $16 \mathrm{~h}$ after treatment both succinate concentrations and the sum of TCA intermediates were increased in zymosan treated and pair fed rats in comparison with ad libitum fed control rats. 
Concentrations of citrate were decreased in zymosan treated rats on day 2 in comparison with ad libitum fed control rats. Succinate concentrations were decreased 6 days after zymosan treatment in comparison with ad libitum fed control rats. Concentrations of malate were increased after $16 \mathrm{~h}$ and 2 days in comparison with pair fed controls and decreased at 6 days after zymosan treatment in comparison with both ad libitum and pair fed animals. The sum of citrate, succinate and malate was decreased on day 6 in comparison with both control groups.

Table 3. Concentrations ( $\mathrm{nmol} / \mathrm{g}$ wet weight) of tricarboxylic acid cycle intermediates (citrate, succinate and malate) measured in muscle 16 hours ( $h$ ) and 2, 4 and 6 days (d) after treatment. Values are given as mean (range) of 6-8 rats. Con: ad libitum fed control; zym: zymosan injected; pf: pair fed rats. *: Significantly different from control; \# significantly different from pair fed.

\begin{tabular}{|c|c|c|c|c|c|c|c|c|c|}
\hline & & & itrate & & decinate & & alate & sun & \\
\hline & con & 169 & $(142-198)$ & 270 & (213-321) & 307 & $(266-347)$ & 746 & (648-838) \\
\hline $16 \mathrm{~h}$ & zym & 167 & $(134-228)$ & 391 * & (335-495) & $338 \#$ & $(285-422)$ & $895^{\circ}$ & $(812-1004)$ \\
\hline & pf & 173 & $(149-204)$ & $372^{\circ}$ & $(327-430)$ & 292 & (224-345) & $837^{*}$ & $(714-934)$ \\
\hline $2 d$ & zym & $124^{*}$ & $(92-155)$ & 285 & $(201-390)$ & $356 \#$ & $(237-480)$ & 772 & $(571-1003)$ \\
\hline & pf & 149 & (116-191) & 286 & $(176-406)$ & 292 & (225-369) & 727 & $(571-870)$ \\
\hline $4 \mathrm{~d}$ & zym & $100^{*}$ & $(50-147)$ & 248 & $(141-348)$ & 255 & $(181-343)$ & 603 & $(450-739)$ \\
\hline & pf & 102 * & $(73-121)$ & 258 & $(195-334)$ & $262^{\circ}$ & $(221-320)$ & $621^{\circ}$ & $(540-755)$ \\
\hline $6 d$ & zym & 150 & $(92-204)$ & $207^{*}$ & $(156-274)$ & $222^{*} \#$ & $(204-260)$ & $579^{*} \#$ & $(484-691)$ \\
\hline wites: & pf & 135 * & $(108-164)$ & 284 & $(197-420)$ & 314 & $(253-410)$ & 733 & (619-951) \\
\hline
\end{tabular}

Concentrations of pyruvate, lactate, ammonia, and glycogen (Table 4)

Concentrations of both lactate and glycogen were decreased in muscle of zymosan treated and pair fed rats in comparison with ad libitum fed control rats $16 \mathrm{~h}$ after treatment. Glycogen concentrations were increased in both experimental groups on day 6 in comparison with ad libitum fed controls.

Concentrations of pyruvate were decreased in muscle $16 \mathrm{~h}$ after zymosan treatment in comparison with ad libitum fed control rats and on day 6 in comparison with both ad libitum and pair fed control rats. Lactate/pyruvate ratios were decreased on day 2 in comparison with ad libitum fed control rats only. Concentrations of glycogen were decreased 2 days after zymosan treatment in comparison with ad libitum fed control rats. 
Table 4. Concentrations of pyruvate ( $\mathrm{nmol} / \mathrm{g}$ wet weight), lactate ( $\mu \mathrm{mol} / \mathrm{g}$ wet weight), ammonia ( $\mathrm{nmol} / \mathrm{g}$ wet weight) and glycogen ( $\mu \mathrm{mol}$ glucosyl units/g wet weight) measured in muscle 16 hours (h) and 2, 4 and 6 days (d) after treatment. Values are given as mean (range) of 6-8 rats. Con: ad libitum fed control; zym: zymosan injected; pf: pair fed rats. *: Significantly different from control; \# significantly different from pair fed.

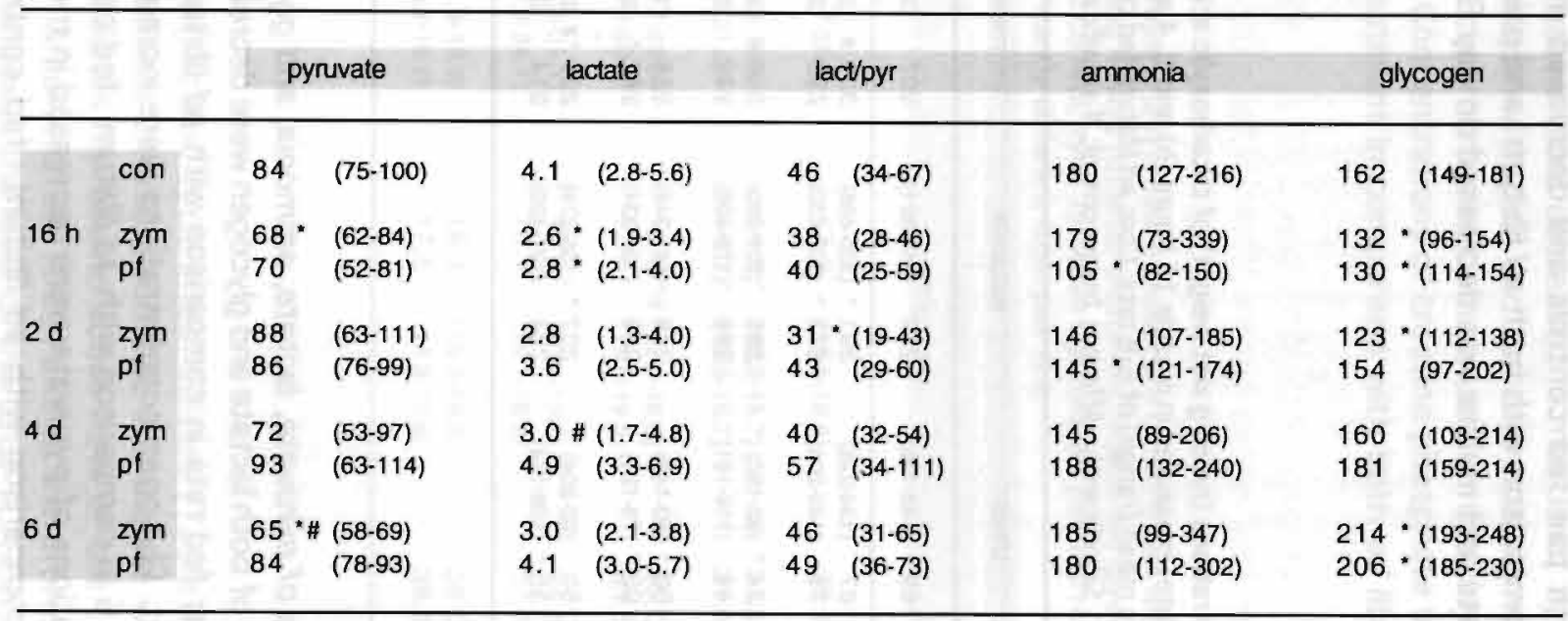




\section{Discussion}

Similar decreases in concentrations of ATP, creatine phosphate, lactate and glycogen and increases in concentrations of AMP and succinate $16 \mathrm{~h}$ after treatment in zymosan treated and pair fed rats indicated that these changes were induced by the reduced food intake. Zymosan induced changes were observed thereafter, including decreased concentrations of creatine phosphate and increased free AMP on day 2. Most changes due to the zymosan challenge were, however, measured during the recovery period; decreased concentrations of pyruvate, TCA cycle intermediates, ATP, and sum of AMP, ADP and ATP, whereas in the pair fed group the abnormalities present after $16 \mathrm{~h}$ tended to normalize at the later time points.

Concentrations of high energy phosphates and TCA cycle intermediates in muscle of zymosan treated rats were decreased to a moderate extent only. Concentrations of creatine phosphate were reduced to $87 \%$ of control 2 days after zymosan injection. ATP levels were 83 and $85 \%$ of the ad libitum fed control values on day 4 and 6 respectively, while TCA cycle intermediates were decreased to $78 \%$ of control on day 6 . In muscle of both patients and animal models dramatic changes in adenine nucleotides have been observed only during critical illness with fairly high mortality rates. Decreased ATP concentrations of approximately $50 \%$ have been measured in critically ill patients with mortality rates over $80 \%$ (Fürst et al 1976, Liaw 1985). In a study of Liaw and colleagues (Liaw et al 1980) in which concentrations of adenine nucleotides have been measured in muscle of moderately, severely and critically ill patients, only during critical illness concentrations of ATP and ADP were decreased and those of AMP increased. Additionally, they have observed a $30 \%$ decrease in concentrations of creatine phosphate in muscle of severely ill and a $50 \%$ decrease in the critically ill patients. Rats with severe burn trauma showed a large $(62 \%)$ decrease in muscle concentrations of ATP (Ardawi 1988). Other animal models with less severe illness or trauma showed no changes (Hotchkiss \& Karl 1992, Jepson et al 1987, Vary et al 1986) or only small changes (Angerảs et al 1991, Astiz et al 1988) in concentrations of adenine nucleotides.

Also other metabolites failed to show substantial changes in skeletal muscle of zymosan treated rats. Free ADP and AMP, which are potent mediators of key enzymes in glycolysis and glycogenolysis and of mitochondrial oxidation (Dudley et al 1987, Newsholme \& Start 1973) did not change dramatically. Increased concentrations would have stimulated AMP deaminase and could have resulted in ammonia production and adenine nucleotide depletion. To calculate concentrations of free ADP and free AMP, magnesium concentrations were assumed to be $1 \mathrm{mM}$. Magnesium concentrations may, however, be reduced in zymosan treated rats as indicated by reduced concentrations in muscle of intensive care patients (Fiaccadori et al 1988). Recalculating concentrations of free $A D P$ and free AMP using reduced magnesium concentrations for the zymosan 
treated rats, resulted in significantly increased concentrations of both metabolites.

Decreased activities of cytochrome $c$ oxidase and citrate synthase as previously observed in muscle of zymosan treated rats up to 6 days after treatment (chapter 4), indicated a reduced mitochondrial content. In a study of Dudley and colleagues (Dudley et al 1987) energy metabolism has been studied in rats with different mitochondrial contents in muscle. Although some minor changes in muscle ATP and creatine phosphate/creatine were observed at rest, the low mitochondria group showed the largest and the high mitochondria group the smallest decreases in high energy phosphates only after in situ electrical stimulation. Also in muscle of tumor bearing rats, decreased concentrations of ATP were observed in the soleus muscle only after intense in situ electrical stimulation (Muscaritoli et al 1992). This suggests that also in muscle of zymosan treated rats the oxidative capacity may be sufficient to prevent dramatic decreases in concentrations of high energy phosphate at rest.

Recently it has been suggested that an increased carbon drain on the TCA cycle due to enhanced breakdown of branched chain amino acids (BCAA) in combination with a reduced supply of new TCA cycle intermediates could cause an energy deficit and muscular fatigue during prolonged exercise (Sahlin et al 1990, Wagenmakers 1992, Wagenmakers et al 1991). In the first reaction of BCAA breakdown, 2-oxoglutarate is used as an amino group acceptor. An increased degradation of BCAA in muscle could, therefore, enhance the use of 2-oxoglutarate and subsequently lead to a carbon drain on the TCA cycle (Wagenmakers 1992, Wagenmakers et al 1991). Zymosan treatment activated the branched chain $\alpha$ keto acid dehydrogenase ( $\mathrm{BC}$-complex; the rate limiting enzyme in the degradation of BCAA) in muscle up to 6 days after zymosan injection (chapter 4) and, therefore, theoretically an increased BCAA degradation in skeletal muscle of zymosan treated rats could lead to a drain on the TCA cycle. In muscle, however, several anaplerotic pathways are present which may supply new TCA cycle intermediates (Aragón \& Lowenstein 1980, Davis et al 1980, Krebs 1975, Veerkamp 1981) and thereby compensate for this drain. Most of these reactions, however, use pyruvate as a carbon precursor indicating that serious problems with maintenance of the level of TCA cycle intermediates and subsequently high energy phosphates may occur when the availability of pyruvate is reduced (Wagenmakers 1992, Wagenmakers et al 1991). Modest decreases of TCA cycle intermediates, ATP and pyruvate in support of this hypothesis were observed only on day 6 after zymosan treatment.

Hotchkiss and colleagues (Hotchkiss \& Karl 1992) suggested that neither cellular hypoxia nor defects in energy-producing metabolic pathways of the cell can adequately account for the metabolic features typical of sepsis. They concluded that, although there are a host of metabolic abnormalities during sepsis, the cell retains its ability to maintain adequate energy stores until terminal stage. Also in this study with zymosan treated rats, as a model for severe illness, no dramatic changes in energy state of the skeletal muscle were measured. 
Decreased activities of citrate synthase and cytochrome $c$ oxidase (chapter 4), however, indicated that the mitochondrial content and thus the maximal oxidative capacity of the muscle was reduced. Therefore, an increased energy demand due to for instance an increased contractile activity might deplete energy stores more dramatically in zymosan treated than in control rats. This will be investigated in chapter 7.

\section{References}

- Angeràs U, Hall-Angeràs M, Wagner KR, James H, Hasselgren P-O and Fisher JE (1991). Tissue metabolite levels in different types of skeletal muscle during sepsis. Metabolism 40: 11471151.

- Anonymous (1979). Postoperative fatigue. Lancet 1: 84-85.

- Aragón JJ and Lowenstein JM (1980). The purine-nucleotide cycle. Comparison of the levels of citric acid cycle intermediates with the operation of the purine nucleotide cycle in rat skeletal muscle during exercise and recovery from exercise. Eur J Biochem 110: 371-377.

- Ardawi MSM (1988). Skeletal muscle glutamine production in thermally injured rats. Clin Sci 74: 165-172.

- Astiz M, Rackow EC, Weil MH and Schumer W (1988). Early impairment of oxidative metabolism and energy production in severe sepsis. Circ Shock 26: 311-320.

- Chad DA and Lacomis D (1994). Critically ill patients with newly acquired weakness: the clinicopathological spectrum. Ann Neurol 35: 257-259.

- Dagley S (1974). Citrate. In: Methods of enzymatic analysis (Bergmeyer HU, eds.). New York and London, Academic Press: 1562-1565.

- Davis EJ, Spydevold $\varnothing$ and Bremer J (1980). Pyruvate carboxylase and propionyl-CoA carboxylase as anaplerotic enzymes in skeletal muscle mitochondria. Eur J Biochem 110: 255-262.

- Dudley GA and Terjung RL (1985). Influence of acidosis on AMP deaminase activity in contracting fast-twitch muscle. Am J Physiol 248: C34-C50.

- Dudley GA, Tullson PC and Terjung RL (1987). Influence of mitochondrial content on the sensitivity of respiratory control. J Biol Chem 262: 9109-9114.

- Fiaccadori E, Del Canale S, Coffrini E, Melej R, Vitali P, Guariglia A and Borghetti A (1988). Muscle and serum magnesium in pulmonary intensive care unit patients. Crit Care Med 16: 751-760.

- Fürst P, Bergström J, Hultman E and Vinnars E (1976). Intermediary energy metabolism for the catabolic state with special regard to muscle tissue. In: Metabolism and the response to injury (Wilkinson AW and Cuthbertson D, eds.). England, Tunbridge Wells: 94-112.

- Harris RC, Hultman E and Nordesjö LO (1974). Glycogen, glycolytic intermediates and highenergy phosphates determined in biopsy samples of musculus quadriceps femoris of man at rest. Methods and variance of values. Scand J Clin Lab Invest 33: 109-120.

- Hotchkiss RS and Karl IE (1992). Reevaluation of the role of cellular hypoxia and bioenergetic failure in sepsis. JAMA 267: 1503-1510.

- Janssen MA, Van Berlo CLH, Van Leeuwen PAM and Soeters PB (1988). The determination of ammonia in plasma and whole blood. In: Advances in ammonia metabolism and hepatic: encephalopathy (Soeters PB, Wilson JHP, Meijer AJ and Holm E, eds.). Amsterdam, Elsevier Science Publishers bv: 587-592.

- Jepson MM, Cox M, Bates PC, Rothwell NJ, Stock MJ, Cady EB and Millward DJ (1987). Regional blood flow and skeletal muscle energy status in endotoxemic rats. Am J Physiol 252: E581E587. 
- Krebs HA (1975). The role of chernical equilibria in organ function. Adv Enzym Regul 15: 449472.

- Liaw KY, Askanazi J, Michelson CB, Kantrowitz LR, Fürst P and Kinney JM (1980). Effect of injury and sepsis on high-energy phosphates in muscle and red cells. J Trauma 20: 755-759.

- Liaw KY (1985). Effect of injury, sepsis, and parenteral nutrition on high-energy phosphates in human liver and muscle. JPEN 9: 28-33.

- Möllering H (1974). L-Malate. In: Methods of enzymatic analysis (Bergmeyer HU, eds.). New York and London, Academic Press: 1589-1593.

- Muscaritoli M, Whitlock D and Meguid MM (1992). Muscle performance and adenine-nucleotides status in MCA-sarcoma tumor-bearing rats. Physiol Behav 52: 803-807.

- Newsholme EA and Start C (1973). Regulation in metabolism. New York, John Wiley \& Sons.

- Sahlin K, Harris RC and Hultman E (1975). Creatine kinase equilibrium and lactate content compared with muscle $\mathrm{pH}$ in tissue samples obtained after isometric exercise. Biochem J 152: 173-180.

- Sahlin K, Katz A and Broberg S (1990). Tricarboxylic acid cycle intermediates in human muscle during prolonged exercise. Am J Physiol 259: C834-C841.

- Schumer W, Erve PR and Obernolte RP (1971). Endotoxemic effect on cardiac and skeletal muscle mitochondria. Surg Gynecol and Obstetrics 133: 433-436.

- Tavakoli H and Mela L (1982). Alterations of mitochondrial metabolism and protein concentrations in subacute septicemia. Infect Immun 38: 536-541.

- Vary TC, Siegel JH, Nakatani T, Sato T and Aoyama H (1986). Effect of sepsis on activity of pyruvate dehydrogenase complex in skeletal muscle and liver. Am J Physiol 250: E634-E640.

- Veerkamp JH (1981). The function of muscle mitochondria. In: Mitochondria and muscle diseases (Busch HFM, Jennekens FGI and Scholte HR, eds.). Beesterzwaag, The Netherlands, Mefar b.v.: 29-50.

- Wagenmakers AJM, Beckers EJ, Brouns F, Kuiper H, Soeters PB, Van der Vusse GJ and Saris WHM (1991). Carbohydrate supplementation, glycogen depletion, and amino acid metabolism during exercise. Am J Physiol 260: E883-E890.

- Wagenmakers AJM (1992). Role of amino acids and ammonia in mechanisms of fatigue. In: Muscle fatigue mechanisms in exercise and training (Marconnet P, Komi PV, Saltin B and Sejersted OM, eds.). Med. Sport Sci. 34. Basel, Karger: 69-86.

- Williamson JR (1974). Succinate. In: Methods of enzymatic analysis (Bergmeyer HU, ed.). New York, Academic Press: 1616-1621. 


\title{
Mitochondrial content and protein synthesis rates in skeletal muscle of zymosan challenged rats.
}

\author{
Olav E. Rooyackers, Sander H. Kersten and Anton J. M. Wagenmakers. Department \\ of Human Biology, University of Limburg, Maastricht, The Netherlands.
}

Submitted for publication

\section{Abstract}

1. Previously we reported decreased activities of mitochondrial marker enzymes in skeletal muscle of a catabolic rat model (zymosan injection). In the present study we investigated whether this actually reflects a reduction of mitochondrial content and whether a decrease in mitochondrial protein synthesis rates could be involved in this potential reduction.

2. Mitochondrial protein content was calculated from the activities of cytochrome $c$ oxidase (mitochondrial marker enzyme) in whole muscle homogenates and in a purified mitochondrial fraction. Mitochondrial morphology was investigated by electron microscopy. In vivo synthesis rates of mitochondrial protein were investigated by measuring incorporation of $\left[{ }^{3} \mathrm{H}\right]$ phenylalanine into mitochondrial protein using the flooding dose technique.

3. Mitochondrial content was reduced to $54 \%$ of pair fed and $71 \%$ of ad libitum fed control rats 2 days after zymosan treatment. Electron micrographs showed swollen and disrupted mitochondria in some areas of skeletal muscle of zymosan treated rats. The decreased mitochondrial protein content 2 days after the zymosan challenge was preceded by a reduced synthesis rate of mitochondrial protein $16 \mathrm{~h}$ after the treatment.

4. Muscle wasting, which is a characteristic feature during severe illness, is accompanied by an even more dramatic loss of mitochondrial protein. This loss of mitochondrial protein due to the catabolic challenge is at least in part the result of decreased protein synthesis rates. 


\section{Introduction}

Severe illness and the following convalescence are characterized by tiredness and exercise intolerance. These features most likely are originated in muscle weakness and increased muscle fatiguability (Anonymous 1979, Chad \& Lacomis 1994). In the field of exercise physiology a relationship between muscle mitochondrial content and muscle endurance performance has been established (Fitts et al 1975, Hoppeler et al 1973). Several reports on impaired mitochondrial function and distorted mitochondrial morphology in muscle of animal models of severe illness (Hersch et al 1990, Schumer et al 1971, Tavakoli \& Mela 1982), therefore, supply a potential mechanism for the muscle weakness during and following severe illness.

Recently we described decreased activities of two mitochondrial enzymes (citrate synthase and cytochrome $c$ oxidase) in muscle of a zymosan-induced rat model of critical illness (chapter 4). These observations suggested a decreased mitochondrial content. The results, however, could be interpreted as a reduction in mitochondrial content, or as a specific loss of the activity of these mitochondrial enzymes. This should be reflected in a decreased specific activity of these enzymes in purified mitochondria (activity per mg of mitochondrial protein). Therefore, we ascertained whether the decreased total activity of cytochrome $c$ oxidase was accompanied by related changes in the specific activity of cytochrome $c$ oxidase in skeletal muscle of zymosan treated rats. These numbers were used to calculate the mitochondrial protein content in muscle by dividing total activity by specific activity. In addition mitochondrial morphology was investigated by electron microscopy.

A general loss of mitochondrial protein can either be the result of enhanced protein degradation rates, decreased synthesis rates or a combination of both. No method is available to estimate mitochondrial protein degradation in vivo and, therefore, only mitochondrial protein synthesis was determined in this study. In a previous study synthesis rates of mixed muscle protein were found to be decreased at 16 hours after zymosan treatment and to be similar as the values of pair fed animals on day 2 and further (chapter 3 ). Additionally, the largest reduction in activity of cytochrome $c$ oxidase occurred after 2 days (chapter 4 ) and, since a decrease in synthesis rates should precede the fall in enzyme activity, mitochondrial protein synthesis rates were measured $16 \mathrm{~h}$ after zymosan treatment.

In addition to mitochondrial protein, other protein fractions (soluble and myofibrillar protein) were obtained during the separation procedure. Protein synthesis rates of these fractions were measured to investigate whether the reduction in muscle protein synthesis rates is a general phenomenon or differs between fractions. 


\section{Methods}

Male Lewis rats of approximately $200-300 \mathrm{~g}$ were obtained from the animal facilities of the University of Limburg. Rats were individually housed in grill bottom cages and were allowed to acclimatize for at least one week. During this period rats were kept in a controlled environment $\left(12\right.$ hour light-dark cycle, $20-21^{\circ} \mathrm{C}$, and $50-60 \%$ humidity) and had free access to water and food (SRM-A, Hope Farms, The Netherlands) containing (wt/wt) approximately $28 \%$ protein, $7 \%$ fat, $54 \%$ carbohydrates, $4 \%$ fibers and $7 \%$ minerals with a trace element and vitamin supplement. Food intake and body weight were measured daily. All the experiments were approved by the animal experimental committee of the University of Limburg.

The zymosan treated rats were intraperitoneally injected with $50 \mathrm{mg}$ of zymosan suspended in $2 \mathrm{ml}$ of sterile liquid paraffin per $100 \mathrm{~g}$ body weight as described before (chapter 3 ). Zymosan treatment decreases food intake during the first 2 days after injection and, therefore, control rats were pair fed. To mimic the pattern of food intake of the zymosan treated rats as closely as possible pair feeding was performed three times a day. Pair fed control rats were injected with paraffin only ( $2 \mathrm{ml}$ per $100 \mathrm{~g}$ body weight). Also a control group with free access to food and without paraffin injection was included in the studies.

\section{Protein fractionation}

Purification of muscle mitochondria was based on a procedure previously described (Glatz \& Veerkamp 1982, Van Hinsbergh et al 1978). After thawing muscle tissue in ice-cold SET buffer ( $0.25 \mathrm{M}$ sucrose, $2 \mathrm{mM}$ EDTA, $10 \mathrm{mM}$ tris- $\mathrm{HCl}$; $\mathrm{pH}$ 7.4 ) the tissue was carefully dissected free of visible fat and connective tissue. After blotting, mincing and weighing the muscle, a 5-7\% muscle homogenate was prepared in SET-buffer using a motor driven teflon pestle and a PotterElvehjem tube. Samples for measurement of mixed muscle protein were taken from this homogenate. Subsequently, the homogenate was centrifuged for $10 \mathrm{~min}$ at $600 \times \mathrm{xg}$, to separate the nuclear-myofibrillar fraction from mitochondrial, microsomal and soluble constituents. The supernatant was centrifuged for $10 \mathrm{~min}$ at $7000 \mathrm{xg}$ to yield a mitochondrial pellet. This pellet was washed twice with $25 \mathrm{ml}$ suspension buffer $(100 \mathrm{mM} \mathrm{KCl}, 1 \mathrm{mM} \mathrm{MgCl}, 0.2 \mathrm{mM}$ EDTA, $0.2 \mathrm{mM}$ ATP, $50 \mathrm{mM}$ tris- $\mathrm{HCl} ; \mathrm{pH}$ 7.4). The final mitochondrial suspension was used for measurements.

The supernatant arising after centrifugation at $7000 \mathrm{xg}$ was subsequently centrifuged for $60 \mathrm{~min}$ at $100000 \mathrm{xg}$ to precipitate small particles, giving rise to a supernatant containing soluble protein. The nuclear-myofibrillar pellet (obtained after the $600 \mathrm{xg}$ spin) was washed with $\mathrm{H}_{2} \mathrm{O}(25 \mathrm{ml}$ per gram of fresh muscle) to release soluble and mitochondrial impurities. Myofibrillar protein within the pellet was subsequently solubilized in $0.6 \mathrm{M} \mathrm{KCl}$ (Starnes et al 1987) (25 ml per gram of fresh muscle) with the aid of an OMNI 1000 polytron. The resulting suspension 
was centrifuged for $10 \mathrm{~min}$ at $33000 \mathrm{xg}$ and the resulting supernatant contained mainly dissolved actin and myosin.

The yield of the mitochondrial purification was about $20 \%$. No proteolytic enzymes were used and, therefore, the preparations predominantly contained subsarcolemmal mitochondria. The intra-assay coefficient of variation of the mitochondrial protein content measurements was $4.4 \%(n=6)$.

\section{Experiment 1 (Mitochondrial protein content in muscle)}

Zymosan treated rats $(n=6)$, pair fed rats $(n=6)$ and ad libitum fed rats $(n=6)$ were sacrificed by cervical dislocation 2 days after treatment. Combined hindquarter muscle was dissected, immediately frozen in liquid nitrogen using a precooled pair of tongs and stored at $-80^{\circ} \mathrm{C}$.

To investigate if the decreased activity of cytochrome $c$ oxidase in muscle of zymosan treated rats is the result of a reduced mitochondrial content, specific activity of cytochrome $c$ oxidase was measured (in units per mg mitochondrial protein). To achieve this, mitochondria were purified from muscle as described before and analyzed for activities of cytochrome $c$ oxidase and for protein content. Using the specific and total cytochrome $c$ oxidase activity in muscle, mitochondrial protein content in $\mathrm{mg}$ per $\mathrm{g}$ muscle was calculated:

mitochondrial content $=$ total activity/specific activity

\section{Experiment 2 (Morphology of muscle mitochondria)}

To obtain an impression of the morphology of mitochondria, muscle specimens were investigated by means of electron microscopy. Gastrocnemius muscle was obtained from zymosan treated $(n=2)$, pair fed $(n=1)$ and ad libitum fed control $(n=1)$ rats. After dissection, portions of the muscle were immediately fixed in $2.5 \%$ glutaraldehyde ( $0.1 \mathrm{M}$ phosphate buffer), post fixed in $1 \%$ osmium tetroxide ( $0.1 \mathrm{M}$ phosphate buffer), dehydrated using alcohol and embedded in epon. Ultra thin sections were stained with uranyl acetate and lead citrate and subsequently examined using a Philips CM10 electron microscope.

\section{Experiment 3 (Fractional synthesis rates of mitochondrial protein)}

Incorporation of $\left[{ }^{3} \mathrm{H}\right]$ phenylalanine into various protein fractions following a flooding dose of intraperitoneally injected $\mathrm{L}-\left[4{ }^{-} \mathrm{H}\right]$ phenylalanine was measured to calculate fractional protein synthesis rates of mixed, mitochondrial, soluble and myofibrillar proteins.

Zymosan treated $(n=10)$, pair fed $(n=10)$ and ad libitum fed rats $(n=8)$ were intraperitoneally injected with $\mathrm{L}-\left[4{ }^{3} \mathrm{H}\right]$ phenylalanine $(150 \mu \mathrm{mol}$ of phenylalanine and $20 \mu \mathrm{Ci}$ of labeled phenylalanine $/ \mathrm{ml} ; 2 \mathrm{ml} / 100 \mathrm{~g}$ body weight) as previously described (Jepson et al 1986). Fifteen min later rats were sacrificed by cervical dislocation and the hindlimbs were transferred to ice-cold water. 
Subsequently, all hindquarter muscle was dissected, immediately frozen using a precooled pair of tongs in liquid nitrogen and stored at $-80^{\circ} \mathrm{C}$.

Muscle protein fractions (mixed protein, mitochondrial protein, soluble protein and myofibrillar protein) were obtained as described before. During this procedure cycloheximide $(0.5 \mathrm{mM})$ was added to all buffers to arrest further incorporation of labeled phenylalanine during fractionation and analysis. Incorporation of $\left[{ }^{3} \mathrm{H}\right]$ phenylalanine into the different protein fractions was measured as previously described (Garlick et al 1980), after protein was precipitated by adding perchloric acid (mixed, mitochondrial and soluble protein) or trichloroacetic acid (myofibrillar protein) to a concentration of $2 \%$. The perchloric acid supernatant of the mixed protein fraction was used to measure specific radioactivity of the precursor pool as previously described (Garlick et al 1980). This specific radioactivity ( $S A_{\text {precursor }}$ ) and the specific radioactivity of protein bound phenylalanine $\left(S_{\text {bound }}\right)$ of the different protein fractions were used to calculate fractional protein synthesis rates (FSR):

$$
\mathrm{FSR}=\frac{\mathrm{SA}_{\text {bound }}}{0.9 \times \mathrm{SA}_{\text {precursor }} \times \text { time }(\text { days })} \times 100 \%
$$

\section{Analysis}

Activities of cytochrome $c$ oxidase were measured as previously described (Gohil et al 1981) using an adaptation of the method for a centrifugal analyzer (COBAS $\mathrm{BIO}$, Roche). Protein concentrations were measured using the Folin reagents method as described by Lowry and colleagues (Lowry et al 1951).

\section{Statistics}

All measurements were performed in duplicate or triplicate except for the mitochondrial protein synthetic rate measurements because insufficient mitochondrial protein was available for duplicate analysis. Values are given as mean (range). The Mann-Whitney U-test was used to determine statistically significant differences. Significance was set at $p<0.05$.

\section{Results}

\section{Mitochondrial protein content}

No differences in activity of cytochrome $c$ oxidase (expressed per $\mathrm{g}$ of muscle) in hindquarter muscle were observed between groups (zymosan treated, pair fed and ad libitum fed) $16 \mathrm{~h}$ after treatment (Table 1). On day 2 the activity was significantly reduced in zymosan treated rats in comparison with both pair fed and ad libitum fed control rats. Pair feeding significantly increased the activity of cytochrome $c$ oxidase.

Specific activity of cytochrome $c$ oxidase (activity expressed per mg of 
Table 1. Activities of cytochrome $c$ oxidase in muscle and in isolated mitochondria measured 16 and 48 hours after treatment are given as mean (range) of 8-10 rats. *: significantly different from ad libitum and \#: pair fed control rats.

\begin{tabular}{|c|c|c|c|c|c|c|c|}
\hline \multirow{2}{*}{ Lenes } & \multirow{2}{*}{$\frac{\text { time }}{16 \mathrm{~h}}$} & \multicolumn{2}{|r|}{ zymosan } & \multicolumn{2}{|c|}{ pair fed } & \multicolumn{2}{|r|}{ control } \\
\hline & & 77.2 & $(52.8-93.1)$ & 83.2 & $(63 .\{-111.2)$ & 77.2 & $(52.1-102.8)$ \\
\hline ( $\mu$ mol/min per 9 muscle) & $48 \mathrm{~h}$ & 68.9 & $\cdot(58.9-75.4)$ & $100.4^{\circ}$ & $(93.0-107.5)$ & 82.6 & $(76.0-91.1)$ \\
\hline Cytochrome $c$ oxidase & $16 \mathrm{~h}$ & 7.1 & $(5,5-7,9)$ & 7.5 & $(6.2 \cdot 8.3)$ & 7.0 & $(5.3-8.4)$ \\
\hline (umol/min per mg mitochondrial protein) & $48 \mathrm{~h}$ & 7.7 & $\cdot(7.2-8.4)$ & 6.1 & $(5.5-7.9\}$ & 6.6 & $(5.5 \cdot-7.3)$ \\
\hline
\end{tabular}

mitochondrial protein) was increased in zymosan treated rats $48 \mathrm{~h}$ after treatment in comparison with both control groups (Table 1). Notwithstanding this increase, the mitochondrial content (mg mitochondrial protein per $\mathrm{g}$ of muscle) was significantly decreased in zymosan treated rats on day 2 in comparison with pair fed and ad libitum fed control rats (Fig. 1). Pair feeding resulted in an increased mitochondrial content in combined hindquarter muscle.

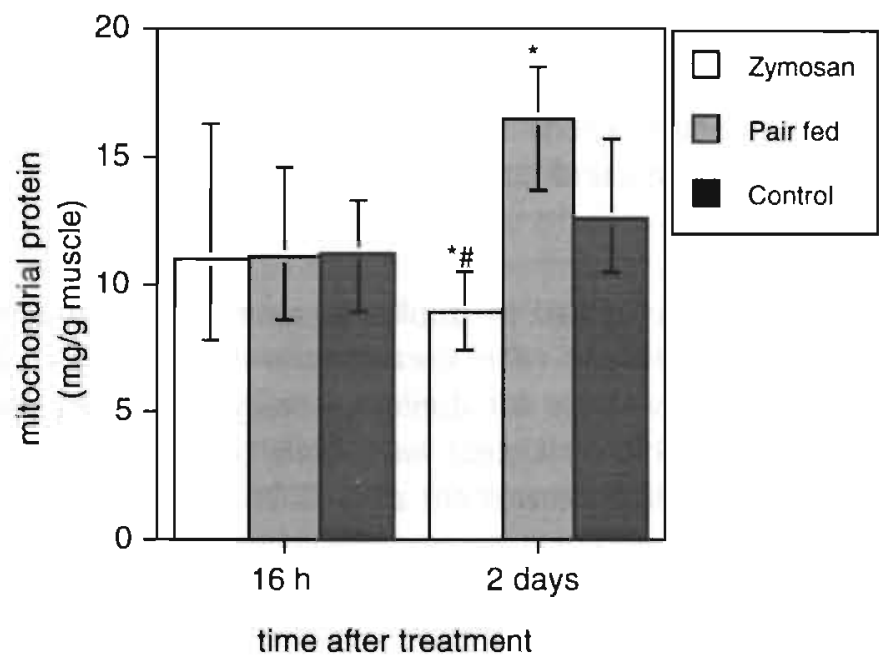

Figure 1. Mitochondrial protein content of combined hindquarter muscle measured $16 \mathrm{~h}$ and 2 days after treatment are given as mean (range) of 8-10 rats. *: significantly different from ad libitum and \#: pair fed control rats.

Both the specific activity of cytochrome $c$ oxidase and mitochondrial content measured were comparable to values obtained by Glatz and Veerkamp (Glatz \& Veerkamp 1982). This indicates that, although the fractionation procedure was slightly modified in our study, a mitochondrial fraction with similar purity was obtained. 

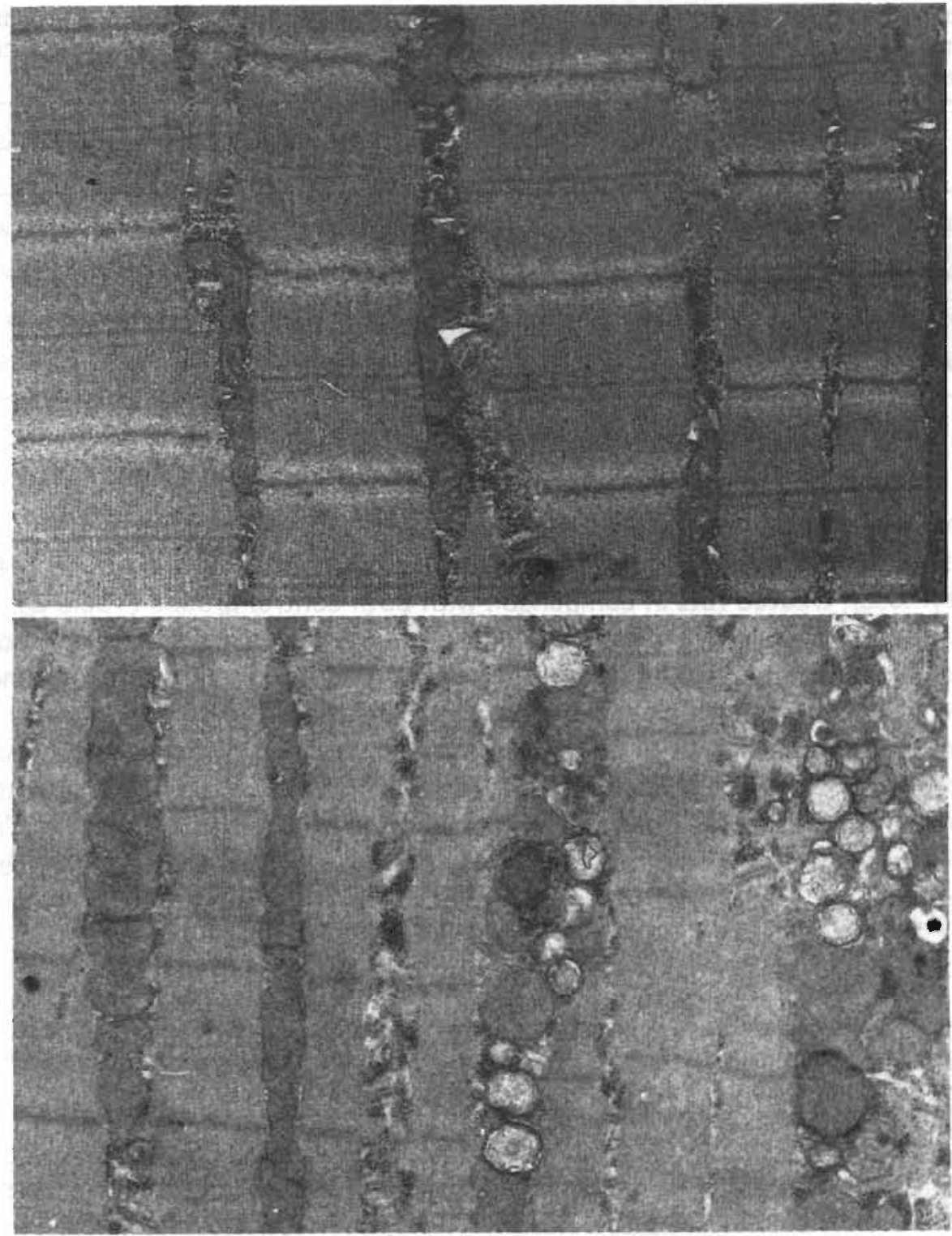

Figure 2. Electron micrograph of gastrocnemius muscle of ad libitum fed control rat (top) and zymosan treated rat (bottom) 6 days after treatment (magn. 13650x).

\section{Mitochondrial morphology}

Muscle morphology studied by electron microscopy showed swollen and disrupted mitochondria in some areas of the gastrocnemius muscle of zymosan treated rats (Fig. 2). Also normal mitochondria were observed. No such impairment was observed in muscle of either ad libitum fed (Fig. 2) and pair fed control rats (not shown). 
Table 2. Fractional synthesis rates (\%/day) of mixed, mitochondrial, soluble and myofibrillar protein measured 48 hours after treatment are given as mean (range) of 8-10 rats. *: significantly different from ad libitum and \#: pair fed control rats.

\begin{tabular}{|c|c|c|c|c|c|c|c|}
\hline & \multicolumn{3}{|c|}{ zymosan } & \multicolumn{2}{|l|}{ pair fed } & \multicolumn{2}{|r|}{ control } \\
\hline & & & of contral & & af control & & \\
\hline mixed protein & 6.9 & (4.3-10.7) & 61 & $8.6 \cdot(7.5-9.8)$ & 75 & 11.4 & $(9.9-12.8)$ \\
\hline mitochondrial protein & 8.3 & - (5.3-14.1) & 52 & $12.1 \cdot(9.4-17.8)$ & 76 & 15.9 & $(14.3-19.0)$ \\
\hline soluble protein & 11.5 & $(4.5-19.2)$ & 73 & $11.6 \cdot(8.0-19.8)$ & 74 & 15.7 & $(11.1-25.3)$ \\
\hline myofibrillat protein & 5.0 & $\because(3.8-6.4)$ & 50 & $7.5 \cdot(6.1-9.0)$ & 77 & 9.9 & $(9.0-11.0)$ \\
\hline
\end{tabular}

\section{Protein synthesis rates}

The fractional synthesis rate of mixed protein of hindquarter muscle was decreased in zymosan treated rats in comparison with both control groups (Table 2). The fractional synthesis rate of mitochondrial protein was also decreased in zymosan rats in comparison with both control groups. The fractional protein synthesis rate of soluble protein was similar in zymosan treated and pair fed rats. The fractional synthesis rate of myofibrillar protein was also decreased in zymosan challenged rats in comparison with pair fed and ad libitum fed rats. Pair feeding significantly decreased fractional synthesis rates of all protein fractions (Table 2 ) indicating that part of the decreases in zymosan treated rats were the result of starvation.

Table 3. Absolute synthesis rates of mixed and mitochondrial protein measured 48 hours after treatment are given as mean (range) of 8-10 rats. *: significantly different from ad libitum and \#: pair fed control rats.

\begin{tabular}{|c|c|c|c|c|}
\hline & zymosan & pair fed & & control \\
\hline mixed proteln (mg /g muscie per day) & $14.1 \cdot(10.1-19.6)$ & $17.9 \cdot(14.6-21.2\rangle$ & 22.6 & $(19.5-28.1)$ \\
\hline mitochondrial protein ( $\mathrm{mg} / \mathrm{g}$ muscle per day) & $0.8 \cdot(0.4 \cdot 1.5)$ & $1.4 \cdot(1.1-2.1)$ & 1.7 & $(14-2,2)$ \\
\hline
\end{tabular}

Absolute protein synthesis rates (mg protein synthesized/g muscle per day) were calculated for total and mitochondrial protein. In the zymosan treated rats absolute synthesis rates of both protein fractions were significantly decreased in comparison with pair fed and ad libitum fed control rats (Table 3). Also pair feeding decreased these parameters significantly although to a lesser extent than in zymosan treated rats. To get an impression of the decrease in synthesis \82 


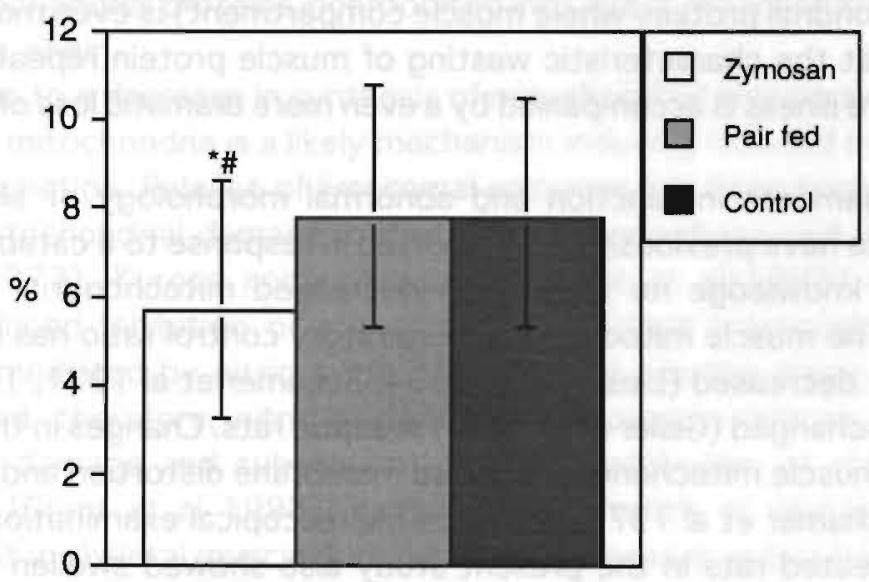

Figure 3. Absolute synthesis rates of mitochondrial protein expressed as percentage of the absolute synthesis rate of mixed protein of combined hindquarter muscle measured 2 days after treatment. Values are given as mean (range) of 8-10 rats. *: significantly different from ad libitum and \#: pair fed control rats.

rates of the mitochondrial protein in proportion to the decrease in mixed protein, absolute synthesis rates of mitochondrial protein were expressed as percentage of absolute synthesis rates of mixed protein of skeletal muscle (Fig. 3). These values indicated that the decrease in mitochondrial protein synthesis in pair fed rats was proportional to the decrease in mixed protein. In zymosan treated rats, however, the decreased percentage indicated that the decrease in mitochondrial protein synthesis was larger than that of mixed protein.

\section{Discussion}

Decreased activities of two mitochondrial enzymes (cytochrome $c$ oxidase and citrate synthase) in skeletal muscle of zymosan treated rats have suggested a reduced mitochondrial content (chapter 4). However, also decreases in specific activity (activity per $\mathrm{mg}$ of mitochondrial protein) of these enzymes may cause a reduced total activity. Measurements of the specific activity in skeletal muscle of zymosan treated rats failed to show such a decrease. Consequently the calculated amount of mitochondrial protein (expressed as $\mathrm{mg}$ protein per $\mathrm{g}$ muscle tissue) proved to be significantly decreased 2 days after treatment. No changes in total protein concentration ( $\mathrm{mg}$ protein $/ \mathrm{g}$ muscle) in muscle of zymosan treated rats have been found previously (chapter 3 ), indicating a specific loss of mitochondrial protein from skeletal muscle due to the zymosan challenge. However, zymosan treated rats lose muscle mass in comparison with both control 
groups (chapter 3 ) which implies that the total amount of muscle mitochondria (mg mitochondrial protein/whole muscle compartment) is even more diminished. It seems that the characteristic wasting of muscle protein repeatedly reported during severe illness is accompanied by a even more dramatic loss of mitochondrial protein.

Derangements in function and abnormal morphology of skeletal muscle mitochondria have previously been reported in response to a catabolic challenge, but to our knowledge no reports on decreased mitochondrial content have appeared. The muscle mitochondrial respiratory control ratio has been reported to be either decreased (Llesuy et al 1994, Schumer et al 1971, Tavakoli \& Mela 1982) or unchanged (Geller et al 1986) in septic rats. Changes in the morphology of skeletal muscle mitochondria included membrane distortion and mitochondrial swelling (Schumer et al 1971). Electron microscopical examination of muscle of zymosan treated rats in the present study also showed swollen and disrupted mitochondria in some areas of skeletal muscle, whereas in other areas mitochondria with normal morphology were present.

In moderately catabolic patients following elective surgery no changes in skeletal muscle activities of the mitochondrial enzyme citrate synthase have been observed (Wernerman et al 1988). However, in critically ill patients activities were dramatically decreased in skeletal muscle (Helliwell et al 1990).

Data from exercise physiology studies have indicated that muscle endurance performance is clearly related to total mitochondrial density or activity (Fitts et al 1975, Hoppeler et al 1973). Decreased mitochondrial content will be reflected in a reduced endurance capacity, most likely because maintenance of muscle ATP levels is compromised (Dudley et al 1987). Consequently critical illnessinduced muscle weakness and fatiguability may at least in part be caused by a decreased mitochondrial content.

The decreased mitochondrial protein content in the zymosan treated rats could at least partly be explained by decreased protein synthesis rates indicated by reduced in vivo incorporation of labelled phenylalanine measured with the flooding dose technique. Especially when expressed as mitochondrial protein synthesized as a percentage of total protein synthesized, a preferential decrease in mitochondrial protein synthesis in zymosan treated rats was observed. Also in the pair fed rats decreased synthesis rates of mitochondrial protein were observed, but these were proportional to the decreased synthesis of mixed protein. Synthesis of mitochondrial protein occurs both in cytosol as well as inside the mitochondria themselves. Mitochondria contain DNA which is utilized to synthesize about $10 \%$ or less of the total mitochondrial protein, including subunits of cytochrome reductase, cytochrome $c$ oxidase and ATPase (Freeman et al 1986, Siddiq et al 1993). When using a flooding dose of labelled amino acid to measure protein synthesis rates, it is assumed that all precursor pools are flooded and that no differences in specific radioactivity exist. We, therefore, assumed that the 
synthesis rates of mitochondrial protein as measured in the present study was that of all mitochondrial proteins incorporated into intact mitochondria regardless of its genomic origin.

In addition to a decrease in synthesis of mitochondrial protein also enhanced breakdown of mitochondria is a likely mechanism inducing reduced mitochondrial content and function. Release of lysosomal enzymes has been suggested to be involved in mitochondrial damage in liver due to hemorrhage and endotoxemia (Mela et al 1973). Kurose and colleagues (Kurose et al 1993) reported an endotoxin-induced inhibition of mitochondrial electron transport in cultured hepatocytes mediated by nitric oxide. Mitochondria are the major site of free radical flux and, therefore, nitric oxide and other oxygen radicals may induce mitochondrial damage and subsequently overall catabolism of non-functional mitochondria (Grant et al 1993). Increased occurrence of oxygen radicals is likely to persist in skeletal muscle during catabolic diseases as has been indicated in septic rat studies (Llesuy et al 1994, Peralta et al 1993).

In vivo fractional protein synthesis rates of muscle mitochondria were higher than those of mixed protein. The contribution of mitochondrial protein synthesis to total muscle protein synthesis calculated from the absolute protein synthesis rates was $8 \%$. Heart mitochondrial fractional protein synthesis rates also measured using the phenylalanine flooding dose technique were reported to be lower than those of mixed protein (Siddiq et al 1993). The contribution to total protein synthesis (20\%), however, was much higher than in skeletal muscle due to a substantially higher mitochondrial content in heart muscle.

Zymosan treatment reduced fractional protein synthesis rates of hindquarter mixed protein to $61 \%$ of control values which is comparable to the decrease previously measured in gastrocnemius muscle of zymosan rats (chapter 3 ). Fractional synthesis rates of both mitochondrial and myofibrillar protein in zymosan treated rats were decreased to approximately $50 \%$ of control. About half of this decrease was originated in the decreased food intake as indicated by the pair fed values. In contrast to this, fractional synthesis rates of soluble protein were decreased to the same extent in both zymosan treated and pair fed rats in comparison with ad libitum fed control rats. Surgical trauma also decreased fractional protein synthesis rates of mixed, soluble and myofibrillar protein in skeletal muscle (Mermel et al 1991), but the decrease in soluble protein was larger than in myofibrillar protein. In the same study also rats with burn trauma were studied. Fractional protein synthesis rates of the three fractions were enhanced in skeletal muscle of these rats (Mermel et al 1991).

In the present study decreased mitochondrial content and abnormal morphology were observed in skeletal muscle of zymosan challenged rats. These features may provide a plausible mechanism for muscle weakness and exercise intolerance observed following a catabolic challenge (inflammation, trauma). The reduced mitochondrial content is at least partly the result of decreased synthesis rates of mitochondrial protein. 


\section{References}

- Anonymous (1979). Postoperative fatigue. Lancet 1: 84-85.

- Chad DA and Lacomis D (1994). Critically ill patients with newly acquired weakness: the clinicopathological spectrum. Ann Neurol 35: 257-259.

- Dudley GA, Tullson PC and Terjung RL (1987). Influence of mitochondrial content on the sensitivity of respiratory control. J Biol Chem 262: 9109-9114.

- Fitts RH, Booth FW, Winder WW and Holloszy JO (1975). Skeletal muscle respiratory capacity, endurance, and glycogen utilization. Am J Physiol 228: 1029-1033.

- Freeman KB, Yatscoff RW and Ridley RG (1986). Experimental approaches to the study of the biogenesis of mammalian mitochondrial proteins. Biochem Cell Biol 64: 1108-1114.

- Garlick PJ, McNurlan MA and Preedy VR (1980). A rapid and convenient technique for measuring the rate of protein synthesis in tissue by injection of $\left[{ }^{3} \mathrm{H}\right]$-phenylalanine. Biochem J 192: 719 723.

- Geller ER, Jankauskas S and Kirkpatrick J (1986). Mitochondrial death in sepsis: a failed concept. J Surg Res 40: 514-517.

- Glatz JFC and Veerkamp JH (1982). Postnatal development of palmitate oxidation and mitochondrial enzyme activities in rat cardiac and skeletal muscle. BBA 711: 327-335.

- Gohil K, Jones DA and Edwards RHT (1981). Analysis of muscle mitochondrial function with techniques applicable to needle biopsy samples. Clin Physiol 1: 195-207.

- Grant AJ, Jessup W and Dean RT (1993). Enhanced enzymatic degradation of radical damaged mitochondrial membrane components. Free Rad Res Comms 19: 125-134.

- Helliwell TR, Griffith RD, Coakley JH, Wagenmakers AJM, NcClelland P, Campbell IT and Bone JM (1990). Muscle morphology and biochemistry in critically-ill patients. J Neurol Sci 98: 329.

- Hersch M, Gnidec AA, Bersten AD, Troster M, Rutledge FS and Sibbald WJ (1990). Histologic and ultrastructural changes in nonpulmonary organs during early hyperdynamic sepsis. Surgery 107: $397-410$.

- Hoppeler H, Lüthi P, Claassen H, Weibel ER and Howald H (1973). The ultrastructure of the normal human skeletal muscle. A morphometric analysis on untrained men, women and welltrained orienteers. Pflügers Archiv 344: 217-232.

- Jepson MM, Pell JM, Bates PC and Millward DJ (1986). The effect of endotoxaemia on protein metabolism in skeletal muscle and liver of fed and fasted rats. Biochem J 235: 329-336.

- Kurose I, Kato S, Ishii H, Fukumura D, Miura S, Suematsu M and Tsuchiya M (1993). Nitric oxide mediates Lipopolysaccharide-Induced alteration of mitochondrial function in cultured hepatocytes and isolated perfused liver. Hepatology 18: 380-388.

- Llesuy S, Evelson P, González-Flecha B, Peralta J, Carreras MC, Poderoso JJ and Boveris A (1994). Oxidative stress in muscle and liver of rats with septic syndrome. Free Rad Biol Med 16: $445-541$.

- Lowry OH, Rosebrough NJ, Farr AL and Randall RJ (1951). Protein measurement with the Folin phenol reagent. J Biol Chem 193: 265-275.

- Mela L, Miller LD, Bacalzo LV, Olofsson K and White RR (1973). Role of intracellular variations of lysosomal enzyme activity and oxygen tension in mitochondrial impairment in endotoxemia and hemorrhage in the rat. Ann Surg 178: 727-735.

- Mermel VL, Wolfe BM, Hansen RJ and Clifford AJ (1991). Comparative effects of thermal and surgical trauma on rat muscle protein metabolism. JPEN 15: 128-136.

- Peralta JG, Llesuy S, Evelson P, Carreras MC, Flecha BG and Poderoso JJ (1993). Oxidative Stress in Skeletal Muscle During Sepsis in Rats. Circ Shock 39: 153-159.

- Schumer W, Erve PR and Obernolte RP (1971). Endotoxemic effect on cardiac and skeletal muscle mitochondria. Surg Gynecol and Obstetrics 133: 433-436.

- Siddiq T, Salisbury JR, Richardson PJ and Preedy VR (1993). Synthesis of ventricular mitochondrial proteins in vivo: effect of acute ethanol toxicity. Alcoholism: Clinical and Experimental Research 17: 894-899. 
- Starnes JW, Beyer RE, Farrar RP and Edington DW (1987). Protein synthesis in skeletal muscle from normal and diabetic rats following increased contractile activity in situ. Res Commun in Chem Path and Pharmacol 58: 339-352.

- Tavakoli H and Mela L (1982). Alterations of mitochondrial metabolism and protein concentrations in subacute septicemia. Infect Immun 38: 536-541.

- Van Hinsbergh VWM, Veerkamp JH and Van Moerkerk HTB (1978). Palmitate oxidation by rat skeletal muscle mitochondria. Comparison of polarographic and radiochemical experiments. Arch Biochem Biophys 190: 762-771.

- Wernerman J, Sylvén C, Jansson E, Von der Decken A and Vinnars E (1988). Enzymatic capacity and protein synthesis in human muscle postoperatively. Acta Chir Scand 154: 489494. 


\section{Energy metabolism and contractility of electrically stimulated skeletal muscle of rats recovering from critical illness.}

Olav E. Rooyackers, Matthijs K.C. Hesselink* and Anton J.M. Wagenmakers. Departments of Human Biology and *Physiology, University of Limburg, Maastricht, The Netherlands.

Submitted for publication

\section{Abstract}

1. Previously it has been shown that zymosan induced critical illness in rats is attended by a decrease in mitochondrial content (maximal aerobic capacity) in skeletal muscle. This may provide a mechanism for muscle weakness present during critical illness and convalescence. In the present study we investigated whether in situ electrical stimulation would result in an increased reduction in adenine nucleotides and creatine phosphates and subsequently a loss of contractility in skeletal muscle of rats recovering from critical illness.

2. Six days after treatment plantar-flexor muscles of the hindlimb of zymosan challenged anesthetized rats were electrically stimulated via the innervating nerve, to develop maximal isometric tetanic contraction. Muscle force was measured as the isometric torque of the plantar-flexor muscles during stimulation. Immediately after stimulation gastrocnemius muscle was rapidly dissected and analyzed for concentrations of high energy phosphates and other metabolites related to energy metabolism.

3. In skeletal muscle of zymosan treated rats decreased concentrations of ATP were measured both at rest and after stimulation in comparison with values obtained from ad libitum and pair fed control rats. However, no major differences in the stimulation induced decreases in high energy phosphates levels were observed between the groups. The zymosan treated rats, however, developed about $85 \%$ less force during the whole stimulation period in comparison with the pair fed controls.

4. We conclude that the primary cause of the loss of muscle force in zymosan treated rats is an insensitivity of skeletal muscle for electrical stimulation. 


\section{Introduction}

Patients recovering from severe catabolic diseases (e.g. major surgery, sepsis or burn injury) often experience muscle weakness and increased fatiguability, sometimes for months after discharge form the hospital. A reduction in both muscle force and endurance performance have been suggested to contribute to the general feeling of tiredness and fatigue (Anonymous 1979, Christensen et al 1985, Zeiderman et al 1990). Several mechanisms, including nerve dysfunction and derangements in function or structure of muscle cells itself have been postulated to be involved in this muscle weakness.

Recently we described a decreased mitochondrial content in skeletal muscle of a zymosan-induced catabolic rat model both during severe illness and recovery (chapter 4 and 6 ). In the field of exercise physiology a relation between mitochondrial content and muscle endurance performance is well established (Fitts et al 1975, Hoppeler et al 1973), supplying a potential mechanism for the critical illness related muscle weakness. However, the decreased mitochondrial content in muscle of zymosan treated rats only had a modest effect on concentrations of high energy phosphates at rest (chapter 5). Therefore, we investigated the hypothesis that the decreased mitochondrial content in muscle of rats recovering from zymosan treatment leads to a reduced capacity to maintain high energy phosphates during electrical stimulation which subsequently will lead to a more rapid loss of muscle force (increased fatiguability).

Zymosan treatment (intraperitoneal injection) results in an acute phase of critical illness for approximately 2 days followed by a prolonged recovery period of at least 10 days (chapter 3 ). In the present study the effect of electrical in situ stimulation was studied in zymosan treated, pair fed and ad libitum fed rats 6 days after treatment, when rats were recovering but still had a substantial reduction of muscle mitochondrial content. Concentrations of high energy phosphates, lactate, pyruvate and glycogen were measured in muscle sampled immediately after stimulation. Concentrations of free ADP and AMP and the ATP/ free ADP ratio were calculated because of their putative role as regulators of glycolysis (Newsholme \& Start 1973) and respiratory control (Dudley et al 1987). In addition the force generated was measured continuously to obtain information about fatiguability in relation to metabolite changes.

\section{Methods}

Male Lewis rats utilized in this study were supplied by the central laboratory animal facilities of the University of Limburg. Rats were individually housed on grid bottom cages in a controlled environment $\left(12\right.$ hour light cycle, $21-22^{\circ} \mathrm{C}$ and $50-60 \%$ humidity). Before the experiment rats were allowed to acclimatize for one week. Unless stated otherwise rats had free access to food and water. 
Experiments were approved by the animal experimental committee of the University of Limburg.

Nine rats of approximately $200 \mathrm{~g}$ were intraperitoneally injected with zymosan suspended in liquid paraffin ( $50 \mathrm{mg} / 2 \mathrm{ml}$ per $100 \mathrm{~g}$ of body weight) as described before (chapter 3 ). Since zymosan treatment reduces food intake, 9 rats were pair fed. The pair fed rats were injected with liquid paraffin only $(2 \mathrm{ml}$ per $100 \mathrm{~g}$ of body weight). Pair feeding was performed three times during the day to make the pattern of food intake comparable with that of zymosan treated rats (chapter 3). Also a group of non treated and ad libitum fed rats was included in this study. During 6 days following treatment, body weight and food intake were determined daily.

On the day of the experiment ( 6 days after treatment) rats were anesthetized using pentobarbital sodium ( $6 \mathrm{mg} / 100 \mathrm{~g}$ body weight). After careful preparation, a stainless steel electrode was hooked to the tibial nerve to stimulate the triceps muscle surae group. Special care was taken to connect the electrode as distal as possible to prevent any contractile activity of antagonist muscles. To ensure rapid dissection and freezing after terminating the stimulation, surrounding skin and subcutaneous muscle tissue were carefully removed without damaging innervation or blood supply. Rats were laid backwards on a heating pad with knee and foot tightly fixed, both under $90^{\circ}$. Maximal isometric tetanic contraction was induced by pulse trains of $0.1 \mathrm{msec}$ square waves at $6 \mathrm{~V}$ and $100 \mathrm{~Hz}$ for a duration of $100 \mathrm{msec}$. As in the experiments of Dudley and colleagues (Dudley et al 1987), this in situ stimulation was continued for 3 minutes with 30 tetani per minute to obtain sufficient changes in metabolites in muscle of control rats.

To obtain a measure of muscle force performed by the plantar-flexor muscles during stimulation, we used a modification of a set-up originally designed to measure isometric torque of dorsi-flexor hindlimb muscles. A precalibrated force transducer (Grass FTO3C) was connected to the very end of the foot plate enabling measurements of isometric torque. Since no valid information concerning the lever arm of the triceps surae muscle group is available, muscle functional capacity was expressed in Newton instead of Newtonmeter. Force measurements were registered on line every 10 seconds. Immediately after stimulation gastrocnemius muscle was rapidly excised and quickly freeze clamped using a pair of tongs cooled in liquid nitrogen. Time between terminating stimulation and freezing was approximately 50 seconds, while time between cutting and freezing was about 5 seconds. Gastrocnemius muscle of the non-stimulated contralateral leg was freeze-clamped immediately thereafter, and served as non-exercised control. Muscles were stored at $-80^{\circ} \mathrm{C}$ until analysis.

Frozen muscle tissue was ground to smaller pieces using a precooled mortar and pestle, and mixed. Part of this mixture (50-100 mg) was used to determine activities of cytochrome $c$ oxidase as an indication of mitochondrial content. A $5 \%$ homogenate was made using an ice cold buffer ( $0.25 \mathrm{M}$ sucrose, $2 \mathrm{mM}$ EDTA and $10 \mathrm{mM}$ Tris/HCl; $\mathrm{pH}=7.4$ ) and a Teflon-glass Potter-Elvehjem homogenizer. 
In this homogenate activities of cytochrome $c$ oxidase were measured using a method described before (Gohil et al 1981), adapted for a centrifugal analyzer (COBAS-B1O, Roche Diagnostics). Glycogen content was determined in another part of the muscle mixture $(10-50 \mathrm{mg}$ ) by measuring the glycosyl units obtained after hydrolysation of extracted glycogen as described previously (chapter 5). Metabolites were extracted from the remainder of the muscle tissue using ice cold $1 \mathrm{M}$ perchloric acid $(1: 5)$. ATP, ADP, AMP, creatine phosphate ( $\mathrm{CrP})$, creatine $(\mathrm{Cr})$, pyruvate and lactate were measured in the neutralized ( $2 \mathrm{M}$ potassium bicarbonate) supernatant using standard enzymatic analysis as described before (Harris et al 1974) adapted for a COBAS-BIO.

Concentrations of free $\operatorname{ADP}\left(\mathrm{ADP}_{f}\right)$ and $\operatorname{AMP}\left(\mathrm{AMP}_{f}\right)$ were calculated using concentrations of reactants and equilibrium constants of the near equilibrium reactions catalyzed by creatine kinase and adenylate kinase as described previously (Dudley \& Terjung 1985, Dudley et al 1987). Free magnesium concentrations were assumed to be $1 \mathrm{mM}$ and not influenced by either treatment and in situ stimulation.

$$
\begin{aligned}
& {\left[\mathrm{ADP}_{1}\right]=\frac{[\mathrm{ATP}][\mathrm{Cr}]}{1.66 \times 10^{9}\left[\mathrm{H}^{*}\right][\mathrm{CrP}]}} \\
& {\left[\mathrm{AMP}_{\mathrm{N}}\right]=\frac{\left[\mathrm{ADP}_{1}\right]^{2}}{1.05[\mathrm{ATP}]}}
\end{aligned}
$$

Concentrations of hydrogen ions $\left[\mathrm{H}^{+}\right]$were obtained from the $\mathrm{pH}$, which was estimated from the relationship between $\mathrm{pH}$ and the sum of the concentrations of lactate and pyruvate (Dudley \& Terjung 1985, Sahlin et al 1975):

$$
\mathrm{pH}=7.06-0.226 \times[\text { lactate }] \times[\text { pyruvate }]
$$

All measurements were performed in duplicate. Values are given as mean (range). Statistical analysis was performed using the nonparametric Mann-Whitney $U$-test. Comparisons between non stimulated and stimulated muscle were made within all three experimental groups (zymosan, pair fed, and control). Zymosan values $(n=7)$ of non stimulated and stimulated muscle were compared with those of pair fed $(n=7)$ and ad libitum fed control $(n=6)$ rats. Significance was set at $p<0.05$. 


\section{Results}

Zymosan treated rats showed the same pattern of illness as described before (chapter 3 ) including an acute phase of critical illness for 2 days followed by a slow recovery. During the acute phase two of the zymosan treated rats died, which is comparable with the $16 \%$ normally found in our experiments. Both food intake (Fig. 1) and body weight (Fig. 2) show the same pattern of changes as observed before (chapter 3 ). Due to the zymosan challenge rats stopped eating for almost three days whereafter intake slowly increased to about $60 \%$ of control on day 6 (Fig. 1). Both zymosan and pair fed rats lost body weight during the first 3 days after which a slow increase is observed (Fig. 2). No catch up growth was present, however.

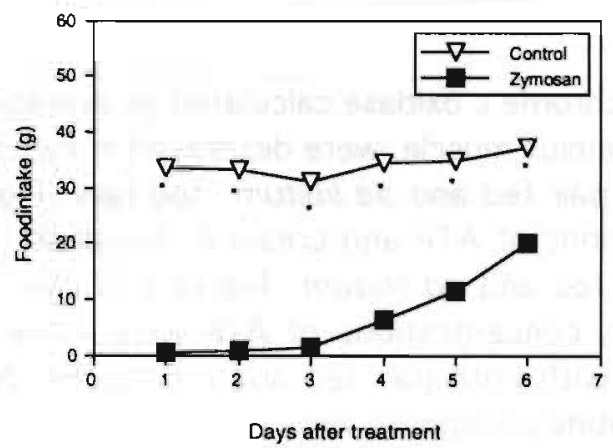

Figure 1. Food intake ( $\mathrm{g} /$ day) of control and zymosan treated rats. *: Significantly different from control at $p<0.05$.

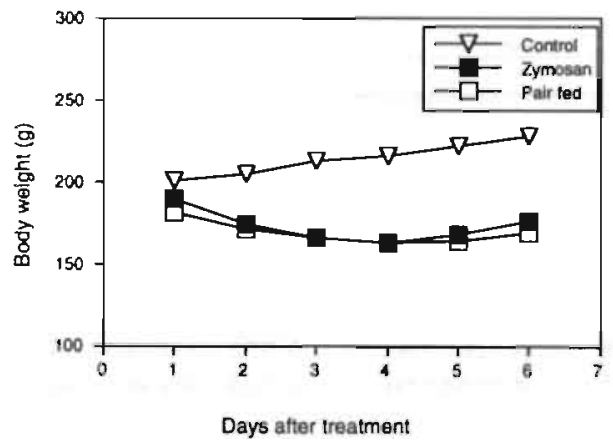

Figure 2. Body weight ( $\mathrm{g}$ ) of control, pair fed and zymosan treated rats. All values of zymosan treated and pair fed rats are significantly different from those of control rats, except on day 1 for zymosan treated rats. 


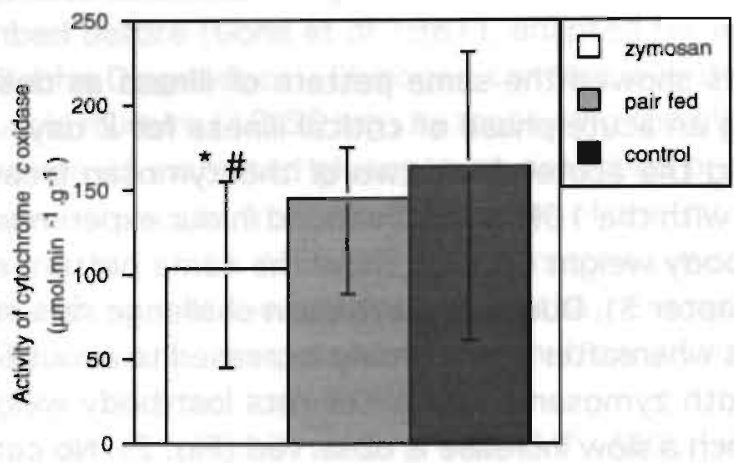

Figure 3. Activities of cytochrome $c$ oxidase $\left(\mu \mathrm{mol} \cdot \mathrm{min}^{-1} \cdot \mathrm{g}^{-1}\right)$ in gastrocnemius muscle of zymosan treated, pair fed and ad libitum fed rats are given as mean and range. *: Significantly different from control; \#: and from pair fed at $p<0.05$.

Activities of cytochrome $c$ oxidase calculated as average of stimulated and unstimulated gastrocnemius muscle, were decreased in zymosan treated rats in comparison with both pair fed and ad libitum fed rats (Fig. 3). After in situ stimulation concentrations of ATP and creatine phosphate were decreased in zymosan treated, pair fed and ad libitum fed rats (Table 1). In the zymosan treated rats, however, concentrations of ATP were lower at rest and after stimulation compared with both pair fed and ad libitum fed control groups. Concentrations of creatine phosphate were reduced at rest in zymosan treated rats. Concentrations of creatine were significantly increased in stimulated muscle

Table 1. Concentrations of ATP, ADP, AMP, creatine ( $\mathrm{Cr}$ ) and creatine phosphate $(\mathrm{Cr} P$ ) at rest and after in situ stimulation (stim) are given as mean (range). *: Significantly different from control; \#: and from pair fed. ๆ: Significantly different from gastrocnemius at rest.

\begin{tabular}{|c|c|c|c|c|c|c|c|}
\hline & & \multicolumn{2}{|c|}{ Zymosan } & \multicolumn{2}{|c|}{ Pair fed } & \multicolumn{2}{|c|}{ Control } \\
\hline \multirow[t]{2}{*}{ ATP $(\mu \mathrm{mol} / \mathrm{g})$} & rest & $6.69 \cdot$ & $(6.21 \cdot 7.11)$ & 8.09 & $(7.20-8.49)$ & 7.90 & $(7.80 \cdot 7.98)$ \\
\hline & stim & $4.57 \cdot \| \pi$ & $(1.94 .5 .81)$ & 6.28 & $\{(5.63 \cdot 7.04\}$ & 6.26 & $(5.00-7.01)$ \\
\hline \multirow[t]{2}{*}{ ADP $(\mu \mathrm{mol} / \mathrm{g})$} & rest & 0.937 & $(0.860 \cdot 1.036)$ & 0.989 & $(0.871-1.141)$ & 0.999 & $(0.947-1.061)$ \\
\hline & stim & $0.696 \cdot \pi$ & $(0.519-0.824)$ & 0.925 & $(0.834-1.020)$ & 1.025 & $(0.913-1.327)$ \\
\hline \multirow[t]{2}{*}{ AMP $(\mu \mathrm{mol} / \mathrm{g})$} & rest & 0.038 & $(0.023 \cdot 0.056)$ & 0.031 & $(0.023-0.043)$ & 0.039 & $(0.031-0.044)$ \\
\hline & stim & $0.045 *$ & $(0.017 \cdot 0.079)$ & 0.025 & $(0.020 \cdot 0.030)$ & 0.031 & $(0.026-0.044)$ \\
\hline \multirow[t]{2}{*}{$\mathrm{Gr} \quad(\mu \mathrm{mol} / \mathrm{g})$} & rest & 16.62 & $(12.60-21.79)$ & 17.25 & $(14.97-18.87)$ & 16.11 & $(13.96-19.33)$ \\
\hline & stim & 21.56 & $(15.99-29.28)$ & 22.86 & $(20.01-25.80)$ & 19.34 & if $(16.44-20.81)$ \\
\hline \multirow[t]{2}{*}{ CrP $(\mu \mathrm{mol} / \mathrm{g})$} & rest & 18.44 & $(15.37-19.92)$ & 21.95 & $(20.37 \cdot 23.50)$ & 21.17 & $(19.61-22.65)$ \\
\hline & stim & $7.74 \pi$ & $(1.87 \cdot 14.41)$ & 11.65 & $(8.87-14.31)$ & 11.57 & $(4.16-17.02)$ \\
\hline
\end{tabular}


Table 2. Concentrations of lactate (lact), pyruvate (pyr), glycogen (glyc) and the lactate/ pyruvate ratio at rest and after in situ stimulation (stim) are given as mean (range). Glycogen concentrations are give as $\mu \mathrm{mol}$ glucosyl units per $\mathrm{g}$ of muscle. *: Significantly different from control; \#: and from pair fed. ๆ: Significantly different from gastrocnemius at rest.

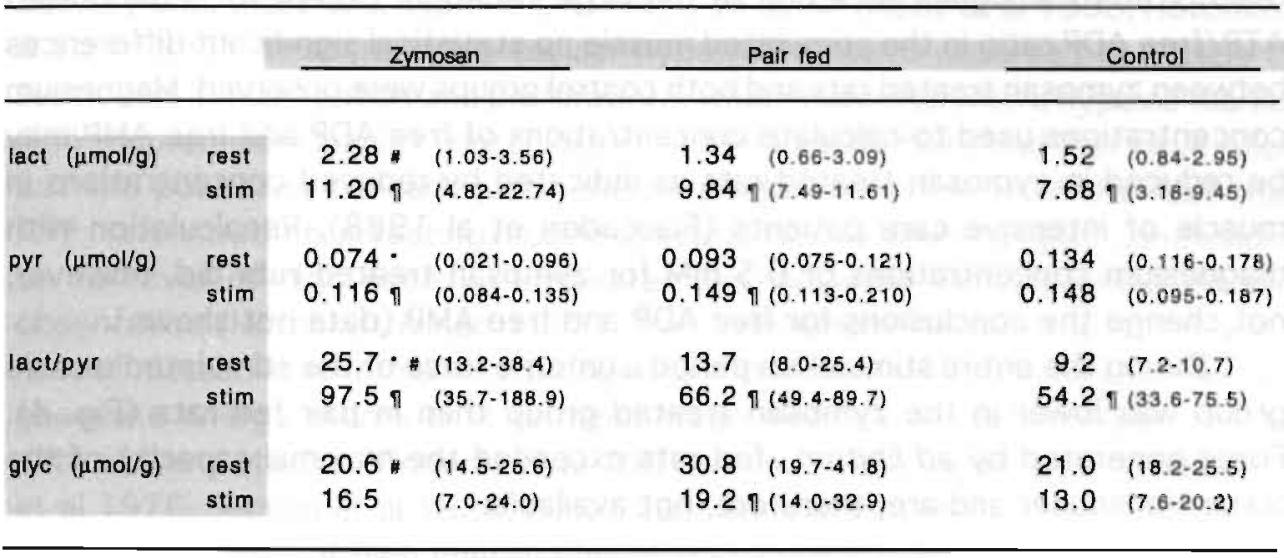

of pair fed and ad libitum fed rats (Table 1). ADP concentrations were decreased due to stimulation in zymosan treated rats only (Table 1 ).

Concentrations of lactate were increased following in situ stimulation (Table 2). At rest concentrations in zymosan treated rats were higher than in pair fed rats. Pyruvate concentrations were decreased in non stimulated muscle of zymosan treated rats in comparison with ad libitum fed rats (Table 2). After stimulation concentrations of pyruvate were increased in zymosan treated and pair fed rats. Lactate/pyruvate ratio was increased following in situ stimulation (Table 2). In non stimulated muscle this ratio was higher in zymosan treated rats. Glycogen content was decreased after stimulation in pair fed rats only (Table 2).

Table 3. Calculated concentrations of free ADP and AMP and the ATP/free ADP ratio at rest and after in situ stimulation (stim) are given as mean (range). *: Significantly different from control; \#: and from pair fed. ๆ: Significantly different from gastrocnemius at rest.

\begin{tabular}{|c|c|c|c|c|c|}
\hline & & & nosan & Pair fed & Control \\
\hline \multirow[t]{2}{*}{ free ADP (nmol/g) } & rest & 37.4 & $(28.8 \cdot 53.0)$ & $40.9 \quad(34.0-46.3)$ & $36.8 \quad(33.2 .43 .4\}$ \\
\hline & stim & 68.1 & $(34.3 \cdot 111.0)$ & $49.3 \pi(39.7-62.9)$ & $44.9 \cap\langle 39.5-50.0\rangle$ \\
\hline freo AMP (nmol/g) & $\begin{array}{l}\text { rest } \\
\text { stim }\end{array}$ & $\begin{array}{l}0.21 \\
1.59 ?\end{array}$ & $\begin{array}{l}(0.11 \cdot 0.40) \\
(0.20-4.85)\end{array}$ & $\begin{array}{l}0.20(0.16-0.25) \\
0.37 \uparrow(0.23-0.54)\end{array}$ & $\begin{array}{l}0.17(0.13-0.23) \\
0.30:(0.21-0.37)\end{array}$ \\
\hline ATPHree ADP & $\begin{array}{l}\text { rest } \\
\text { stim }\end{array}$ & $\begin{array}{l}188.9 \\
91.4 \cdot\end{array}$ & $\begin{array}{l}(125.8-247.4) \\
(19.5 \cdot 166.9)\end{array}$ & $\begin{array}{l}199.4 \quad(182.3 \cdot 224.3) \\
132.8 \uparrow(103 .+\cdot 163.4)\end{array}$ & $\begin{array}{l}217.1 \quad(1 \mathrm{~B} 0.7 \cdot 240.2) \\
146.3 \text { (129.6-177.6) }\end{array}$ \\
\hline
\end{tabular}


Concentrations of the putative metabolic modulators, free ADP and free AMP, and the ATP/free ADP ratio were increased after stimulation in all groups (Table 3 ). Only the increase in free ADP in the zymosan treated rats did not reach statistical significance due to the large variation. Except for a decreased ATP/free ADP ratio in the stimulated muscle no statistical significant differences between zymosan treated rats and both control groups were observed. Magnesium concentrations used to calculate concentrations of free ADP and free AMP may be reduced in zymosan treated rats as indicated by reduced concentrations in muscle of intensive care patients (Fiaccadori et al 1988). Recalculation with magnesium concentrations of $0.5 \mathrm{mM}$ for zymosan treated rats did, however, not change the conclusions for free ADP and free AMP (data not shown).

During the entire stimulation period isometric force of the stimulated muscle group was lower in the zymosan treated group than in pair fed rats (Fig. 4). Force generated by ad libitum fed rats exceeded the maximal capacity of the force transducer and are, therefore, not available.

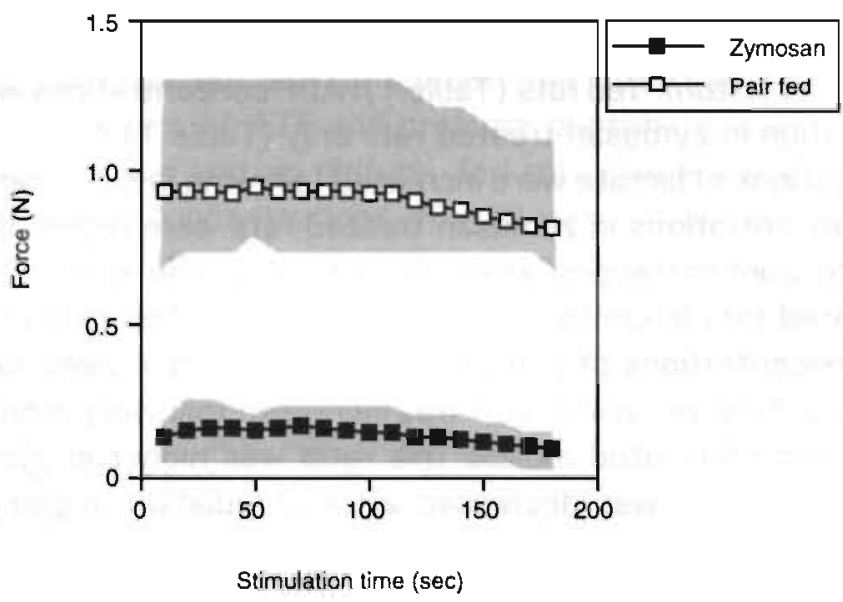

Figure 4. Force developed $(\mathrm{N})$ during in situ electrical stimulation, measured as isometric torque in zymosan treated and pair fed rats. Values are given as mean and range (grey areas). Force developed by the ad libitum fed rats exceeded maximal capacity of the force transducer and are, therefore, not available. All values of zymosan treated rats are significantly lower than those of pair fed rats.

\section{Discussion}

Several mechanisms have been postulated underlying critical illness related muscle weakness. Increased lactate concentrations in plasma of critically ill patients and animal models suggested that energy metabolism is impaired. This could either be caused by muscular hypoxia due to reduced microcirculatory blood flow, or by a derangement in energy producing pathways in the cell itself (Hotchkiss \& 
Karl 1992). In a recent review Hotchkiss and Karl have concluded that neither of these mechanisms are present in skeletal muscle during sepsıs (Hotchkiss $\&$ Karl 1992). No decrease in lactate concentrations was observed with increased oxygen delivery and, therefore, hypoxia is not likely to occur (Astiz et al 1988, Hotchkiss \& Karl 1992). In addition, no cellular hypoxia has been observed in muscle of septic rats (cecal ligation and perforation), when measured with a hypoxic marker ( $\left[{ }^{8} \mathrm{~F}\right]$ fluoromisonidazole) (Hotchkiss et al 1991). Hotchkiss and Karl have ruled out the possibility of inadequate energy production because of the fact that ATP concentrations in resting muscle of septic rats were unchanged. Conclusions on turnover of high energy phosphates can, however, not be based on this observation (Hotchkiss \& Karl 1992). They concluded that although there are a host of metabolic abnormalities during sepsis, the cell retains its ability to maintain adequate energy stores until terminal stage. This conclusion is supported by data of many studies (Angerås et al 1991, Ardawi 1988, Astiz et al 1988, Fürst et al 1976, Jepson et al 1987, Liaw 1985, Song et al 1992, Vary et al 1986).

Maintenance of high energy phosphates seems to be in contradiction with severe illness related derangement in muscle mitochondrial function (Schumer et al 1971, Tavakoli \& Mela 1982) and the decreased mitochondrial content in skeletal muscle of zymosan treated rats (chapter 4 and 6 ). Modest but significant changes in concentrations of high energy phosphates and tricarboxylic acid cycle intermediates have been observed in resting muscle of zymosan treated rats 2 days after the challenge when activities of cytochrome $c$ oxidase (mitochondrial marker enzyme) were reduced the most (chapter 4 and 5). Similarly in the present study, the zymosan challenge induced modest decreases in concentrations of ATP and creatine phosphate at rest (respectively 83 and $84 \%$ of pair fed control values) while activities of cytochrome $c$ oxidase were decreased to $72 \%$ of pair fed control values. A decreased mitochondrial content has been found to influence high energy phosphates mainly during an increased contractile activity induced by in situ electrical stimulation (Dudley et al 1987). In the zymosan treated rats concentrations of ATP were significantly lower after in situ electrical stimulation in comparison with both control groups. However, the decrease due to stimulation was not different from that in pair fed and ad libitum fed rats (data not shown). Except for a stimulation induced decrease in total ADP concentrations in zymosan treated rats, no differences in stimulation induced metabolite changes between the groups were observed. These findings are in contradiction with other studies which show no changes in ADP concentrations due to electrical stimulation (Dudley et al 1987, Muscaritoli et al 1992).

The comparable decreases in high energy phosphates between zymosan treated and control rats would not have been anticipated on basis of the study of Dudley and colleagues (Dudley et al 1987). In their study rats with a higher mitochondrial content in gastrocnemius muscle had smaller decreases in high energy phosphates during in situ stimulation in comparison with rats with medium and low mitochondrial contents. The decreased capacity to maintain high energy 
phosphates in the low mitochondrial content group resulted in an increased fatiguability of muscle, indicated by a more rapid loss of force. The force developed by the zymosan treated rats was in contrast to the rats with the low mitochondrial content from the study of Dudley and colleagues (1) already dramatically decreased at the start of the stimulation protocol, and (2) far more reduced in comparison with the control rats. Part of the reduced force developed by zymosan treated rats, may be the result of a loss of muscle mass characteristic for severe illness. Muscle weight in zymosan treated rats, however, was reduced to $78 \%$ of pair fed rats (chapter 3 ) indicating that only a minor part of the decrease in muscle force is caused by muscle wasting. These results, therefore, indicate that the zymosan treatment has led to an insensitivity of muscle for electrical stimulation.

The lower force development of skeletal muscle of zymosan treated rats in comparison with pair fed rats implies a lower rate of ATP consumption and consequently smaller decreases in ATP due to electrical stimulation were expected. However, comparable decreases were observed, indicating that the oxidative capacity of muscle of zymosan treated rats is so low that ATP levels fall more rapidly than in muscle of control rats at a given force level or work rate. Although, not the primary cause of muscle weakness in the zymosan treated rats, this mechanism may contribute to the increased fatiguability of muscle during critical illness of patients and may even become a significant problem later during recovery.

The insensitivity of skeletal muscle of the zymosan treated rats for stimulation most likely is the result of a derangement in the nervous system or in one or more steps of the excitation/contraction coupling mechanism. In the present study in situ stimulation was performed via the tibial nerve and, therefore, reduced muscle function in zymosan treated rats may be related to an impaired peripheral nerve excitability. A newly acquired polyneuropathy involving axonal degeneration has been reported to occur in $70 \%$ of patients with sepsis and multiple organ failure and seems to play a role in skeletal and respiratory muscle weakness (Chad \& Lacomis 1994, Witt et al 1991). Autopsy studies have indicated that damage to the peripheral nervous system is more severe than to the central nervous system (Bolton et al 1993). Also derangements in the excitation/ contraction coupling mechanism may be involved in the loss of muscle contractility. Decreased membrane potentials, due to changes in electrolyte distribution, have been reported in skeletal muscle during catabolic challenges (Cunningham et al 1971, Gibson et al 1977) and will lead to loss of contractility (Sjøgaard et al 1985). Another possibility is that disturbances in second messengers (CAMP, inositol triphosphate) lead to increased cytoplasmic calcium concentrations and subsequently impaired muscle contraction (Tomera 1991, Tomera \& Martyn 1990).

Several mechanisms seem to be involved in severe illness related muscle weakness. These include a decreased oxidative capacity and an insensitivity for 
electrical stimulation. The latter seems to be the primary cause of the loss of muscle force during the early recovery period in the zymosan treated rats. The first may be more important during the prolonged recovery phase from critical illness. Future research is needed to investigate whether muscle weakness of critically ill patients is caused by similar mechanisms.

\section{References}

- Angeràs U, Hall-Angerảs $M$, Wagner KR, James H, Hasselgren P-O and Fisher JE (1991). Tissue metabolite levels in different types of skeletal muscle during sepsis. Metabolism 40: $1147-$ 1151.

- Anonymous (1979). Postoperative fatigue. Lancet 1:84-85.

- Ardawi MSM (1988). Skeletal muscle glutamine production in thermally injured rats. Clin Sci 74: 165-172.

- Astiz M, Rackow EC, Weil MH and Schumer W (1988). Early impairment of oxidative metabolism and energy production in severe sepsis. Circ Shock 26: 311-320.

- Bolton CF, Young GB and Zochodne DW (1993). The neurological complications of sepsis. Ann Neurol 33: 94-100.

- Chad DA and Lacomis D (1994). Critically ill patients with newly acquired weakness: the clinicopathological spectrum. Ann Neurol 35: 257-259.

- Christensen T, Wulff C, Fuglsang-Frederikson A and Kehlet H (1985). Electrical activity and arm muscle force in postoperative fatigue. Acta Chir Scand 151: 1-5.

- Cunningham JN, Carter NW, Rector FC and Seldin DW (1971). Resting transmembrane potential difference of skeletal muscle in normal subjects and severely ill patients. J Clin Invest 50: 4959.

- Dudley GA and Terjung RL (1985). Influence of acidosis on AMP deaminase activity in contracting fast-twitch muscle. Am J Physiol 248: C34-C50.

- Dudley GA, Tullson PC and Terjung RL (1987). Influence of mitochondrial content on the sensitivity of respiratory control. J Biol Chem 262: 9109-9114.

- Fiaccadori E, Del Canale S, Coffrini E, Melej R, Vitali P, Guariglia A and Borghetti A (1988). Muscle and serum magnesium in pulmonary intensive care unit patients. Crit Care Med 16: 751-760.

- Fitts RH, Booth FW, Winder WW and Holloszy JO (1975). Skeletal muscle respiratory capacity, endurance, and glycogen utilization. Am J Physiol 228: 1029-1033.

- Fürst P, Bergström J, Hultman E and Vinnars E (1976). Intermediary energy metabolism for the catabolic state with special regard to muscle tissue. In: Metabolism and the response to injury (Wilkinson AW and Cuthbertson D, eds.). England, Tunbridge Wells: 94-112.

- Gibson WH, Cook JJ, Gatipon G and Moses ME (1977). Effect of endotoxin shock on skeletal muscle cell membrane potential. Surgery 81: 571-577.

- Gohil K, Jones DA and Edwards RHT (1981). Analysis of muscle mitochondrial function with techniques applicable to needle biopsy samples. Clin Physiol 1: 195-207.

- Harris RC, Hultman E and Nordesjö LO (1974). Glycogen, glycolytic intermediates and high energy phosphates determined in biopsy samples of musculus quadriceps femoris of man at rest. Methods and variance of values. Scand J Clin Lab Invest 33: 109-120.

- Hoppeler H, Lüthi P, Claassen H, Weibel ER and Howald H (1973). The ultrastructure of the normal human skeletal muscle. A morphometric analysis on untrained men, women and welltrained orienteers. Pflügers Archiv 344: $217-232$.

- Hotchkiss RS, Rust RS, Dence CS, Wasserman TH, Song SK, Hwang DR, Karl IE and Welch MJ (1991). Evaluation of the role of cellular hypoxia in sepsis by the hypoxic marker $\left[{ }^{18} \mathrm{~F}\right]$ fluoromisonidazole. Am J Physiol 261: R965-R972. 
- Hotchkiss RS and Karl IE (1992). Reevaluation of the role of cellular hypoxia and bioenergetic failure in sepsis. JAMA 267: 1503-1510.

- Jepson MM, Cox M, Bates PC, Rothwell NJ, Stock MJ, Cady EB and Millward DJ (1987). Regional blood flow and skeletal muscle energy status in endotoxemic rats. Am J Physiol 252: E581E587.

- Liaw KY (1985). Effect of injury, sepsis, and parenteral nutrition on high-energy phosphates in human liver and muscle. JPEN 9: 28-33.

- Muscaritoli M, Whitlock D and Meguid MM (1992). Muscle performance and adenine-nucleotides status in MCA-sarcoma tumor-bearing rats. Physiol Behav 52: 803-807.

- Newsholme EA and Start C (1973). Regulation in metabolism. New York, John Wiley \& Sons.

- Sahlin K, Harris RC and Hultman E (1975). Creatine kinase equilibrium and lactate content compared with muscle $\mathrm{pH}$ in tissue samples obtained after isometric exercise. Biochem $\mathrm{J} 152$ : 173-180.

- Schumer W, Erve PR and Obernolte RP (1971). Endotoxemic effect on cardiac and skeletal muscle mitochondria. Surg Gynecol and Obstetrics 133: 433-436.

- Sjøgaard G, Adams RP and Saltin B (1985). Water and ion shifts in skeletal muscle of humans with intense dynamic knee extension. Am J Physiol 248: R190-R196.

- Song SK, Hotchkiss RS, Karl IE and Ackerman JJH (1992). Concurrent quantification of tissue metabolism and blood flow via ${ }^{3} \mathrm{H} /{ }^{3} \mathrm{P}$ NMR in vivo. III. Alterations of muscle blood flow and metabolism during sepsis. Magn Res Med 25: 67-77.

- Tavakoli $H$ and Mela L (1982). Alterations of mitochondrial metabolism and protein concentrations in subacute septicemia. Infect Immun 38: 536-541.

- Tomera JF and Martyn J (1990). Effects of endotoxin infection on cyclic nucleotides in ventricular and gastrocnemius muscle. Circulatory Shock 32: 281-292.

- Tomera JF (1991). The effect of burn trauma on adenosine 3':5'cyclic monophosphate, inositol triphosphate, and contraction in mouse gastrocnemius muscle. J Burn Care Rehabil 12: 485497.

- Vary TC, Siegel JH, Nakatani T, Sato T and Aoyama H (1986). Effect of sepsis on activity of pyruvate dehydrogenase complex in skeletal muscle and liver. Am J Physiol 250: E634-E640.

- Witt NJ, Zochodne DW, Bolton CF, Grand'Maison F, Wells G, Young B and Sibbald WJ (1991). Peripheral nerve function in sepsis and multiple organ failure. Chest 99: 176-184.

- Zeiderman MR, Welchew EA and Clark RG (1990). Changes in cardiorespiratory and muscle function associated with development of postoperative fatigue. $\mathrm{Br} J$ Surg 77: 576-580. 


\section{Effect of an enterally administered glutamine rich protein on the catabolic response to a zymosan challenge in rats.}

Olav E. Rooyackers, Peter B. Soeters*, Wim H.M. Saris and Anton J.M. Wagenmakers. Departments of Human Biology and *Surgery, University of Limburg, Maastricht, The Netherlands.

Submitted for publication

\section{Abstract}

1. Glutamine is considered to be a conditionally essential amino acid during critical illness and has, therefore, been advocated to be included in nutrition supplied in these situations. In the present studies we investigated whether a diet with a protein source rich in glutamine can restore depleted glutamine pools (plasma and muscle) and counteract the wasting of muscle in a rat model of critical illness. Intraperitoneal injection of zymosan was used to induce an acute phase of critical illness ( 2 days) followed by prolonged recovery.

2. A glutamine rich protein source was obtained by mixing a wheat protein hydrolysate (25\% glutamine) with a whey protein isolate (to prevent essential amino acid deficiency). The effect of an adequate diet containing this mixture was studied in healthy control rats, in rats fed the diet before a zymosan challenge and in rats fed the diet 12 days following zymosan treatment.

3. Feeding healthy control rats for two weeks with the glutamine rich diet increased the two main glutamine pools (plasma and muscle). However, no effect was observed on the following zymosan induced changes: (1) decreased glutamine and arginine concentrations (plasma and muscle), (2) wasting of muscle protein and (3) decreased mitochondrial content in skeletal muscle.

4. We conclude that enterally supplemented glutamine as a diet with a glutamine rich protein source can be used to increase the glutamine plasma and muscle pools in healthy rats. No effect, however was observed on the depleted glutamine stores and wasting of skeletal muscle in zymosan treated rats. 


\section{Introduction}

Glutamine has many regulatory functions in intermediary metabolism. It is a carrier of nitrogen between cells, and both a preferred respiratory fuel and a precursor for nucleic acids and nucleotides for rapidly proliferating cells, e.g. lymphocytes and enterocytes (Bulus et al 1989). Skeletal muscle is the main source of glutamine production and also contains the largest intracellular glutamine pool. During disease and especially critical illness this muscle glutamine content decreases. Petersson and colleagues (Petersson et al 1992) observed decreased glutamine concentration in muscle up to 30 days following elective surgery. Wasting of muscle mass which is an other characteristic feature of severe illness, may additionally decrease the capacity of skeletal muscle to produce sufficient glutamine. Due to its key metabolic functions and the decreased content in muscle, glutamine is considered to be conditionally essential (Lacey \& Wilmore 1990). Supplying patients with extra glutamine, therefore, seems a desirable strategy.

Critically ill patients often receive total parenteral nutrition (TPN). Normally no glutamine is present in the TPN because of its instability in solutions. Also the limited solubility of glutamine makes it difficult to supply enough glutamine as free amino acid. Therefore, alternative products such as glutamine containing dipeptides have extensively been investigated (Adibi 1989, Fürst et al 1990, Roth et al 1988, Stehle et al 1989, Tamada et al 1992, Vinnars et al 1990). Due to the high costs of these dipeptides usage in the clinic will be limited. We, therefore, investigated the effect of an adequate diet containing a hydrolysate of wheat protein, which is rich in glutamine, on the course of illness (measured as daily food intake and weight gain) and the wasting of skeletal muscle in a rat model of critical illness.

Wheat protein contains more glutamine than any other protein. Gene sequencing indicated that approximately $35 \%$ of the amino acid residues are glutamine (Lacey \& Wilmore 1990). To obtain a soluble tasteful protein source rich in glutamine a wheat protein hydrolysate was used. This hydrolysate was mixed with whey protein to prevent essential amino acid deficiency. A first experiment was designed to elucidate whether healthy control rats would eat the diet and whether concentrations of glutamine in plasma and muscle could be enhanced. In two additional experiments the diet was tested for its potential to modify the catabolic response to a zymosan challenge in rats. Previously we have shown that a single intraperitoneal injection of zymosan suspended in liquid paraffin induced a two day phase of critical illness with severe muscle wasting followed by a prolonged recovery phase for at least 10 days (chapter 3 ). Concentrations of glutamine were decreased in this rat model in muscle up to day 6 and in plasma on day 6 and 12 after treatment.

In these latter two experiments the ability of the glutamine rich diet to restore the zymosan-induced depleted glutamine stores and to reduce the severity 
of illness and the wasting of muscle protein was studied. A positive relationship. between muscle glutamine concentrations and muscle protein synthesis rates as; previously reported (Millward et al 1989, MacLennan et al 1987) has frequently been used to underline the potential of glutamine interventions to counteract muscle wasting during severe illness. In addition to the muscle protein wasting we recently reported a wasting of mitochondrial protein in skeletal muscle which appears to be even more dramatic (chapter 6) and, therefore also a marker of mitochondrial content (activity of the mitochondrial enzyme cytochrome $c$ oxidase) was measured.

\section{Methods}

\section{Animals}

Male Lewis rats of approximately $200 \mathrm{~g}$ were obtained from the central animal facilities of the University of Limburg. They were individually housed and kept in a controlled environment ( 12 hour light cycle, $21-22^{\circ} \mathrm{C}$ and $50-60 \%$ humidity). Rats were allowed to acclimatize for one week. The experiments were approved by the animal experimental committee of the University of Limburg.

The zymosan treated rats were intraperitoneally injected with $50 \mathrm{mg}$ of zymosan (Sigma) suspended in $2 \mathrm{ml}$ of liquid paraffin (Merck) per $100 \mathrm{~g}$ body weight (chapter 3 ).

\section{Wheat protein hydrolysate}

A glutamine rich peptide mixture (DMV International, Veghel, The Netherlands) was essentially obtained by hydrolyzing wheat protein with a mixture of endopeptidases followed by filtration technology to remove the fat fraction in the raw material. After concentration, the material was spray-dried. The use of specific endopeptidases ensures low free amino acid amounts in the end product. A powder with the following features was obtained:

$\begin{array}{ll}\text { Moisture } & <5 \% \\ \text { Nitrogen (Kjeldahl) } & 13.6 \% \\ \text { Fat } & <0.1 \% \\ \text { Free amino acids } & <3 \% \\ \text { Free glutamine } & <0.2 \% \\ \text { Peptide-bound glutamine } & 25 \% .\end{array}$

Peptide-bound glutamine was measured indirectly through estimation of amide residues, essentially according to Wilcox (Wilcox 1976). In short, amide residues of glutamine and asparagine were converted to ammonia during a mild hydrolysis $\left(110^{\circ} \mathrm{C}, 3\right.$ hours, $2 \mathrm{M} \mathrm{HCl}$ ). Ammonia was enzymatically analyzed (Boehringer test kit 54946). Since the amount of aspartic acid obtained after total acid 
hydrolysis was only $2 \%$, the release of ammonia is mainly dependent on the glutamine content in the peptide mixture. The Wilcox method was validated, showing that ammonia release reached a plateau after $3 \mathrm{~h}$ of hydrolysis which did not change thereafter up to $24 \mathrm{~h}$.

The amino acid composition of the peptide preparation was obtained using total acid hydrolysis $\left(110^{\circ} \mathrm{C}, 24\right.$ hours, $\left.6 \mathrm{M} \mathrm{HCl}\right)$ and subsequent separation and quantification by ion exchange chromatography. Cystein and tryptophan were analyzed independently by performic acid oxidation and alkaline hydrolysis respectively.

The peptide mixture was analyzed by HPLC gel permeation chromatography by using a Pharmacia Superose HR 10/30 column with $100 \mathrm{mM}$ Tris $(\mathrm{pH}=8), 6 \mathrm{M}$ urea as eluent and UV detection of the peptide bond at $220 \mathrm{~nm}$. The following size distribution was obtained:

$\begin{array}{ll}>20 \mathrm{kD} \text { (kilodalton) } & 0 \% \\ >10 \mathrm{kD} & 1.7 \% \\ 10-5 \mathrm{kD} & 13.7 \% \\ 5-3 \mathrm{kD} & 23.9 \% \\ 3-2 \mathrm{kD} & 19.9 \% \\ 2-1 \mathrm{kD} & 27.0 \% \\ <1 \mathrm{kD} & 13.8 \% .\end{array}$

Diets

The wheat protein hydrolysate was mixed with a bovine whey protein isolate (DMV-International) to prevent essential amino acid deficiency. The isolate contained $13.5 \%$ of nitrogen; the protein consisted of approximately $85 \%$ Blactoglobulin and $15 \% \alpha$-lactoglobulin. A mixture of $80 \%$ wheat protein hydrolysate and $20 \%$ whey protein hydrolysate was prepared to fulfill the amino acid requirements for rats (NRC Nutrient Requirements of Laboratory Animals, 1978). This protein source was mixed with other non protein constituents to obtain a diet comparable to the control diet (SRM-A, Hope Farms, The Netherlands) normally fed to the rats (Table 1). The rats had free access to food and water.

\section{Experiment 1}

In the first experiment non treated rats were fed with either the control diet $(n=6)$ or the glutamine rich diet $(n=6)$ for 2 weeks. Food intake and body weight were determined daily. On the day of sacrifice food was removed from the rats at 8.00 am Between 12.00 am and $2.00 \mathrm{pm}$ rats were killed by cervical dislocation and mixed blood was sampled after decapitation. Gastrocnemius muscle was rapidly removed, freeze clamped using a precooled pair of tongs and stored at $80^{\circ} \mathrm{C}$ until analysis. Collected blood was centrifuged and plasma stored until analysis at $-80^{\circ} \mathrm{C}$. Concentrations of glutamate and glutamine in plasma and muscle were measured. 
control diet

\begin{tabular}{|c|c|c|}
\hline protein & 252 & 252 \\
\hline fat & 65 & 65 \\
\hline fibers & 32 & 31 \\
\hline minerals & 60 & 43 \\
\hline moisture & 114 & 109 \\
\hline carbohydrates & 480 & 469 \\
\hline \multicolumn{3}{|l|}{ amino acids } \\
\hline He & 9.5 & 9.5 \\
\hline Leu & 17.3 & 18.0 \\
\hline Val & 12.5 & 10.7 \\
\hline BCAA & 39.4 & 38.2 \\
\hline Lys & 13.7 & 6.9 \\
\hline Met & 5.6 & 3.7 \\
\hline Cys & 3.4 & 4.4 \\
\hline Phe & 9.6 & 12.0 \\
\hline Tyr & 7.1 & 7.1 \\
\hline Thr & 9.0 & 7.7 \\
\hline Trp & 2.4 & 2.1 \\
\hline QAA & 90.2 & 82.0 \\
\hline Glu+GIn & 40.1 & 81.3 \\
\hline Glu & $20.1^{*}$ & 30.9 \\
\hline Gin & $20.1^{*}$ & 50.5 \\
\hline Asp+Asn & 19.2 & 10.9 \\
\hline Arg & 14.5 & 7.9 \\
\hline Ala & 15.7 & 7.8 \\
\hline Gly & 20.8 & 7.0 \\
\hline Pro & 17.1 & 27.6 \\
\hline Ser & 10.9 & 12.6 \\
\hline His & 5.4 & 4.4 \\
\hline total & 233.9 & 241.6 \\
\hline $\mathrm{Na}$ & 4.5 & 5.6 \\
\hline K & 7.3 & 7.4 \\
\hline $\mathrm{a}$ & 9.8 & 9.8 \\
\hline $\mathrm{Mg}$ & 1.4 & 1.5 \\
\hline$P$ & 9.8 & 7.2 \\
\hline $\mathrm{Cl}$ & 8.1 & 9.6 \\
\hline
\end{tabular}

Table 1. Composition of the control diet and the glutamine rich diet ( $\mathrm{g} / \mathrm{kg}$ food). Data on the composition of the control diet (SRM-A, Hope Farms, The Netherlands) were obtained from the supplier. *:No information about the separate Glu and GIn content was available but because mainly (70\%) animal proteins were used in this diet the Gln content was estimated to be half of the sum of Glu and GIn. The composition of the glutamine rich diet was calculated from information on the protein free diet from Hope Farms and information on the amino acid composition of the protein source. The protein source contained $80 \%$ of a wheat protein hydrolysate and $20 \%$ of a whey protein isolate. Amino acid compositions were measured by DMV International (wheat protein hydrolysate) and obtained from the composition of individual milk proteins (whey protein isolate) as given by Walstra and Jennes (Walstra et al., 1984). eAA: essential amino acids. BCAA: branched chain amino acids.

\section{Experiment 2}

In this experiment rats were fed either the control diet $(n=22)$ or the glutamine rich diet $(n=22)$ for two weeks. After two weeks 6 rats out of each group were sacrificed to verify results of the first experiment. The other rats were injected with zymosan suspended in liquid paraffin, after which they had free access to the same diet as before the injection. Two and 6 days after the challenge, rats of both diet groups were sacrificed. On the day of sacrifice, food was removed from the rats at 8.00 am Between 12.00 am and $2.00 \mathrm{pm}$ rats were killed by cervical dislocation and mixed blood was sampled after decapitation. Gastrocnemius muscle and liver were rapidly removed, weighed, and muscle was 
freeze clamped using a precooled pair of tongs and subsequently stored at $-80^{\circ} \mathrm{C}$ until analysis. Collected blood was centrifuged and plasma stored at $-80^{\circ} \mathrm{C}$ until analysis. Concentrations of glutamate, glutamine and arginine in plasma and muscle, muscle protein and muscle activities of the mitochondrial marker enzyme cytochrome $c$ oxidase were determined.

\section{Experiment 3}

In this last experiment the effect of the glutamine rich diet is tested during recovery from zymosan induced critical illness. After one week of acclimatization 12 rats were injected with zymosan. Half of the rats had free access to the control diet and the other half to the glutamine rich diet. Also a control group with non treated rats and access to the control diet was included in this study $(n=6)$. On the day of sacrifice (12 days after treatment), food was removed from the rats at 8.00 am Between 12.00 am and $2.00 \mathrm{pm}$ rats were killed by cervical dislocation and mixed blood was sampled after decapitation. Gastrocnemius muscle, liver and blood were processed as in experiment 2 . Concentrations of glutamate, glutamine and arginine in plasma and muscle, muscle protein and muscle activities of the mitochondrial marker enzyme cytochrome $c$ oxidase were determined.

\section{Analysis}

Protein of plasma and gastrocnemius muscle was precipitated using perchloric acid. The supernatant was neutralized with potassium bicarbonate and used to determine glutamate, glutamine and arginine. These amino acids were measured using previously described enzymatic methods (Gäde 1990, Lund 1990) modified for a centrifugal analyzer (COBAS-BIO, Roche Diagnostica). The protein pellet of the gastrocnemius muscle was used to determine the protein concentration of muscle as described before (Lowry et al 1951).

To obtain information concerning the mitochondrial content of the gastrocnemius muscle, maximal activities of the mitochondrial enzyme cytochrome $c$ oxidase were measured. A part of the gastrocnemius muscle (about $50 \mathrm{mg}$ ) was used to make a $5 \%$ homogenate using ice cold SET-buffer $(0.25 \mathrm{M}$ sucrose, $2 \mathrm{mM}$ EDTA and $10 \mathrm{mM}$ Tris/HCl; $\mathrm{pH}=7.4$ ) and a Teflon-glass Potter-Elvehjem homogenizer. Activity of cytochrome $c$ oxidase was measured using a modification of a previous described method (Gohil et al 1981) for a centrifugal analyzer (COBAS-BIO, Roche Diagnostica).

\section{Statistics}

All measurements were done in duplicate. Values are given as mean (range). The Mann-Whitney U-test was used to determine statistical differences between groups. Significance was set at $p<0.05$. 


\section{Results}

Experiment 7 (effect of glutamine rich diet on glutamine pools in healthy control rats)

Rats tolerated the diet containing the glutamine rich peptide mixture well. No significant difference in mean food intake was observed between the two diet groups $(22.6 \mathrm{~g} /$ day for the control versus $21.3 \mathrm{~g} /$ day for the glutamine rich diet) although a lower intake of the glutamine rich diet was observed on days 11,12 and 13 (Fig. 1). No differences in body weight were observed between the two groups except for the last day of the experiment (Fig. 2).

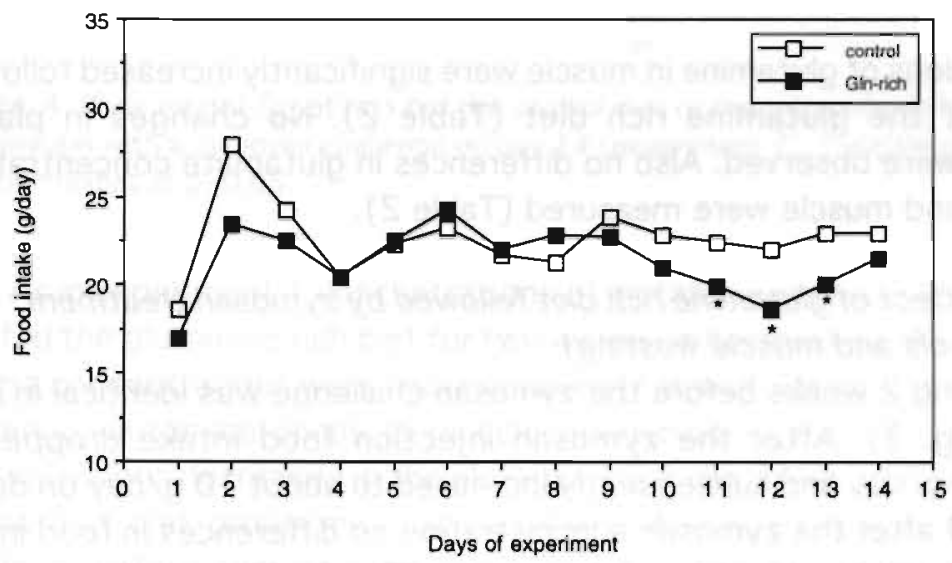

Figure 1. Food intake ( $\mathrm{g} /$ day) of rats fed the control diet or the glutamine rich diet for 2 weeks (experiment 1). *: Significantly different from the control diet at $p<0.05$.

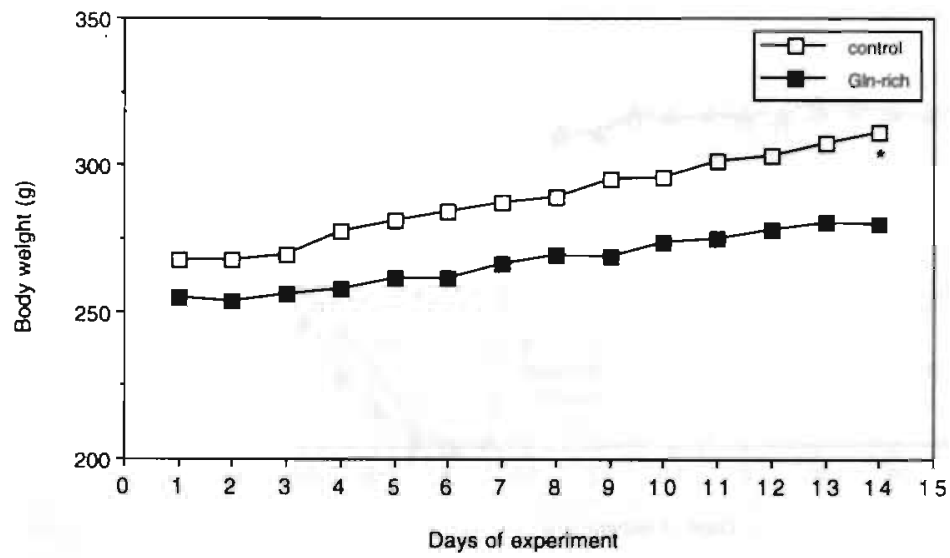

Figure 2. Body weight $(\mathrm{g})$ of rats fed the control diet or the glutamine rich diet for 2 weeks (experiment 1). *: Significantly different from the control diet at $p<0.05$. 
Table 2. Gastrocnemius and plasma concentrations of Glu and Gln measured 2 weeks after feeding the rats a control diet or a glutamine rich diet (experiment 1). Values are given as mean (range) of 6 rats. *: Significantly different from the control diet group.

\begin{tabular}{|c|c|c|c|c|c|c|c|}
\hline & \multicolumn{3}{|c|}{ muscle } & \multicolumn{4}{|c|}{ plasma } \\
\hline & & $\begin{array}{l}\mu \mathrm{mol} / \mathrm{g} \\
\text { veight) }\end{array}$ & $\begin{array}{l}\text { Gln ( } \mu \mathrm{mol} / \mathrm{g} \\
\text { wet weight) }\end{array}$ & 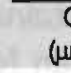 & (1) & $(\mu$ & noli) \\
\hline control & 2.6 & $(2.0-2.9)$ & $2.8 \quad(2.4-3.4)$ & 141 & $(104-205)$ & 727 & $(631-887)$ \\
\hline Gin-rich & 2.4 & $(2.0-2.9)$ & $3.2^{*}(2.5-3.8)$ & 128 & $(99-153)$ & 818 & (704-933) \\
\hline
\end{tabular}

Concentrations of glutamine in muscle were significantly increased following consumption of the glutamine rich diet (Table 2). No changes in plasma concentrations were observed. Also no differences in glutamate concentrations in both plasma and muscle were measured (Table 2).

Experiment 2 (effect of glutamine rich diet followed by zymosan treatment on glutamine pools and muscle wasting)

Food intake during 2 weeks before the zymosan challenge was identical in both diet groups (Fig. 3). After the zymosan injection food intake dropped to approximately $0 \mathrm{~g} /$ day and subsequently increased to about $10 \mathrm{~g} /$ day on day 6 . Except for day 4 after the zymosan administration no differences in food intake were observed between the two diets groups (Fig. 3). Due to the zymosan injection rats lost body weight but no differences were observed between the diet groups (Fig. 4).

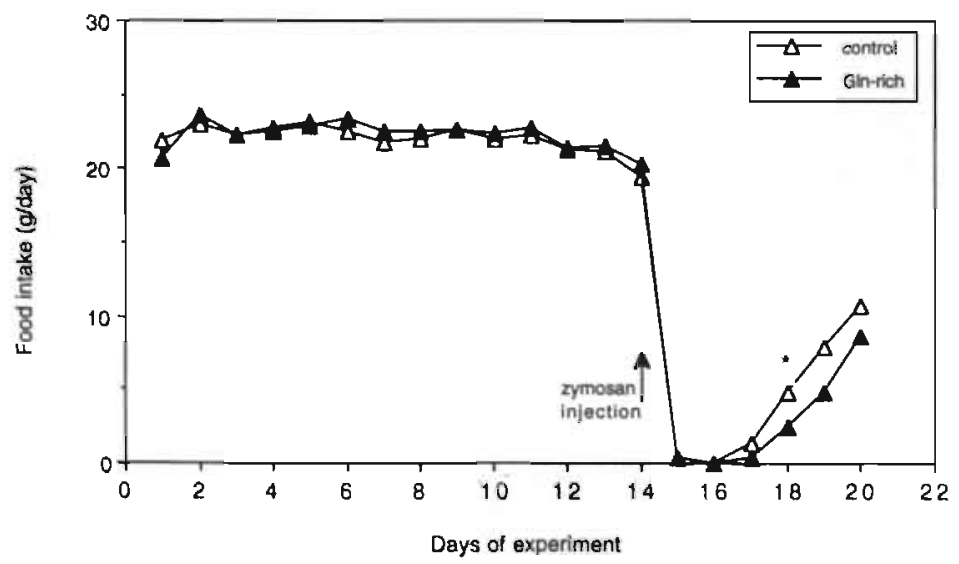

Figure 3. Food intake $(\mathrm{g} /$ day) of rats fed the control diet or the glutamine rich diet for 20 days in combination with a zymosan challenge on day 14 (experiment 2). *: Significantly different from the control diet at $p<0.05$. 


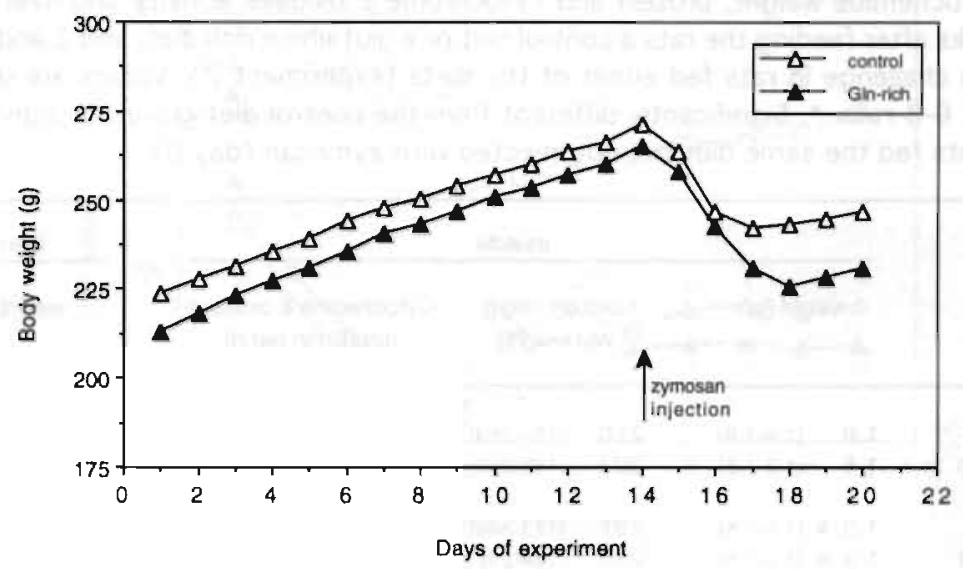

Figure 4. Body weight $(\mathrm{g})$ of rats fed the control diet or the glutamine rich diet for 20 days in combination with a zymosan challenge on day 14 (experiment 2). *: Significantly different from the control diet at $p<0.05$.

As in experiment 1 concentrations of glutamine were increased in muscle of rats fed the glutamine rich diet for two weeks. In contrast to the first experiment plasma concentrations were also increased (Table 3, day 0 ). Due to the zymosan challenge glutamine levels in muscle decreased in both diet groups. Plasma concentrations decreased in the glutamine rich diet group to the same level as in the control diet group measured 2 and 6 days after the zymosan challenge (Table 3 ). In both muscle and plasma concentrations of arginine were reduced 2 and 6 days after zymosan injection (Table 3). Concentrations of arginine were decreased in muscle two weeks after the glutamine rich diet and 6 days after the zymosan challenge in the glutamine rich diet group in comparison with the control diet group.

Table 3. Gastrocnemius and plasma concentrations of Glu, Gln and Arg measured 2 weeks after feeding the rats a control diet or a glutamine rich diet, and 2 and 6 days after a zymosan challenge in rats fed either of the diets (experiment 2). Values are given as mean (range) of 68 rats. *: Significantly different from the control diet group; \#: significantly different from rats fed the same diet but not injected with zymosan (day 0 ).

\begin{tabular}{|c|c|c|c|c|c|c|c|c|c|c|c|}
\hline & \multirow[b]{2}{*}{ diat } & \multicolumn{4}{|c|}{ muscle } & \multicolumn{6}{|c|}{ plasma } \\
\hline & & \multicolumn{2}{|c|}{$\begin{array}{l}\text { Glu (umol'g } \\
\text { wat waight) }\end{array}$} & $\begin{array}{l}\text { Gin (umovg } \\
\text { wet woight) }\end{array}$ & $\begin{array}{l}\text { Arg fumoilg } \\
\text { wet woight }\end{array}$ & \multicolumn{2}{|c|}{$\begin{array}{c}\text { Cu } \\
\text { Gurnol) }\end{array}$} & \multicolumn{2}{|c|}{$\underset{\text { (umoli) }}{\text { Gin }}$} & \multicolumn{2}{|c|}{$\begin{array}{c}\text { Arg } \\
\text { (umoli) }\end{array}$} \\
\hline \multirow[t]{2}{*}{ Day 0} & control & 2.2 & $(2.1-2.3)$ & $3.3 \quad(3.1-3.6)$ & $0.35 \quad(0.25-0.38)$ & 135 & $(115-156)$ & 639 & $(604-715)$ & 223 & (158-254) \\
\hline & Gin-rich & 2.3 & $(2,1-2.4)$ & $4.1 \cdot(3.5-4.7)$ & $0.28 \cdot(0.22-0.35)$ & 136 & $(112-155)$ & $776^{\circ}$ & $(747-818)$ & 212 & (149-251) \\
\hline \multirow[t]{2}{*}{ Day 2} & control & 2.3 & $(2.0-2.7)$ & $2.0 \div(1.7-2.5)$ & $0.11 *(0.07-0.16)$ & 107 & $(84-130)$ & 586 & $(526-652)$ & 142 & $(92 \cdot 175)$ \\
\hline & Gin-rich & 2.3 & $(1,8-3,3)$ & $2.0 \cdot(1.6-2.3)$ & $0.14 \cdot(0.13-0.16)$ & 96 & - $(82-103)$ & 615 & $(522-763)$ & $157 \%$ & (129-218) \\
\hline \multirow[t]{2}{*}{ Day 6} & control & 2.1 & $(1.8-2.5)$ & $2.8 \quad(2.3-3.5)$ & $0.18 \cdot(0.14-0.23)$ & 143 & $(137 \cdot 156)$ & 620 & (538-708) & $138 \varepsilon$ & $(121-175)$ \\
\hline & Gin-rich & 2.0 & $(1.4 \cdot 2.5)$ & $2.9=(1.9-3.7)$ & $0.11 \cdot(0.00-0.12)$ & 134 & $(112 \cdot 178)$ & 700 & (554-844) & $116 \%$ & $(93-141)$ \\
\hline
\end{tabular}


Table 4. Gastrocnemius weight, protein and cytochrome $c$ oxidase activity and liver weight measured 2 weeks after feeding the rats a control diet or a glutamine rich diet, and 2 and 6 days after a zymosan challenge in rats fed either of the diets (experiment 2). Values are given as mean (range) of 6-8 rats. *: Significantly different from the control diet group; \#: significantly different from rats fed the same diet but not injected with zymosan (day 0 ).

\begin{tabular}{|c|c|c|c|c|c|c|c|}
\hline & \multirow[b]{2}{*}{ diet } & \multicolumn{4}{|c|}{ muscle } & \multicolumn{2}{|c|}{ liver } \\
\hline & & weight (g) & \multicolumn{2}{|c|}{$\begin{array}{l}\text { protein (mg/g } \\
\text { wet weight) }\end{array}$} & $\begin{array}{l}\text { Cytochrome c oxidase } \\
\text { ( } \mu \text { mol/min per g) }\end{array}$ & \multicolumn{2}{|c|}{ weight (g) } \\
\hline \multirow[t]{2}{*}{ Day 0} & control & $(1.4-1.8)$ & 220 & (151-269) & (94-161) & 11.4 & $(10.3-13.3)$ \\
\hline & Gln-rich & $1.6 \quad(1.3-1.8)$ & 223 & (188-250) & (85-173) & 11.5 & (10.3-12.6) \\
\hline \multirow[t]{2}{*}{ Day 2} & control & $1.3 \#(1.1-1.5)$ & 237 & $(173-304)$ & $70 \#(55-91)$ & 9.9 & $(7.9-10.7)$ \\
\hline & Gin-rich & $1.3 \#(1.2-1.5)$ & 236 & (189-292) & $91 \quad(55-120)$ & 10.4 & $(8.5-12.7)$ \\
\hline \multirow[t]{2}{*}{ Day 6} & control & $1.1 \#(1.0-1.3)$ & 213 & $(182-242)$ & $89 \#(54-130)$ & 11.9 & $(9.9-13.9)$ \\
\hline & Gln-rich & $1.0 \#(0.8-1.3)$ & 225 & (185-255) & $85 \#(65-116)$ & 11.6 & (9.3-15.1) \\
\hline
\end{tabular}

Both muscle weight and activity of cytochrome $c$ oxidase were decreased 2 and 6 days after the zymosan challenge, but no differences between the two diet groups were observed (Table 4 ). Also muscle protein concentrations and liver weight showed no differences between the diet groups (Table 4). Liver weights were measured because of the characteristic increase seen during severe illness. This increase is not observed here because zymosan treated rats are not compared with pair fed controls which normally show a dramatic decrease in liver weight (chapter 3 ).

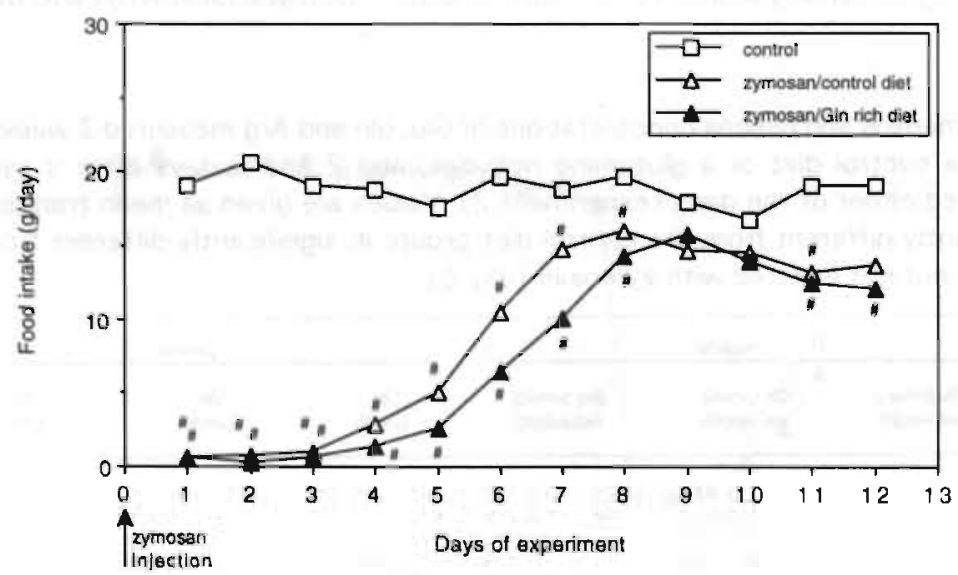

Figure 5. Food intake ( $\mathrm{g} /$ day) of rats fed the control diet or the glutamine rich diet for 12 days following a zymosan challenge and of nontreated rats fed the control diet (experiment 3 ). \#: Significantly different from the control rats at $p<0.05$. 


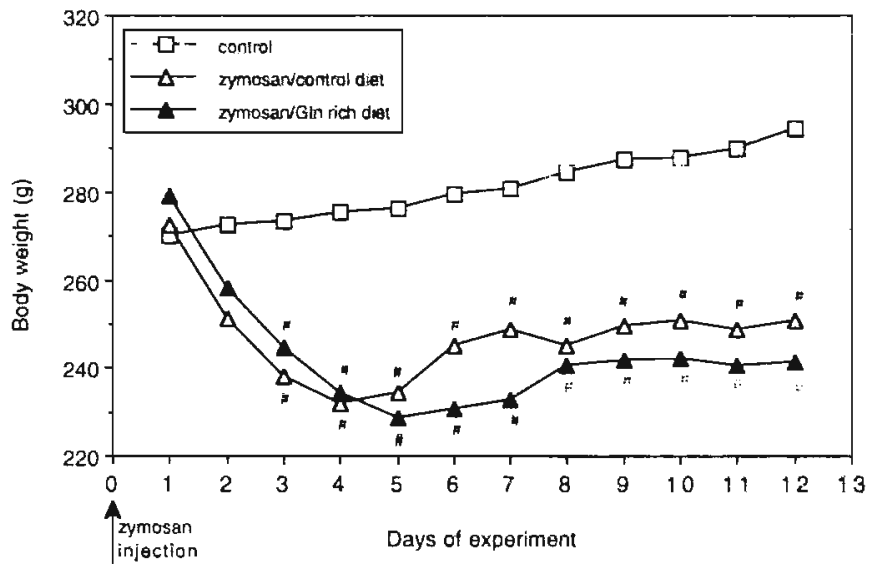

Figure 6. Body weight $(g)$ of rats fed the control diet or the glutamine rich diet for 12 days following a zymosan challenge and of nontreated rats fed the control diet (experiment 3 ). \#: Significantly different from the control rats at $p<0.05$.

Experiment 3 (effect of glutamine rich diet following a zymosan challenge on glutamine pools and muscle wasting)

Food intake which was dramatically decreased on the first days after the zymosan challenge increased again from day 4 on, reached a peak on day 8,9 , but plateaued at $60-80 \%$ of the normal intake thereafter (Fig. 5). No differences between the two diet groups were observed. The zymosan injected rats lost body weight for 5 days, followed by a small increase after which body weight reached a plateau (Fig. 6). No differences between rats fed with the different diets were observed.

Twelve days after the zymosan challenge muscle concentrations of glutamate, glutamine and arginine were not different in comparison with healthy control rats. Also no differences between the two diet groups were observed (Table 5). Plasma concentrations of these amino acids were not different between the two diet groups but they were significantly reduced in comparison with healthy control rats (Table 5).

Table 5. Gastrocnemius and plasma concentrations of Glu, Gln and Arg measured 12 days after a zymosan challenge in rats fed a control diet or a glutamine rich diet following the challenge, and in nontreated rats fed the control diet (experiment 3 ). Values are given as mean (range) of 5-6 rats. \#: Significantly different from the control group.

\begin{tabular}{|c|c|c|c|c|c|c|c|c|c|c|c|}
\hline & \multicolumn{6}{|c|}{ muscle } & \multicolumn{5}{|c|}{ plasma } \\
\hline & \multicolumn{2}{|c|}{$\begin{array}{l}\text { Glu (umol/g } \\
\text { wot veight) }\end{array}$} & \multicolumn{2}{|c|}{$\begin{array}{l}\text { Gh (umol/y } \\
\text { wel weight) }\end{array}$} & \multicolumn{2}{|c|}{$\begin{array}{l}\text { Arg (urrolvg } \\
\text { wet weight) }\end{array}$} & \multicolumn{2}{|c|}{$\underset{\text { (umovi) }}{\text { Glu }}$} & \multicolumn{2}{|c|}{$\underset{\text { (undin) }}{\text { Cin }}$} & $\begin{array}{r}\text { Arg } \\
\text { Gumol!? }\end{array}$ \\
\hline control (healthy rat) & 2.5 & $(2.2-3.0)$ & 3.4 & $(2.7-4.4)$ & 0.26 & $(0.16-0.36)$ & 174 & $(131-219)$ & 727 & $(588-810)$ & $(188-220)$ \\
\hline zymosan/control diet & 2.1 & $(1.6 .2 .9)$ & 3.3 & $(2,6-4.0)$ & 0.33 & $(0.21-0.40)$ & 89 & $8(69-97)$ & 545 & (493-594) & $125=(104-148)$ \\
\hline zymosan/Gin-rich die? & 2.0 & $(1.7-2.5)$ & 3.3 & $(2,3-4,0)$ & 0.34 & $(0.25-0.48)$ & 74 & - (48-98) & 522 & ( $(416-594)$ & $119=(100-159)$ \\
\hline
\end{tabular}


Table 6. Gastrocnemius weight, protein and cytochrome $c$ oxidase activity and liver weight measured 12 days after a zymosan challenge in rats fed a control diet or a glutamine rich diet following the challenge, and in nontreated rats fed the control diet (experiment 3 ). Values are given as mean (range) of 5-6 rats. \#: Significantly different from the control group.

\begin{tabular}{|c|c|c|c|c|c|c|}
\hline & \multicolumn{5}{|c|}{ muscle } & \multirow{2}{*}{$\begin{array}{c}\text { liver } \\
\text { weight (g) }\end{array}$} \\
\hline & weight (g) & & $\begin{array}{l}\text { otein } \\
g / g)\end{array}$ & $\begin{array}{r}\text { Cytochror } \\
\text { ( } \mu \mathrm{mo}\end{array}$ & $\begin{array}{l}\text { ne c oxidase } \\
\text { /min per g) }\end{array}$ & \\
\hline control (healthy rat) & $1.8 \quad(1.6-2.0)$ & 217 & (183.263) & 186 & $(142-214)$ & $(9.2-12.2)$ \\
\hline zymosan/control diet & $1.1 \#(0.9-1.3)$ & 208 & $(182-226)$ & 170 & $(99-250)$ & $12.8 \#(11.6-14.1)$ \\
\hline zymosan/Gin-rich diet & $1.1 \#(0.9-1.3)$ & 200 & (157-222) & 153 & $(128-204)$ & $12.1 \quad(9.8-15.0)$ \\
\hline
\end{tabular}

No differences in muscle weight, protein concentration, activity of cytochrome $c$ oxidase and liver weight were observed between the two diets (Table 6). Muscle and liver weights were significantly different (respectively lower and higher) in comparison with the control rats not receiving zymosan.

\section{Discussion}

The wheat protein hydrolysate used in the present studies contained approximately $25 \%$ glutamine and had a good solubility and taste. The diet composed with a mixture of this wheat protein hydrolysate and a whey protein isolate contained approximately $50 \mathrm{~g}$ glutamine per $\mathrm{kg}$, which is $30 \mathrm{~g}$ more than the control diet contained. The glutamine rich diet was equally well tolerated by the rats as the normal diet. Comparable growth rates of rats fed either of the diets suggested that the glutamine rich diet was absorbed and metabolized as well as the control diet.

Feeding rats with the glutamine rich diet for 2 weeks increased concentrations of glutamine in the two largest glutamine pools of the body (muscle and plasma) as measured in two experiments. A similar increase in plasma and muscle (extensor digitorus longus but not the soleus) has been observed in rats fed a normal chow supplemented with free glutamine for two weeks (Opara et al 1992). Due to the zymosan challenge concentrations of glutamine were reduced in muscle 2 and 6 days after treatment as observed before (chapter 3 ). No differences in concentrations measured on these days were observed between animals that have been fed the glutamine rich or the control diet. Food intake during the first 6 days after zymosan injection was rather low and possibly the glutamine intake was too low to expect any effect. Therefore, influence of the diets was studied during a longer period following the zymosan challenge, when food intake was improved. On day 12 after zymosan administration muscle concentrations of 
glutamine were back to normal in both diet groups. Plasma concentrations were, however, reduced in zymosan treated rats in comparison with healthy control rats. Food intake during the last 6 days of the 12 day period was $60-80 \%$ of the normal intake. Assuming that the extra glutamine from the glutamine rich diet was absorbed by the intestine, zymosan treated rats on this diet received $16.2 \mathrm{mmol}$ of glutamine extra in this period (average of $1.4 \mathrm{mmol} / \mathrm{day}$ ). This high amount of extra glutamine (total body pool of rats is about $0.7 \mathrm{mmol}$ ) did, however, not result in an increased concentration of glutamine in muscle or an increase in the zymosan-induced low plasma glutamine concentrations.

The glutamine rich diet had no influence on the severity of the zymosan induced illness as indicated by the comparable patterns of food intake and body weight obtained with both diets. No differences in muscle weight, muscle protein and muscle mitochondrial content between the two diet groups were observed in the zymosan treated rats. The fact that on days 6 and 12 after zymosan treatment a reduced muscle mass was observed in combination with normal glutamine concentrations suggested that muscle glutamine concentrations are not directly related to net protein gain. These results indicate that enteral glutamine interventions may be of limited value to improve muscle mass.

In addition the effect of the glutamine rich diet on concentrations of arginine was studied. Concentrations of arginine in both muscle and plasma decreased due to the zymosan challenge as observed before (chapter 3 ). Next to glutamine also arginine has been suggested to become important during severe illness (Barbul 1986). Glutamine can be metabolized in the small intestine to citrulline which can be utilized by the kidney to produce arginine and, therefore, extra dietary glutamine might have influenced arginine levels. However, no increased concentrations of arginine were observed in the glutamine rich diet group. Muscle concentrations were even decreased two weeks after the feeding and 6 days after the zymosan challenge in the group of rats on the experimental diet. These changes probably were a reflection of the lower arginine content of the glutamine rich diet $(7.9 \mathrm{~g} / \mathrm{kg}$ food versus $14.5 \mathrm{~g} / \mathrm{kg}$ in the control diet).

Several studies have shown that addition of glutamine to parenteral nutrition (TPN) can restore glutamine pools in muscle of postoperative patients (Fürst et al 1990, Hammarqvist et al 1989, Vinnars et al 1990, Wernerman et al 1989) although in most studies no full normalization was obtained. Roth and colleagues (Roth et al 1990) were unable to obtain an effect on the depleted muscle pool when infusing $40 \mathrm{~g}$ of alanyl-glutamine in patients with pancreatitis. In animal studies using glutamine supplemented TPN regimens in models of catabolism, fully or partly restored glutamine pools were observed in muscle (Ardawi \& Majzoub 1991, Wusteman \& Elia 1991, Yoshida et al 1992). In a study of Karner and colleagues (Karner et al 1989), however, no effect of intravenous glutamine administration on the depleted muscle pool was observed in septic dogs. In the present study feeding severely ill rats or rats recovering from critical illness with 
a diet rich in glutamine had no influence on the size of its stores during severe illness and recovery. Klimberg and colleagues (Klimberg et al 1990b) have studied the effect of feeding tumor bearing rats with a elementary diet enriched with free glutamine on loss of glutamine from muscle. This intervention resulted in significantly higher glutamine concentrations in muscle in comparison with the control diet. Food intake was approximately $70 \%$ of normal which is comparable to the intake of the zymosan treated rats during recovery. The control diet they used, however, was an elementary diet without any glutamine whereas in our study diets low and high in glutamine content were used. In all the above mentioned studies investigating the effect of glutamine supplementation, control groups received no glutamine at all.

Feeding rats a high protein diet ( $70 \%$ casein) for 20 days resulted in an increased utilization of glutamine by the liver (Rémésy et al 1988). No increase in arterial concentration of glutamine was observed in this study. In contrast, Moundras and colleagues (Moundras et al 1993) showed that feeding rats a normal diet supplemented with free glutamine increased concentrations of glutamine in plasma. In the present study it seemed that at least part of the extra glutamine from the enriched diet was available for peripheral tissues as indicated by the increased glutamine pool size in muscle of rats not receiving zymosan. Possibly zymosan treated rats had an increased utilization of glutamine by splanchnic tissues leaving no extra glutamine for peripheral muscle tissue. Increased glutamine oxidation rates have been reported in a rat model of sepsis (Yoshida et al 1991) and are most likely originated in the splanchnic tissues (Souba 1991, Souba \& Austgen 1990). From increased uptake of glutamine by liver and spleen following surgery in pigs Deutz and colleagues (Deutz et al 1992) proposed that cells of the immune system utilize more glutamine postoperatively. Also small intestine utilizes glutamine as an important fuel and could play a role, although reports on the effect of catabolic stress in the postabsorptive situation are contradictory (Deutz et al 1992, Souba \& Austgen 1990). It seems likely that immediately after the zymosan challenge and during recovery the extra glutamine available in muscle and plasma or supplemented via the glutamine rich diet is utilized by splanchnic tissues, especially liver and spleen and possibly small intestine.

Several studies in which glutamine was supplemented either parenterally or enterally reported improved small intestine integrity and morphology in both catabolic animal models (Ardawi 1992, Fox et al 1988, Jacobs et al 1988, Klimberg et al 1990a) and postoperative patients (Van der Hulst et al 1993). Also a positive effect of glutamine enriched TPN on glutathione production by liver in a rat model of hepatic injury has been described (Hong et al 1992). One study in which a similar glutamine rich hydrolysate was used as in the present study reported minor improvements in digestive enzyme activities in the digestive tract of methotrexate treated rats (Tanabe et al 1993). Therefore, the influence of glutamine rich diets on small intestine, liver and spleen during recovery from 
critical illness needs more research.

We conclude that enterally supplemented glutamine as a diet with a glutamine rich protein source increased muscle and plasma concentrations of glutamine when fed to healthy rats. No influence, however, was observed in critically ill rats or rats recovering from severe illness regarding the decreased glutamine pools or the wasting of muscle protein and mitochondria. The extra enterally administered glutamine apparently has no beneficial effect on net protein retention in muscle. It may, however, have beneficial effects on the intestine and the immune system which was not under investigation in this study.

\section{References}

- Adibi SA (1989). Intravenous use of glutamine in peptide form: clinical applications of old and new observations. Metabolism 38(supp/1): 89-92.

- Ardawi MS and Majzoub MF (1991). Glutamine metabolism in skeletal muscle of septic rats. Metabolism 40: 155-164.

- Ardawi MSM (1992). Effects of epidermal growth factor and glutamine-supplemented parenteral nutrition on small bowel of septic rats. Clin Sci 82: 573-580.

- Barbul A (1986). Arginine: biochemistry, physiology, and therapeutic implications. JPEN 10: 227-238.

- Bulus N, Cersosimo E, Ghishan F and Abumrad NN (1989). Physiological importance of glutamine. Metabolism 38(suppl 1): 1-5.

- Deutz NEP, Reijven PLM, Athanasas G and Soeters PB (1992). Post-operative changes in hepatic, intestinal, splenic and muscle fluxes of amino acids and ammonia in pigs. Clin Sci 83 : 607-614.

- Fox AD, Kripke SA, DePaula J, Berman JM, Settle RG and Rombeau JL (1988). Effect of glutamine-supplemented enteral diet on methotrexate-induced enterocolitis. JPEN 12: 325331.

- Fürst P, Albers S and Stehle P (1990). Glutamine-containing dipeptides in par̃enteral nutrition. JPEN 14: 118S-124S.

- Gäde G (1990). Arginine and arginine phosphate. In: Methods of enzymatic analysis (Bergmeyer HU, eds.). 8. Weinheim, VCH Publicers: 425-431.

- Gohil K, Jones DA and Edwards RHT (1981). Analysis of muscle mitochondrial function with techniques applicable to needle biopsy samples. Clin Physiol 1: 195-207.

- Hammarqvist F, Wernerman J, Ali R, Von der Decken A and Vinnars E (1989). Addition of glutamine to total parenteral nutrition after elective abdominal surgery spares free glutamine in muscle, counteracts the fall in muscle protein synthesis and improves nitrogen balance. Ann Surg 209: 455-461.

- Hong RW, Rounds JD, Helton WS, Robinson MK and Wilmore DW (1992). Glutamine preserves liver glutathione after lethal hepatic injury. Ann Surg 215: 114-119.

- Jacobs DO, Evans DA, Mealy K, O'Dwyer ST, Smith RJ and Wilmore DW (1988). Combined effect of glutamine and epidermal growth factor on rat intestine. Surgery 104: 358-364.

- Karner J, Roth E, Ollenschläger G, Fürst P, Simmel A and Karner J (1989). Glutamine-containing dipeptides as infusion substrates in the septic state. Surgery 106: 893-900.

- Klimberg VS, Salloum RM, Karper M, Plumley DA, Dolson DJ, Hautemaki D, Menderihall WR, Bova FC, Bland KI, Copeland EM and Souba WW (1990a). Oral glutamine accelerates healing of the small intestine and improves outcome after whole abdominal radiation. Arch Surg 125: 1040-1045.

- Klimberg VS, Souba WW, Salloum RM, Piumley DA, Cohen FS, Dolson DJ, Bland KI and Copeland 
EM (1990b). Glutamine-enriched diets support muscle glutamine metabolism without stimulating tumor growth. J Surg Res 48: 319-323.

- Lacey JM and Wilmore DW (1990). Is glutamine a conditionally essential amino acid? Nutr Rev 48: 297-309.

- Lowry OH, Rosebrough NJ, Farr AL and Randall RJ (1951). Protein measurement with the Folin phenol reagent. J Biol Chem 193: 265-275.

- Lund P (1990). L-glutamine and L-glutamate. In: Methods of enzymatic analysis (Bergmeyer HU, eds.). 8. Weinheim, VCH Publicers: 357-363.

- MacLennan PA, Brown RA and Rennie MJ (1987). A positive relationship between protein synthetic rate and intracellular glutamine concentration in perfused rat skeletal muscle. FEBS Letters 215: 187-191.

- Millward DJ, Jepson MM and Oer A (1989). Muscle glutamine concentration and protein turnover in vivo in malnutrition and in endotoxemia,. Metabolism 38(suppl 1): 6-13.

- Moundras C, Rémésy C, Bercovici D and Demigné C (1993). Effect of dietary supplementation with glutamic acid or glutamine on the splanchnic and muscle metabolism of glucogenic amino acids in the rat. J Nutr Biochem 4: 222-228.

- Opara E, Parry-Billings $M$ and Newsholme EA (1993). Effects of glutamine feeding on plasma and muscle glutamine levels and on glutamine synthetase activity in the rat. Proc Nutr Soc 52: 69A.

- Petersson B, Vinnars E, Waller S-O and Wernerman J (1992). Long-term changes in muscle free amino acid levels after elective abdominal surgery. Br J Surg 79: 212-216.

- Rémésy C, Morand C, Demigné C and Fafournoux P (1988). Control of hepatic utilization of glutamine by transport processes or cellular metabolism in rats fed a high protein diet. $\mathrm{J}$ Nutr 118: 569-578.

- Roth E, Karner J, Ollenschläger G, Karner J, Simmel A, Fürst P and Funovics J (1988). Alanylglutamine reduces muscle loss of alanine and glutamine in post-operative anaesthetized dogs. Clin Sci 75: 641-648.

- Roth E, Karner J and Ollenschlager G (1990). Glutamine: an anabolic effector? JPEN 14: 130S$136 \mathrm{~S}$.

- Souba WW and Austgen TR (1990). Interorgan glutamine flow following surgery and infection. JPEN 14: 90S-93S.

- Souba WW (1991). Glutamine: a key substrate for the splanchnic bed. Annu Rev Nutr 11: 285-308.

- Stehle P, Zander J, Mertes N, Albers S, Puchstein C and Lawin P (1989). Effect of parenteral glutamine dipeptide supplements on muscle glutamine loss and nitrogen balance after major injury. Lancet 1: 231-233.

- Tamada H, Nezu R, Imamura I, Matsuo Y, Takagi Y, Kamata S and Okada A (1992). The dipeptide alanyl-glutamine prevents intestinal mucosal atrophy in parenterally fed rats. JPEN 16: $110-116$.

- Tanabe S, Watanabe M and Arai S (1993). Production of a high-glutamine oligopeptide fraction from gluten by enzymatic treatment and evaluation of its nutritional effect on the small intestine of rats. J Food Biochem 16: 235-248.

- Van der Hulst RRWJ, Van Kreel BK, Von Meyenfeldt MF, Brummer R-JM, Arends J-W, Deutz NEP and Soeters PB (1993). Glutamine and the preservation of gut integrity. Lancet 341: 1363-1365.

- Vinnars E, Hammerqvist F, Von der Decken A and Wernerman J (1990). Role of glutamine and its analogs in posttraumatic muscle protein and amino acid metabolism. JPEN 14: 125 S1295.

- Walstra P and Jennes R (1984). Dairy chemistry and physics. New York, Wiley and Sons.

- Wernerman J, Hammerqvist F, Ali MR and Vinnars E (1989). Glutamine and ornithine- $\alpha$ ketoglutarate but not branched-chain amino acids reduce the loss of muscle glutamine after surgical trauma. Metabolism 38(suppl 1): 63-66. 
- Wilcox PE (1967). Determination of amide residues by chemical methods. In: Methods in Enzymology (Hirs CHW, eds.). 11. New York, Academic Press: 63-70.

- Wusteman M and Elia M (1991). Effect of glutamine infusions on glutamine concentration and protein synthetic rate in rat muscle. JPEN 15: 521-525.

- Yoshida S, Lanza-Jacoby S and Stein TP (1991). Leucine and glutamine metabolism in septic rats. Biochem J 276: 405-409.

- Yoshida S, Leskiw MJ, Schluter MD, Bush KT, Nagale RG, Lanza-Jacoby S and Stein TP (1992). Effect of total parenteral nutrition, systemic sepsis, and glutamine on gut mucosa in rats. Am J Physiol 263: E368-E373. 


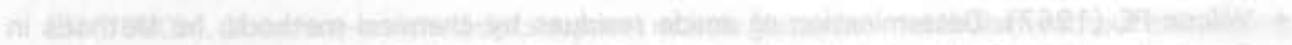

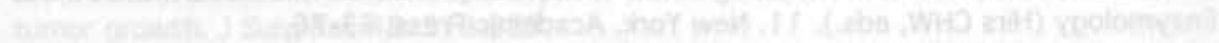

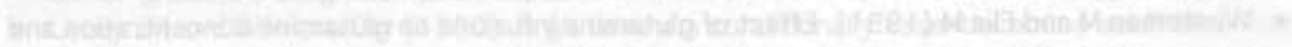

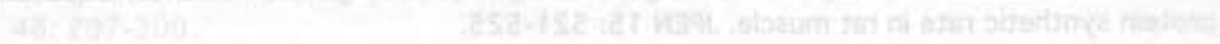

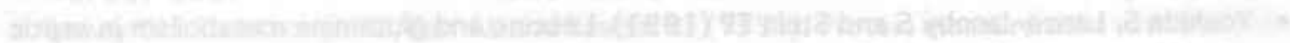

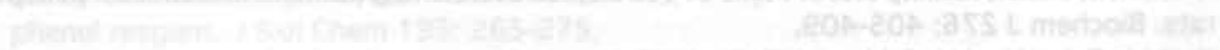

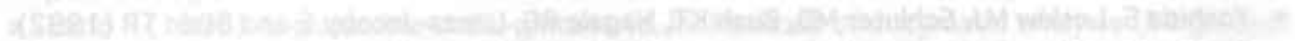

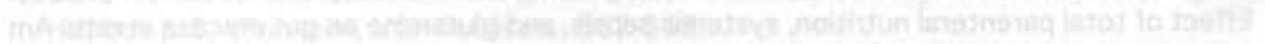

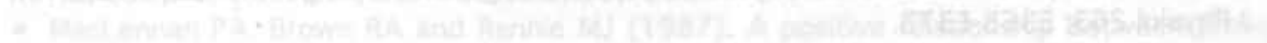

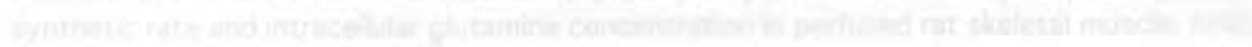

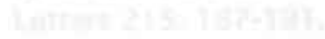

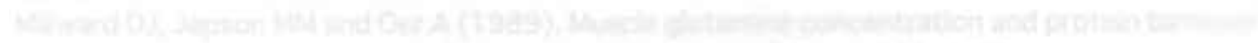

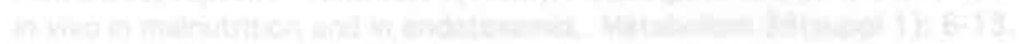

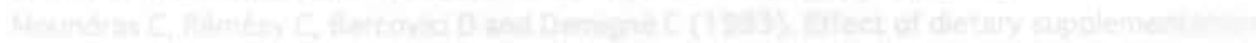

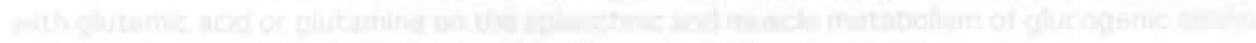

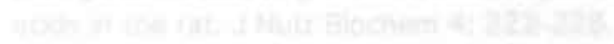

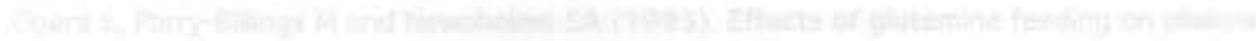

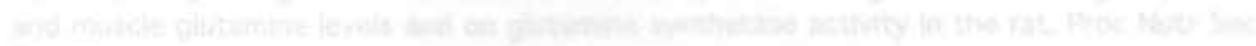

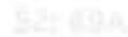

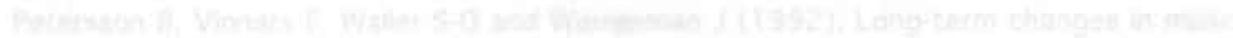

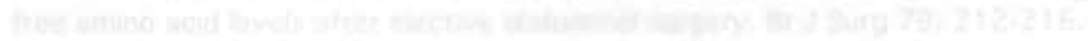

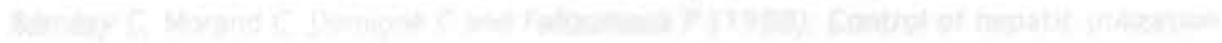

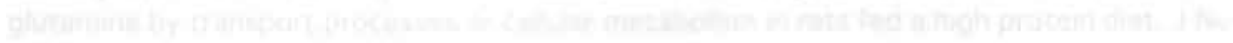

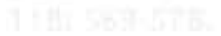

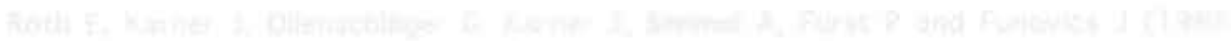

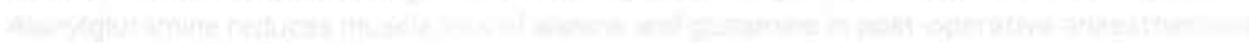

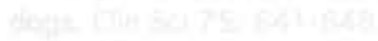

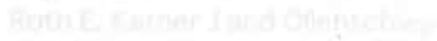

1 3has.

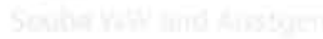

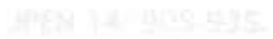

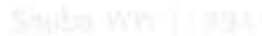




\section{General discussion}

In the preceding studies, described in this thesis, several aspects of muscle wasting characteristic for severe illness were investigated. Muscle wasting was not only considered as wasting of skeletal muscle mass or protein but also as a loss of muscle function. Studies were performed both during the acute phase of critical illness and during a period of prolonged recovery in a zymosan induced catabolic rat model.

Skeletal muscle plays an important role in whole body glutamine metabolism due to its large pool of free glutamine and its significant glutamine production. Wasting of muscle mass is likely to have a significant impact on glutamine metabolism during disease. In addition, loss of glutamine from the muscle pool has been suggested to lead to a negative protein balance in muscle and this provided the rationale for studying effects of glutamine interventions on muscle wasting.

In this last chapter the main issues and several new points will be discussed concerning (1) muscle wasting in relation to derangements in protein-, amino acid-, and energy metabolism, and (2) muscle wasting and the role of glutamine. 


\section{Muscle wasting in zymosan treated rats}

In the zymosan treated rats wasting of muscle protein occurred during the first two days after the challenge. During the following recovery period (up to 12 days after the challenge) no more muscle mass was lost, but also no gain of muscle was observed (chapter 3 ). Food intake of the zymosan treated rats is approximately $70 \%$ of normal from day 5 till 12 and, therefore, the model is ideal to study the effect of nutritional intervention on the gain of muscle mass following critical illness.

The wasting of muscle mass was accompanied by a loss of skeletal muscle contractility (chapter 7). The loss of contractility is most likely an important factor in the cause of general fatigue experienced by patients recovering from a severe insult. Muscle weight was decreased by $22 \%$ which indicated that only a minor part the total $85 \%$ decrease in muscle force generated by zymosan treated rats can be attributed to loss of muscle mass. The zymosan model, therefore, supplies a good model to study interventions not only on the gain of muscle mass but also on the recovery of muscle function following severe illness.

\section{Muscle wasting and the derangement in protein metabolism}

In zymosan treated rats muscle wasting was at least in part the result of decreased protein synthesis rates. Results from catabolic animal models are contradictory on this point with decreased (Emery et al 1984, Frayn \& Maycock 1979, Hasselgren et al 1984, Jepson et al 1986, Wusteman et al 1990), unchanged (Emery \& Ghusain-Choueiri 1994, Hasselgren et al 1986, Odessey \& Parr 1982, Preedy et al 1988, Sakamoto et al 1983) or increased (Pomposelli et al 1985, Shangraw \& Turinsky 1984) protein synthesis rates measured in skeletal muscle. As already stressed in chapter 1 many factors, such as variation in techniques, severity and type of insult, time of sampling and probably very important and often underestimated, food intake, may be responsible for these contradictions.

Food intake is one of the main modulators of protein metabolism and should, therefore, be carefully controlled in experimental procedures. From a first study, not reported in this thesis, it became clear that not only the amount of food consumed, but also the pattern of food intake is of importance. In this first study the amount of food consumed was controlled by pair feeding in the morning only. Measurements were performed the next day, implying that pair fed rats, who eat all the food offered at once, were starved for at least 24 hours, while ad libitum fed zymosan treated rats eat until 4 hours before the measurements. Muscle protein synthesis rates obtained in this study were lower in pair fed than in zymosan treated rats indicating a substantial influence of the extended starvation period in the pair fed rats. In the study described in chapter 3 pair feeding was performed three times during the day, taking care of the pattern of 
food intake as well. Both zymosan treated and pair fed rats were consequently starved for 4 hours before the measurements. A greater decrease in muscle protein synthesis rates in zymosan treated rats $16 \mathrm{~h}$ after treatment and comparable rates thereafter, clearly indicate the importance of carefully controlling both amount and pattern of food intake.

Net loss of muscle protein is the result of an imbalance between protein synthesis and degradation rates. In chapter 2 a method used to measure both synthesis and degradation rates reliably in humans and larger animals was studied for its potential use in rats. However, because of a high variation in values obtained and because of the fact that the results obtained after starvation were in contradiction to decreased protein synthesis rates previously reported (Cheng et al 1987, Millward et al 1976, Preedy \& Sugden 1989), it was decided not to use this method. Consequently, only protein synthesis rates were measured in the preceding studies using the phenylalanine flooding dose technique.

Protein degradation rates can be estimated indirectly from growth rates (mg of protein gained or lost per day) and the measured protein synthesis rates. Two major problems with these calculations are (1) that in normal situations only small amounts of protein are gained or lost which can not be determined accurately and (2) that protein synthesis rates measured at one particular time point have to be assumed to reflect synthesis rates for the whole period growth rates were obtained. Changes in muscle protein mass were large during the first two days after zymosan treatment (chapter 3 ) and, therefore, an estimation of protein degradation rates was calculated. Decreases in total muscle protein (chapter 3, table 1 ) and mean protein synthesis rates at $16 \mathrm{~h}$ and 2 days (chapter 3 , table 3 ) were used to perform the calculations. Fractional degradation rates of $28.6 \%$ in muscle of zymosan treated rats and $22.0 \%$ in pair fed rats were obtained, indicating that the greater loss of muscle protein in zymosan treated rats is most likely the result of both lower synthesis and higher degradation rates.

\section{Muscle wasting and the derangement in amino acid metabolism}

It has been suggested that following injury or infection, amino acids from skeletal muscle are redistributed (1) for gluconeogenesis, (2) for synthesis of acute phase proteins in liver, (3) as both building blocks and fuel for immune cells in the whole organism and specifically in spleen and liver, and (4) for repair of wounds. During this stress phase there is little need to use skeletal muscle for movement and, therefore, sacrifice of a part of this compartment tc improve healing and defence could be useful. With increasing severity and duration of the insult, however, loss of muscle protein may become so substantial that production of crucial amino acids diminishes and that subsequently defence decreases and 
mortality increases.

The major part of amino acids released by skeletal muscle is composed of alanine and glutamine. Alanine is the most important amino acid for gluconeogenesis in liver and glutamine is mainly utilized by cells of the immune system and possibly gut. The amounts of alanine and glutamine released are larger than can be derived from their content in the protein degraded, indicating de novo synthesis of both amino acids in skeletal muscle. Both amino acids can be synthesized in muscle in reactions using glutamate as a precursor for glutamine and as an amino group donor for alanine synthesis (Fig. 1). Glutamate is derived from net protein breakdown and de novo synthesis; (1) in a reaction using aspartate and 2-oxoglutarate to yield glutamate and oxaloacetate and (2) in a reaction using 2-oxoglutarate and branched chain amino acids (BCAA) to yield both glutamate and the corresponding branched chain keto acids (Fig. 1). Increased release of alanine and glutamine during catabolic stress, therefore, is in agreement with the increased breakdown of BCAA (chapter 4). Possibly via a substrate triggered activation of the BC-complex (branched chain $\alpha$-keto acid dehydrogenase; rate limiting enzyme in BCAA degradative pathway in skeletal muscle) an increased breakdown of BCAA ensures that a large part of the amino acids derived from net protein breakdown are directed to production of glutamate and subsequently alanine and glutamine. The surplus of amino acids resulting from net muscle protein breakdown are most likely utilized for the synthesis of other proteins in other tissues (e.g. acute phase proteins, immune cells and immunoglobulines) which are important to respond to, and overcome a catabolic insult.

\section{Muscle wasting (weakness) and the derangement in energy metabolism}

Loss of muscle contractility and increased muscle fatiguability, characteristic for critical illness and especially recovery, are undoubtedly at least in part the result of loss of muscle mass. However, cellular factors such as derangements in energy metabolism or loss of excitability of membranes may also be involved.

One of the important working hypotheses before starting the work presented in this thesis and related to an impaired energy production in skeletal muscle during severe catabolic stress has been briefly described in chapter 5 . The hypothesis became apparent from exercise physiology studies and was based on a hypothetical link between an increased breakdown of BCAA leading to a net carbon drain on the TCA cycle and subsequently an impaired energy production.

As visualized in figure 1 an increased BCAA breakdown leads to an enhanced utilization of the tricarboxylic acid (TCA) cycle intermediate 2-oxoglutarate as an amino group acceptor. Of the three BCAA both valine and isoleucine can 


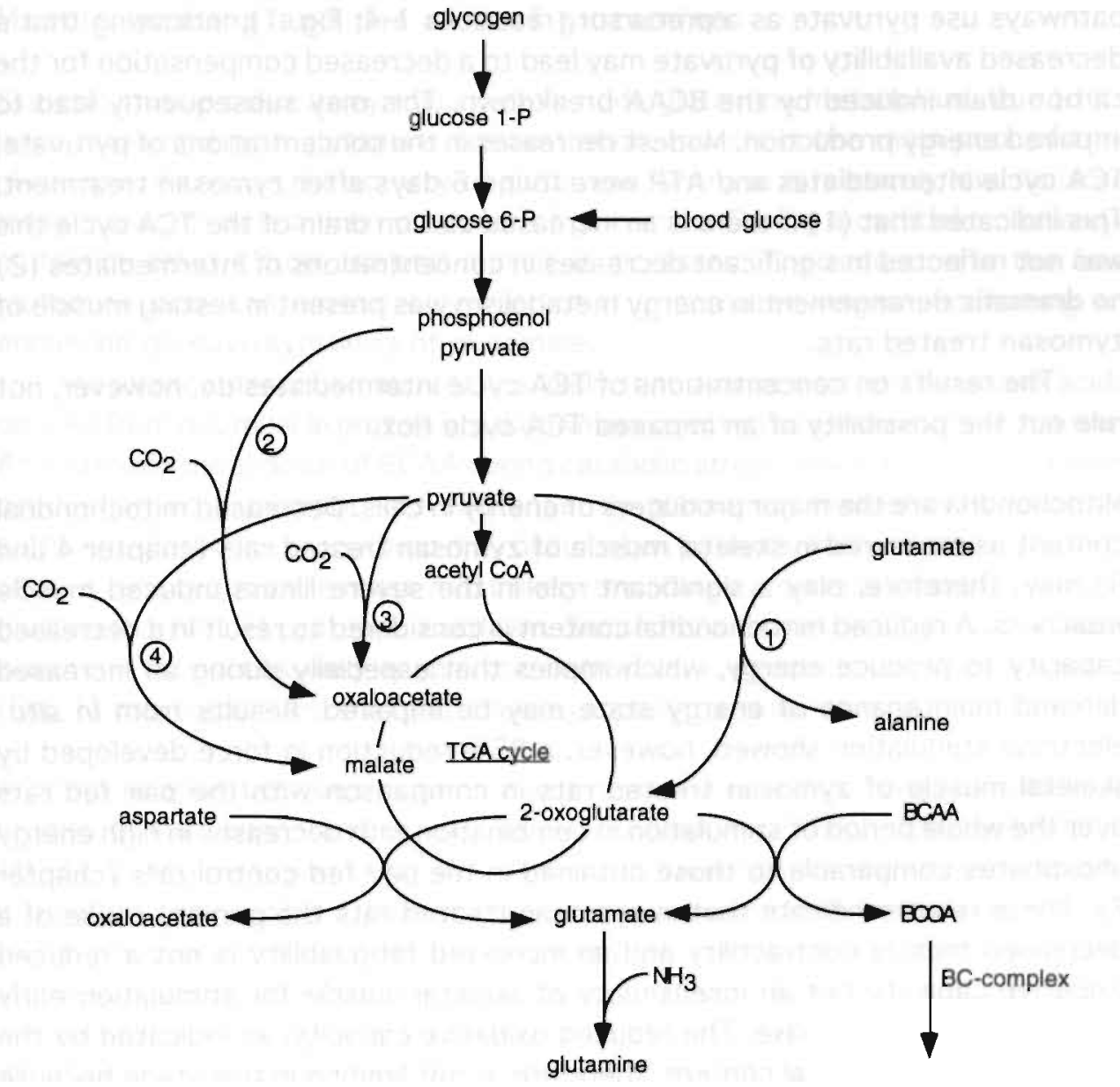

Figure 1. Hypothetical draining effect of BCAA breakdown (BCAA amino transferase) regulated by the $\mathrm{BC}$-complex (rate limiting enzyme in muscle) on TCA cycle intermediates counteracted by anaplerotic conversion of pyruvate to TCA cycle intermediates (route 1-4), 1: alanine aminotransferase (glutamate + pyruvate $\rightarrow$ alanine +2 -oxoglutarate); 2 : phosphoenol pyruvate carboxykinase (phophoenolpyruvate $+\mathrm{GTP}+\mathrm{CO} 2 \rightarrow \mathrm{GDP}+$ oxaloacetate); 3 : pyruvate carboxylase (pyruvate $+\mathrm{CO}_{2}+\mathrm{ATP} \rightarrow \mathrm{ADP}+\mathrm{P}_{1}+$ oxaloacetate); 4 : NADP-specific malic enzyme (pyruvate $+\mathrm{CO}_{2}+\mathrm{NADPH}+\mathrm{H}^{+} \rightarrow \mathrm{NADP}^{+}+$malate).

supply new carbon skeletons for TCA cycle intermediates via succinyl-CoA. However, an increased breakdown of BCAA results in a net drain of carbon skeletons from the TCA cycle, because leucine does not supply new carbon skeletons for TCA cycle intermediates and because part of the carbon skeletons from BCAA are excreted from muscle as branched chain 2-oxo acids and possibly branched chain fatty acids (Lee \& Davis 1986, Wagenmakers et al 1985).

This carbon drain on the TCA cycle normally is compensated by production of new intermediates via several other anaplerotic pathways (Aragón \& Lowenstein 1980, Davis et al 1980, Krebs 1975, Veerkamp 1981). Most of these anaplerotic 
pathways use pyruvate as a precursor (reactions 1-4; Fig. 1), indicating that a decreased availability of pyruvate may lead to a decreased compensation for the carbon drain induced by the BCAA breakdown. This may subsequently lead to impaired energy production. Modest decreases in the concentrations of pyruvate, TCA cycle intermediates and ATP were found 6 days after zymosan treatment. This indicated that ( 1 ) if there is an increased carbon drain of the TCA cycle this was not reflected in significant decreases in concentrations of intermediates (2) no dramatic derangement in energy metabolism was present in resting muscle of zymosan treated rats.

The results on concentrations of TCA cycle intermediates do, however, not rule out the possibility of an impaired TCA cycle flux.

Mitochondria are the major producers of energy in cells. Decreased mitochondrial content as measured in skeletal muscle of zymosan treated rats (chapter 4 and 6) may, therefore, play a significant role in the severe illness induced muscle weakness. A reduced mitochondrial content is considered to result in a decreased capacity to produce energy, which implies that especially during an increased demand maintenance of energy state may be impaired. Results from in situ electrical stimulation showed, however, a $85 \%$ reduction in force developed by skeletal muscle of zymosan treated rats in comparison with the pair fed rats over the whole period of stimulation in combination with decreases in high energy phosphates comparable to those obtained in the pair fed control rats (chapter 7 ). These results indicate that in zymosan treated rats the primary cause of a decreased muscle contractility and an increased fatiguability is not a reduced oxidative capacity but an insensitivity of skeletal muscle for stimulation early during the recovery phase. The reduced oxidative capacity, as indicated by the decreased mitochondrial content, therefore, is not limiting in this stage because no contractions are performed and subsequently no extra energy is requested. As discussed in chapter 7 (page 98) the combination of a reduced force performance and comparable decreased in high energy phosphates indicated that the ATP turnover may be reduced as a consequence of the decreased oxidative capacity in muscle of zymosan treated rats. Possibly the decreased mitochondrial content will become a significant problem later during recovery when muscle excitability is improved.

Both decreased muscle tension and contractility, and denervation have been reported to induce muscle atrophy accompanied by decreased protein synthesis rates (Goldspink 1976, Sugden \& Fuller 1991). In addition Hundal and colleagues have reported decreased concentrations of glutamine in denervated rat muscle (Hundal et al 1990). These findings indicate that the decreased contractility and the functional denervation of skeletal muscle of zymosan treated rats may be involved both in the decreased concentrations of glutamine and the decreased protein synthesis rates. 


\section{Muscle wasting and the role of glutamine}

Skeletal muscle plays a key role in whole body glutamine metabolism. Due to its large mass and high glutamine concentration, muscle is the main pool of free glutamine. Although the activity of glutamine synthase is relatively low, its large mass makes muscle a main producer of glutamine. During a catabolic challenge glutamine release from skeletal muscle is increased. The reduction in the free glutamine pool can explain only part of this increased release, indicating an enhanced de novo synthesis of glutamine.

As already described above, it is likely that a large part of the amino acids derived from net muscle protein breakdown are directed to synthesis of glutamine. An increased breakdown of BCAA during catabolic stress may lead to an increased production of glutamate and subsequently glutamine. Problems to maintain sufficient glutamine production may occur when patients become depleted. First of all a reduced muscle mass most likely implicates a decreased production of glutamine from net protein breakdown. Secondly, a decreased supply of carbon skeletons via successively anaplerotic pathways, 2-oxoglutarate and glutamate (Fig. 1) may impair de novo glutamine synthesis by skeletal muscle.

A direct relation between glutamine and muscle wasting has been provided by studies of MacLennan and colleagues (MacLennan et al 1987, MacLennan et al 1988). During perfusion of rat hindlimb with different glutamine concentrations, a positive relationship between muscle protein synthesis rates and muscle glutamine concentrations became apparent (MacLennan et al 1987). A similar study suggested an inhibitory relationship between glutamine concentrations and muscle protein breakdown (MacLennan et al 1988). From these results an important role for glutamine as a determinant of muscle mass has been suggested. Many investigators referred to this hypothesis to underline the potentia! of glutamine intervention in preserving muscle mass during catabolic stress. Results from several studies performed by Millward and Jepson (Jepson et al 1988, Millward et al 1989) supported the hypothesis, with a strong correlation between glutamine concentrations and muscle protein synthesis rates measured in vivo in rats under different situations (malnutrition, starvation, glucocorticoid treatment and endotoxemia). They stated that a causal relationship was likely, but also a factor inducing both changes in protein synthesis rate and glutamine concentrations in parallel but independently may be involved. From studying both glutamine concentrations and protein synthesis rates in skeletal muscle over a prolonged period after zymosan treatment it became clear that the relationship is not a universal one. Normalized protein synthesis rates do occur while glutamine concentrations are still decreased during recovery from zymosan treatment (Fig. 3 in chapter 3). Also if all values (from zymosan treated, pair fed and ad libitum fed rats) obtained in this study were used, no relationship was present (Fig. 2). Additionally, other studies have indicated that these variables 
do not always correlate (Rooyackers et al 1992, Wusteman \& Elia 1991, Wusteman et al 1990). Possibly a common factor such as cytokines, hormones (e.g. insulin and thyroid) or cell volume induces a parallel decrease in concentrations of glutamine and protein synthesis rates in skeletal muscle due to an acute metabolic stress (disease, starvation), whereas this is not apparent during more chronic situations and recovery.

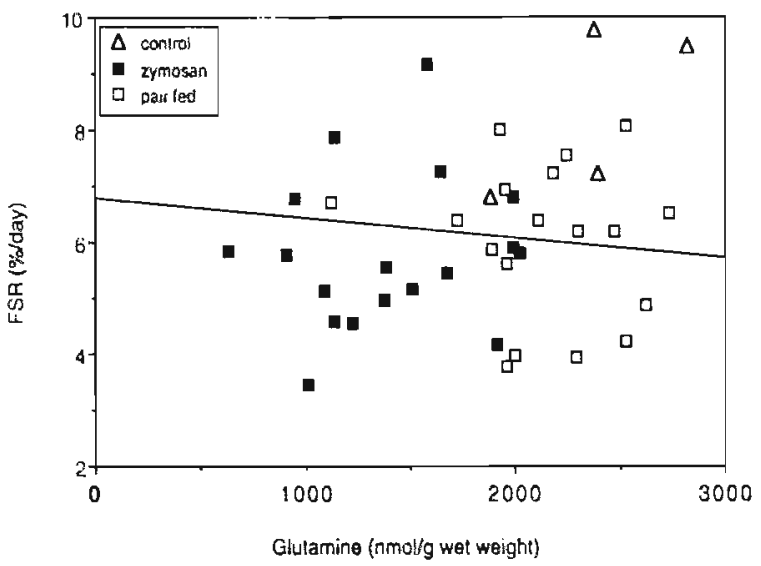

Figure 2. Relationship $\left(y=6.8-0.0003 x ; R^{\prime}=0.09 ; p=0.16\right)$ between muscle concentrations of glutamine and muscle fractional protein synthesis rates (FSR) measured in zymosan treated and pair fed rats on day 2, 4 and 6 after treatment and in ad libitum fed control rats. The Spearman rank correlation was used for statistical analysis.

The ultimate goal of the studies was to investigate the effect of a nutritional glutamine intervention on muscle wasting and weakness as described and studied in the zymosan-induced catabolic rat model. However, a diet containing a protein source rich in glutamine did not affect parameters of muscle wasting (muscle weight, muscle protein and concentrations of glutamine and arginine) and the oxidative capacity (activities of cytochrome $c$ oxidase) in zymosan treated rats (chapter 8 ). Most likely the extra glutamine supplied by the diet was utilized by splanchnic tissues, which were the first tissues to be confronted with the extra glutamine, and did not become available for the peripheral muscle tissue. During catabolic stress liver takes up more glutamine. Possibly also small intestine utilizes more glutamine supplied via the lumen in these situations. Therefore, the dietary glutamine intervention may support splanchnic tissues in their response to a catabolic challenge but have no direct peripheral effects.

Long-term administration of parenteral nutrition (TPN) without glutamine to rats leads to impaired intestinal integrity and morphology (villous atrophy), decreased protein and DNA content, decreased activities of digestive enzymes and bacterial translocation. Many of these features have been reported to be 
counteracted by supplying glutamine with the TPN (Alverdy et al 1992, Burke et al 1989, Hwang et al 1986, O'Dwyer et al 1989, Tamada et al 1992). However, also studies with no effect of glutamine supplementation have recently been published (Bark et al 1994, McArdle 1994, Xu et al 1993). In studies using catabolic rat models both parenteral (Ardawi 1992, Jacobs et al 1988) and enteral (Fox et al 1988, Klimberg et al 1990, O'Dwyer et al 1987, Tanabe et al 1993 ) glutamine supplementations have been reported to improve small intestine integrity (increased DNA and protein content, decreased bacterial translocation, improved morphology) and survival. In surgical patients improved gut integrity and reduced permeability have been reported when using TPN enriched with glutamine containing dipeptides (Van der Hulst et al 1993). In a study of Ziegler and colleagues (Ziegler et al 1992) glutamine supplementation to TPN decreased the incidence of clinical infection, lowered rates of microbial colonization and shortened hospital stay. These studies indicate a potential beneficial effect of glutamine intervention on small intestine, liver and the immune system.

Taken together, supplying zymosan treated rats with a diet containing extra glutamine as a glutamine rich protein source had no effect on muscle wasting. In addition, the fact that no correlation between muscle glutamine and protein synthesis was observed during recovery from the zymosan challenge, indicates that glutamine intervention to improve muscle mass may be of limited value. The diet is, however, well tolerated and most likely metabolized by the rats and therefore, further research on the potential of the diet to support splanchnic tissues and the immune system during severe illness and recovery is needed.

\section{Directions for future research}

The zymosan induced catabolic rat model is very well suited for studying metabolic derangements, the cause of muscle weakness and the effect of nutritional interventions. One should keep in mind that changes in metabolite concentrations should be interpreted with caution. The flux through the pool, which may be independent of the pool size, is the essential variable that should be quantified to draw ultimate conclusions about changes in supply or availability of metabolites. More research, therefore, should be focused on glutamine production by skeletal muscle in relation to the size of the muscle mass (machinery to produce glutamine). Does muscle wasting and depletion reduce the capacity of the body to produce glutamine? Especially in depleted patients challenged with an insult (injury, infection) a reduced capacity to produce glutamine may limit optimal defence, repair and eventually survival.

Results from chapter 7 indicated that muscle weakness seems to be the result of an insensitivity of skeletal muscle to stimulation, most likely as a result of 
nerve dysfunction or a derangement in one of the steps of the excitation/ contraction coupling mechanism. A first step in defining the defect in a direct approach could be to perform in situ stimulation on the muscle itself and thereby bypass possible nerve dysfunction. In addition intracellular calcium concentrations and membrane potential should be measured in skeletal muscle.

In addition the presence and the consequence of a decreased mitochondrial content in skeletal muscle during a prolonged period of recovery should be investigated.

The dramatic loss of muscle force generation by the zymosan treated rats supplies an ideal parameter for functional endpoint measurements when studying nutritional or therapeutic interventions. Future research should aim at investigating whether this variable also is an useful endpoint in nutritional intervention studies in patients.

The effect of a dietary intervention with a glutamine rich protein source on splanchnic tissues and the immune system needs more research. Decreased protein synthesis rates of the mucosal layer of the small intestine 6 days after zymosan treatment in combination with decreased plasma concentrations of glutamine were observed in zymosan treated rats (chapter 3 ) and supply a model to study the effect of such a diet on the gut. Spleen, which is a key tissue in the immune system, takes up more glutamine postoperatively. Protein synthesis rates of the spleen or of immunoglobulins, with and without glutamine intervention could be measured to study the effect of glutamine interventions on the immune system.

\section{References}

- Alverdy JA, Aoys E, Weiss-Carrington P and Burke DA (1992). The effect of glutamine-enriched TPN on gut immune cellularity. J Surg Res 52: 34-38.

- Aragón JJ and Lowenstein JM (1980). The purine-nucleotide cycle. Comparison of the levels of citric acid cycle intermediates with the operation of the purine nucleotide cycle in rat skeletal muscle during exercise and recovery from exercise. Eur J Biochem 110: 371-377.

- Ardawi MSM (1992). Effects of epidermal growth factor and glutamine-supplemented parenteral nutrition on small bowel of septic rats. Clin Sci 82: 573-580.

- Bark T, Svenberg T, Theodorsson E, Uribe A and Wennberg A (1994). Glutamine supplementation does not prevent small bowel mucosal atrophy after total parental nutrition in the rat. Clin Nutr 13: 79-84.

- Burke DJ, Alverdy JC, Aoys E and Moss GS (1989). Glutamine-supplemented total parenteral nutrition improves gut immune function. Arch Surg 124: 1396-1399.

- Cheng KN, Pacy PJ, Dworzak F, Ford GC and Halliday D (1987). Influence of fasting on leucine and muscle protein metabolism across the human forearm determined using $L-\left[1-{ }^{13} \mathrm{C},{ }^{15} \mathrm{~N}\right]$ leucine as a tracer. Clin Sci 73: 241-246.

- Davis EJ, Spydevold $\emptyset$ and Bremer J (1980). Pyruvate carboxylase and propionyl-CoA carboxylase as anaplerotic enzymes in skeletal muscle mitochondria. Eur J Biochem 110: 255-262.

- Emery PW, Lovell L and Rennie MJ (1984). Protein synthesis measured in vivo in muscle and 
liver of cachectic tumor-bearing rats. Canc Res 44: 2779-2.784.

- Emery PW and Ghusain-Choueiri A (1994). Effect of surgical trauma on muscle protein synthesis in the rat. Brit $J$ Surg 81: 539-542.

- Fox AD, Kripke SA, DePaula J, Berman JM, Settle RG and Rombeau JL (1988). Effect of glutamine-supplemented enteral diet on methotrexate-induced enterocolitis. JPEN 12: 325331.

- Frayn KN and Maycock PF (1979). Regulation of protein metabolism by a physiological concentration of insulin in mouse soleus and extensor digitorum longus muscles. Biochem $\mathrm{J}$ 184: 323-330.

- Goldspink DF (1976). The effect of denervation on protein turnover of rat skeletal muscle. Biochem J 156: 71-80.

- Hasselgren P-O, Jagenburg R, Karlström L, Pedersen P and Seeman T (1984)..Changes of protein metabolism in liver and skeletal muscle following trauma complicated by sepsis. J Trauma 24: 224-228.

- Hasselgren P-O, Talamini M, James H and Fisher JE (1986). Protein metabolism in different types of skeletal muscle during early and late sepsis in rats. Arch Surg 121: 918-923.

- Hundal HS, Babij P, Watt PW, Ward MR and Rennie MJ (1990). Glutamine transport and metabolism in denervated rat skeletal muscle. Am J Physiol 259: E148-E154.

- Hwang TL, O'Dwyer ST, Smith RJ and Wilmore DW (1986). Preservation of small bowel mucosa using glutamine-enriched parenteral nutrition. Surg Forum 37: 56-58.

- Jacobs DO, Evans DA, Mealy K, O'Dwyer ST, Smith RJ and Wilmore DW (1988). Combined effect of glutamine and epidermal growth factor on rat intestine. Surgery 104: 358-364.

- Jepson MM, Pell JM, Bates PC and Millward DJ (1986). The effect of endotoxaemia on protein metabolism in skeletal muscle and liver of fed and fasted rats. Biochem J 235: 329-336.

- Jepson MM, Bates PC, Broadbent P, Pell JM and Millward DJ (1988). Relationship between glutamine concentration and protein synthesis in rat skeletal muscle. Am J Physiol 255: E1 66E172.

- Klimberg VS, Salloum RM, Karper M, Plumley DA, Dolson DJ, Hautemaki D, Mendenhall WR, Bova FC, Bland KI, Copeland EM and Souba WW (1990). Oral glutamine accelerates healing of the small intestine and improves outcome after whole abdominal radiation. Arch Surg 125: 1040-1045.

- Krebs HA (1975). The role of chemical equilibria in organ function. Adv Enzym Regul 15: 449472.

- Lee SC and Davis EJ (1986). Amino acid catabolism by perfused rat hindquarter. The metabolic fates of valine. Biochem J 233: 621-630.

- MacLennan PA, Brown RA and Rennie MJ (1987). A positive relationship between protein synthetic rate and intracellular glutamine concentration in perfused rat skeletal muscle. FEBS letters 215: 187-191.

- MacLennan PA, Smith K, Weryk B, Watt PW and Rennie MJ (1988). Inhibition of protein breakdown by glutamine in perfused rat skeletal muscle. FEBS letters 237: 133-136.

- McArdle MH (1994). Protection from radiation injury by elemental diet: does added glutamine change the effect? Gut (suppl 1): S60-S64.

- Millward DJ, Garlick PJ, Nnanyelugo DO and Waterlow JC (1976). The relative importance of muscle protein synthesis and breakdown in the regulation of muscle mass. Biochem $\mathrm{J} 456$ : 185-188.

- Millward DJ, Jepson MM and Omer A (1989). Muscle glutamine concentration and protein turnover in vivo in malnutrition an in endotoxemia. Metabolism 38(suppl 1): 6-13.

- O'Dwyer ST, Scott T, Smith RJ and Wilmore DW (1987). 5-Fluorouracil toxicity on small intestine mucosa but not white blood cells in decreased by glutamine. Clin Res 3.5: 369.

- O'Dwyer ST, Smith RJ, Hwang TL and Wilmore DW (1989). Maintenance of small bowel mucosa with glutamine-enriched parenteral nutrition. JPEN 13: 579-585.

- Odessey R and Parr B (1982). Effect of insulin and leucine on protein turnover in rat soleus muscle after burn injury. Metabolısm 31: 82-87. 
- Pomposelli JJ, Palombo JD, Hamawy KJ, Bistrian BR, Blackburn GL and Moldawer LL (1985). Comparison of different techniques for estimating rates of protein synthesis in vivo in healthy and bacteremic rats. Biochem J 226: 37-42.

- Preedy VR, Paska L, Sugden PH, Schofield PS and Sugden MC (1988). The effect of surgical stress and short-time fasting on protein synthesis in vivo in diverse tissues of the mature rat. Biochem J 250: 179-188.

- Preedy VR and Sugden PH (1989). The effect of fasting or hypoxia on rates of protein synthesis in vivo in subcellular fractions of rat heart and gastrocnemius muscle. Biochem J 257: 519527.

- Rooyackers OE, Faes M, Wierts JW, Wagenmakers AJM and Hornstra G (1992). The effect of fish oil feeding on muscle metabolism during endotoxemia. Clin Nutr 11 (spec suppl): 2-3.

- Sakamoto A, Moldawer LL, Palombo JD, Desai SP, Bistrian BR and Blackburn GL (1983). Alterations in tyrosine and protein kinetics produced by injury and branched chain amino acid administration in rats. Clin Sci 64: 312-331.

- Shangraw RE and Turinsky J (1984). Altered protein kinetics in vivo after single-limb burn injury. Biochem J 223: 747-753.

- Sugden PH and Fuller SJ (1991). Review article. Regulation of protein turnover in skeletal and cardiac muscle. Biochem J 273: 21-37.

- Tamada H, Nezu R, Imamura I, Matsuo Y, Takagi Y, Kamata S and Okada A (1992). The dipeptide alanyl-glutamine prevents intestinal mucosal atrophy in parenterally fed rats. JPEN 16: $110-116$.

- Tanabe S, Watanabe M and Arai S (1993). Production of a high-glutamine oligopeptide fraction from gluten by enzymatic treatment and evaluation of its nutritional effect on the small intestine. J Food Biochem 16: 235-248.

- Van der Hulst RRWJ, Van Kreel BK, Von Meyenfeldt MF, Brummer RM, Arends, Deutz NEP and Soeters PB (1993). Glutamine and the preservation of gut integrity. Lancet 341: 13631365.

- Veerkamp JH (1981). The function of muscle mitochondria. In: Mitochondria and muscle diseases (Busch HFM, Jennekens FGI and Scholte HR, eds.). Beesterzwaag, The Netherlands, Mefar b.v.: 29-50.

- Wagenmakers AJM, Salden HJM and Veerkamp JH (1985). The metabolic fate of branchedchain amino acids and 2-oxo acids in rat muscle homogenated and diaphragms. Int $\mathrm{J}$ Biochem 17: $957-965$.

- Wusteman M, Wight DGD and Elia M (1990). Protein metabolism after injury with turpentine: a rat model for clinical trauma. Am J Physiol 259: E763-E769.

- Wusteman M and Elia M (1991). Effect of glutamine infusions on glutamine concentration and protein synthetic rate in rat muscle. JPEN 15: 521-525.

- Xu D, Qi L, Thirstrup C, Berg R and Dietch EA (1993). Elemental diet-induced bacterial translocation and immunosuppression is not reversed by glutamine. J Trauma 35: 821-824.

- Ziegler TR, Young LS, Benfell K, Scheltinga M, Hortos K, Bye R, Morrow FD, Jacobs DO, Smith RJ, Antin JH and Wilmore DW (1992). Clinical and metabolic efficacy of glutamine-supplemented parenteral nutrition after bone marrow transplantation. A randomized, double-blind, controlled study. Ann Inter Med 116: 821-828. 


\section{Summary}

In response to a severe insult (e.g. injury, inflammation or cancer) patients are in a so-called catabolic state. Net breakdown (catabolism) of predominantly protein is manifested in a for severe illness characteristic wasting of muscle mass. This wasting of muscle protein and an additional loss of muscle contractility indicate that skeletal muscle is an important tissue in the metabolic response to a catabolic challenge. In addition muscle is the main source of glutamine production. Glutamine is an important fuel for the gut and the immune system and has been suggested to become essential during severe illness. In this thesis derangements in protein, amino acid and energy metabolism in skeletal muscle and the role of glutamine have been studied in a catabolic rat model.

Muscle protein wasting can either be the result of a decreased synthesis rate, an increased degradation rate or a combination of both. No reliable method is available for measuring in vivo protein degradation rates in rats. In large animals and human subjects amino acid tracer kinetics have been used to measure protein synthesis and degradation rates simultaneously in vivo. In chapter 2 it was investigated whether this method can be used in rats. However, due to a high variation and due to the fact that protein synthesis rates obtained after starvation were not in line with those obtained with generally accepted methods, it was decided not to use this method. Therefore, in this thesis only protein synthesis rates were measured using the phenylalanine flooding dose technique.

A single intraperitoneal injection with zymosan suspended in liquid paraffin was used to derive a catabolic rat model. A model with a reproducible pattern of illness was obtained in this way. An acute phase of critical illness ( 2 days) with an average mortality of $20 \%$ was followed by a prolonged recovery phase for at least 10 days without mortality and signs of severe illness (chapter 3 ). Zymosan treatment substantially reduced food intake and, therefore, control rats were pair fed.

Zymosan treated rats lost muscle mass during the acute phase of critical illness. At least part of this loss was the result of a decreased protein synthesis rate. In addition also other metabolic responses were observed which are characteristic for severe illness (e.g. decreased muscle concentrations of glutamine, increased liver mass and enhanced liver protein synthesis rates) (chapter 3 ). The prolonged recovery period with a substantial food intake (60$80 \%$ of control) makes the model suited for nutritional intervention studies.

During severe illness increased oxidation of branched chain amino acids has frequently been reported. In chapter 4 an increased activity of the rate limiting enzyme in the degradative pathway of branched chain amino acids (BCAA), the branched-chain 2-oxoacid dehydrogenase complex, has been observed in muscle of zymosan treated rats. This furnishes a possible mechanism for the increased oxidation of BCAA during catabolic diseases. An increased breakdown of BCAA will lead to an increased synthesis of glutamate. Glutamate can subsequently be 
used to synthesize alanine and glutamine. These latter two are important amino acids during disease, respectively for gluconeogenesis and as a fuel for rapidly dividing cells (e.g. enterocytes, lymphocytes and macrophages). The increased breakdown of BCAA, therefore, provides a possible mechanism to direct amino acids, derived from net muscle protein breakdown, for a large part to alanine and glutamine synthesis.

During severe illness and especially the following recovery phase, patients often complain of muscle weakness and increased fatiguability. Zymosan treatment of rats resulted in an $85 \%$ loss of muscle force generated during in situ electrical stimulation. Since muscle mass decreased by $22 \%$ it is concluded that the decrease in muscle mass explains only part of the force loss. In chapter 6 a decrease in muscle mitochondrial protein content was observed in zymosan treated rats. This decrease, which was even more dramatic than the wasting of total muscle protein, was at least in part the result of a decreased synthesis rate of mitochondrial protein. In exercise physiology a clear relationship has been established between muscle mitochondrial content and muscle endurance performance. This supplies a possible mechanism for the severe illness related muscle weakness. However, the decrease in mitochondrial content in skeletal muscle of zymosan treated rats was accompanied by only a modest decrease in concentrations of high energy phosphates in resting muscle (chapter 5).

A reduced mitochondrial content has been shown to lead to a decreased capacity to produce energy and, therefore, impaired energy production is more likely to arise during an increased activity. During in situ electrical stimulation of skeletal muscle no differences were observed in changes in high energy phosphates between zymosan treated and pair fed control rats (chapter 7 ). These results indicate that the $85 \%$ reduction in force generated by the zymosan treated rats most likely results from an insensitivity of muscle for stimulation. This insensitivity is possibly caused by a temporary derangement in the nervous system or in one of the steps of the excitation-contraction coupling mechanism. However, a decreased mitochondrial content may have implications for muscle function and fatiguability during prolonged recovery from critical illness.

It has been suggested that glutamine becomes conditionally essential during severe illness and, therefore, many glutamine intervention studies have been and are being performed. A positive relation between muscle glutamine concentration and protein synthesis rated has been reported in the literature and has been used to underline the potential of glutamine interventions to preserve muscle mass. However, in skeletal muscle of rats recovering from the zymosan challenge normalized protein synthesis rates were observed, while glutamine concentrations were still decreased (chapter 3 ). These results indicate that the positive relationship between these two features is not a universal one.

In chapter 8 a glutamine intervention, using a diet with a protein source rich in glutamine, resulted in increased concentrations of glutamine in muscle and plasma when applied to healthy rats not injected with zymosan. However, 
the diet had no influence on the catabolic response to a zymosan challenge measured as severity of illness (food intake and body weight), depleted glutamine stores, and wasting of skeletal muscle (both total and mitochondrial protein). The diet was ingested and absorbed by the zymosan treated rats. Most likely all the extra glutamine supplied in this way is extracted by splanchnic tissues.

\section{Main conclusions}

- Injecting rats with zymosan resulted in a catabolic model with an acute phase of critical illness for 2 days followed by a prolonged recovery phase (at least 10 days). The model is suited for investigation of biochemical mechanisms behind metabolic derangements during both phases and for studies of nutritional interventions during recovery.

- Wasting of muscle protein, taking place during the acute phase of critical illness in zymosan treated rats, was at least in part the result of decreased protein synthesis rates.

- During severe illness the mitochondrial protein content in skeletal muscle is reduced to a greater extent than total muscle protein. Part of this loss was the result of decreased synthesis rates of mitochondrial protein. These were substantially more decreased than synthesis rates of total muscle protein.

- A loss of muscle contractility was observed in the zymosan treated rats and seemed to be the result of an impairment in the nervous system or in the excitation/contraction coupling mechanism. During prolonged recovery from critical illness the decreased mitochondrial content may have important implications for muscle function.

- Nutritional intervention with a diet containing a protein source rich in glutamine is capable of increasing the muscle and plasma glutamine pools in healthy control rats. However, this diet had no effect on the zymosan induced severity of illness, the reduction in the glutamine pools and the wasting of muscle protein (neither total nor mitochondrial protein). 


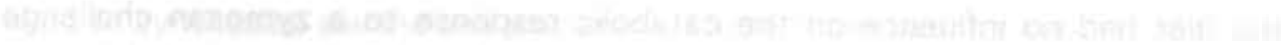

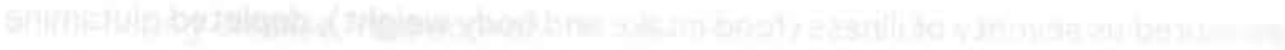

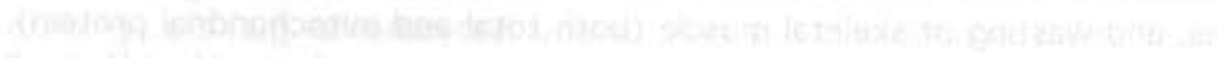

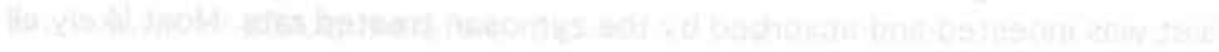

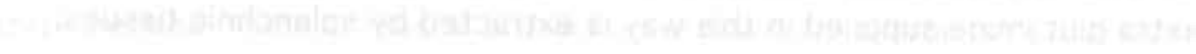




\section{Samenvatting}

Tijdens ernstige ziekte (zoals ernstige verwondingen, infecties of kanker) raken patiënten in een katabole situatie. Netto afbraak (katabolisme) van voornamelijk eiwit leidt tot een voor ernstige ziekte karakteristiek verlies van spiermassa. Gedurende de herstelfase na ernstige ziekte klagen patiënten vaak over een verminderde spierkracht. Het verlies van spiermassa en van spierfunctie duiden erop dat de skeletspier een belangrijk weefsel is in de metabole reactie op ernstige ziekte en tijdens de herstelfase. Daarnaast is de skeletspier de belangrijkste bron van glutamine. In de literatuur is gesuggereerd dat glutamine een essentieel nutriënt is tijdens ernstige ziekte en dat het in deze situaties dient toegevoegd te worden aan de voeding. In dit proefschrift zijn ontsporingen in eiwit-, aminozuuren energiemetabolisme in de skeletspier en de rol van glutamine hierbij bestudeerd in een katabool rattenmodel.

Verlies van spiereiwit is het gevolg van een daling in de eiwitsynthese snelheid, een stijging in de eiwitafbraak snelheid of een combinatie van deze twee. $\mathrm{Er}$ is maar één methode voorhanden om betrouwbaar in vivo eiwitafbraak snelheden te meten. Deze methode is gebaseerd op aminozuur tracerkinetiek en wordt gebruikt om bij grote proefdieren en bij de mens zowel eiwitsynthese als afbraak snelheden te meten. In hoofdstuk 2 is getest of deze methode bruikbaar is bij ratten. Vanwege een grote variatie in de gemeten waarden en vanwege het feit dat de eiwitsynthese snelheden verkregen na vasten niet overeen kwamen met deze gemeten met geaccepteerde methoden, is besloten deze methode verder niet te gebruiken. In de overige experimenten zijn daarom alleen eiwitsynthese snelheden gemeten.

Om een katabool rattenmodel te verkrijgen, is gebruik gemaakt van een eenmalige intraperitoneale injectie met zymosan gesuspendeerd in vloeibare paraffine. Zymosan is een extract van gist en stimuleert het complement systeem en macrofagen. Het rattenmodel laat een reproduceerbaar ziektebeeld zien. Een acute fase van ernstige ziekte ( 2 dagen) met een matige sterfte $(20 \%)$ wordt gevolgd door een lange herstel fase van tenminste 10 dagen zonder sterfte en zonder tekenen van ernstige ziekte (hoofdstuk 3 ). Omdat de behandeling met zymosan een aanzienlijke daling in de voerinname tot gevolg heeft, is aan de controle ratten dezelfde hoeveelheid voer verstrekt (paarsgewijs gevoed).

Tijdens de acute fase van ernstige ziekte is verlies van spiermassa waargenomen bij de zymosan geïnjecteerde ratten. Dit verlies was gedeeltelijk het gevolg van verlaagde eiwitsynthese snelheden. Daarnaast zijn in de zymosan geïnjecteerde ratten nog andere metabole veranderingen waargenomen die karakteristiek zijn voor ernstige ziekte. De spier glutamine concentratie was verlaagd, de lever vergroot en de lever eiwitsynthese snelheden verhoogd (hoofdstuk 3 ). De kombinatie van een lange herstelperiode en een redelijke voerinname (60-80\% van normaal) maken het zymosan model uitermate geschikt voor voedingsinterventiestudies. 
Tijdens ernstige ziekte worden meer essentiële vertakte keten aminozuren geoxideerd. In hoofdstuk 4 is in de skeletspier van de zymosan geïnjecteerde ratten een verhoogde activiteit waargenomen van het snelheidsbepalende enzym in de afbraak van vertakte keten aminozuren, het zgn. vertakte keten $\alpha$-ketozuur dehydrogenase complex. Deze waarneming verschaft een mogelijk mechanisme voor de, tijdens ernstige ziekte waargenomen, toename in oxidatie van vertakte keten aminozuren. Een verhoogde afbraak van vertakte keten aminozuren leidt tot een toename in de synthese van glutamaat. Glutamaat kan vervolgens gebruikt worden voor de aanmaak van alanine en glutamine. Deze laatste twee aminozuren zijn belangrijk tijdens ziekte, respektievelijk voor gluconeogenese en als brandstof voor sneldelende cellen (lymfocyten, enterocyten en macrofagen). Mogelijk is de verhoogde afbraak van vertakte keten aminozuren een mechanisme om een groot deel van de aminozuren afkomstig van netto eiwitafbraak richting glutamine en alanine synthese te dirigeren.

Patiënten klagen tijdens ernstige ziekte en vooral tijdens het herstel hiervan over spierzwakte en een toegenomen vermoeidheid. Ook de zymosan geïnjecteerde ratten vertonen een verlies van spierkracht. Tijdens in situ electrostimulatie van de skeletspier in zymosan behandelde ratten is een afname van $85 \%$ in spierkracht waargenomen. Aangezien de afname in spiermassa in de zymosan geïnjecteerde ratten $22 \%$ bedroeg, kan slechts een deel van het verlies aan spierkracht hierdoor verklaard worden. In hoofdstuk 6 is een daling waargenomen van het mitochondriële eiwitgehalte in de spier van de zymosan geïnjecteerde ratten. Deze daling, die groter is dan de daling in totaal spiereiwit, was tenminste voor een deel het gevolg van een verlaging in de synthese snelheid van mitochondrieel eiwit. In de inspanningsfysiologie is een duidelijke relatie aangetoond tussen het mitochondrieel gehalte en het uithoudingsvermogen van de skeletspier. Het lijkt daarom mogelijk dat een laag mitochondrieel gehalte de spierzwakte tijdens ernstige ziekte kan verklaren. Het verlaagde mitochondrieel gehalte in de skeletspier van de zymosan geïnjecteerde ratten ging echter gepaard met slechts geringe veranderingen in de concentraties van energie-rijke fosfaten in de rustende spier (hoofdstuk 5). Dit betekent, dat het lage mitochondrieel gehalte geen grote invloed lijkt te hebben op het behoud van de energiestatus tijdens rust.

In hoofdstuk 7 is de mogelijkheid bestudeerd dat een verlaagd mitochondrieel gehalte met name tijdens een verhoogde activiteit resulteert in een energieprobleem in de skeletspier. Als gevolg van electrostimulatie van de skeletspier in situ (teneinde een verhoogd energieverbruik te induceren) zijn echter geen verschillen in de, door de stimulatie geinduceerde, veranderingen in energie-rijke fosfaten waargenomen tussen de zymosan geïnjecteerde en paarsgewijs gevoede controle ratten (hoofdstuk 7). Deze resultaten suggereren dat de waargenomen afname van $85 \%$ in spierkracht in de zymosan geïnjecteerde ratten waarschijnlijk het resultaat is van een verminderde stimuleerbaarheid van de spier. Dit is mogelijk het gevolg van een ontregeling in het zenuwstelsel of in 
een van de stappen van het excitatie-contractie koppelingsmechanisme van de skeletspier. Het is echter zeer wel mogelijk dat het verlaagd mitochondrieel gehalte wel tijdens verder herstel van ernstige ziekte zorgt voor energieproblemen in de spier en een toegenomen vermoeiheid.

Van glutamine wordt gesuggereerd dat het gedurende ernstige ziekte een essentieel nutriënt is, en daarom zijn en worden veel interventiestudies met glutamine uitgevoerd. In de literatuur is een positief verband gerapporteerd tussen spier glutamine concentratie en spiereiwitsynthese snelheid. Op basis van dit verband is gesuggereerd dat glutamine interventies het verlies van spiereiwit tijdens ernstige ziekte kunnen verminderen. In de skeletspier van ratten herstellende van de zymosan injectie zijn echter normale eiwitsynthese snelheden waargenomen terwijl glutamine concentraties nog verlaagd waren (hoofdstuk 3 ). Deze resultaten laten zien dat het positieve verband tussen beide parameters niet altijd aanwezig is.

De in hoofdstuk 8 beschreven glutamine interventie, uitgevoerd met een voer met een eiwitbron rijk aan glutamine, resulteerde in verhoogde glutamine concentraties in spier en plasma van controle ratten. Dit voer had echter geen invloed op de katabole reactie na een zymosan injectie. Er zijn geen verschillen gemeten in de ernst van de ziekte (voerinname en lichaamsgewicht), in de lagere glutamine concentraties in spier en plasma en in het verlies van spiereiwit (noch totaal noch mitochondrieel). Doordat een relatie tussen de glutamine concentratie en de eiwitsynthese snelheid in skeletspier niet altijd opgaat en omdat geen effect van de glutamine interventie op de grootte van de spier glutamine pool is waargenomen, lijkt het erop dat de spier geen goed doelorgaan is voor glutamine interventie. Het voer werd echter door de zymosan geïjecteerde ratten normaal gegeten en gemetaboliseerd. Hoogstwaarschijnlijk is al het extra glutamine uit het voer opgenomen door de organen in het splanchnische gebied en kan hier een effect van glutamine interventie verwacht worden.

\section{Belangrijkste conclusies}

- Het injecteren van ratten met zymosan levert een katabool rattenmodel op met een acute fase van ernstige ziekte ( 2 dagen) gevolgd door een langdurige herstel fase (minstens 10 dagen). Het verkregen model is geschikt voor het bestuderen van biochemische mechanismen die ten grondslag liggen aan de metabole ontsporingen gedurende zowel de acute als de herstelfase en voor het bestuderen van voedingsinterventies tijdens herstel.

- Het verlies van spiermassa dat optreedt tijdens de acute fase van enstige ziekte is tenminste voor een deel het gevolg van verlaagde eiwitsynthese snelheden. 
- Als gevolg van ernstige ziekte is het mitochondrieel eiwitgehalte van de skeletspier sterker verlaagd dan het totale spiereiwit. Deze daling is gedeeltelijk het gevolg van een relatief sterkere daling van de synthese snelheid van mitochondrieel eiwit.

- De verminderde spiercontractiliteit in de zymosan geïnjecteerde ratten lijkt het resultaat te zijn van een ontregeling in het zenuwstelsel of in een van de stappen van het excitatie-contractie koppelingsmechanisme. Mogelijk leidt het verlaagde mitochondrieel gehalte wel tijdens een latere fase van herstel tot een verminderde spierfunctie en een toegenomen vermoeidheid.

- Voedingsinterventie met een voer dat een eiwitbron rijk aan glutamine bevat, heeft een vergroting van de belangrijkste glutamine voorraden (spier en plasma) tot gevolg bij controle ratten. Het voer heeft echter bij de zymosan geïnjecteerde ratten geen effect op de ernst van de ziekte, op de verminderde glutamine voorraden en op het verlies van spiereiwit (noch totaal noch mitochondrieel). 


\title{
Met dank aan:
}

\author{
Juliette \\ Marco \\ Jan \\ Thea
}

Ton Wagenmakers

Wim Saris

Peter Soeters

Mieke Faes

Sander Kersten

Annemie Gijsen

Joan Senden

Ed Beckers

Paul Schoffelen

Jo Wierts

Nicole Bitch

Gerard Hornstra

Gerrit van Hall

Marc Stuart

Matthijs Hesselink

Jos Kop

Ton van den Bogaard

Frans Weekers

Mick Deutz

Cees Dejong

Dave Halliday

Dwight Matthews

Maarten von Meyenfeldt

Ger van der Vusse

Hans Sauerwein

Jan Steijns

Toon van Hooydonk

Mike Rennie

Peter MacLennan

CPV

Humane Biologie

DMV International 


\section{Curriculum vitae}

Olav Rooyackers werd op 20 april 1965 geboren in Eindhoven. Na drie jaar brugklas (CAS te Asten) vertoefde hij de resterende schooljaren (1980-1983) op het Atheneum (Peeland College te Deurne). Tijdens de hierop volgende studie biologie aan de toemalige Landbouw Hogeschool te Wageningen heeft hij zich gespecialiseerd in de richting dierfysiologie. Dit werd bereikt dmv een afstudeervak Dierfysiologie by Dr. Schreurs (Vakgroep Fysiologie van Mens en Dier) en een stage by Prof. Rennie in Schotland (Department of Anatomy and Physiology, University of Dundee). Daarnaast verbleef hij in het kader van een afstudeervak Immunology enige tijd bij Dr. Bianchi aan het Centraal Diergeneeskundig Instituut in Lelystad. Na het behalen van de ingenieurs titel in de Landbouwwetenschappen in september 1989 heeft hij gedurende drie maanden op vrijwilige basis een aio project ondersteund aan de vakgroep Experimentele Diermorfologie en Celbiologie (Landbouwuniversiteit te Wageningen). Van mei 1990 tot augustus 1994 werkte hij zelf als aio bij de vakgroep Humane Biologie aan de Rijksuniversiteit Limburg waar het onderzoek beschreven in de voorafgaande pagina's is uitgevoerd. Vanaf februari 1995 zal hij als postdoc werkzaam zijn bij Prof. Nair aan de vakgroep Endocrinology van de Mayo Clinic (Rochester, USA). 
